\title{
Scaling of Remote Sensing Information for Orchard Management
}
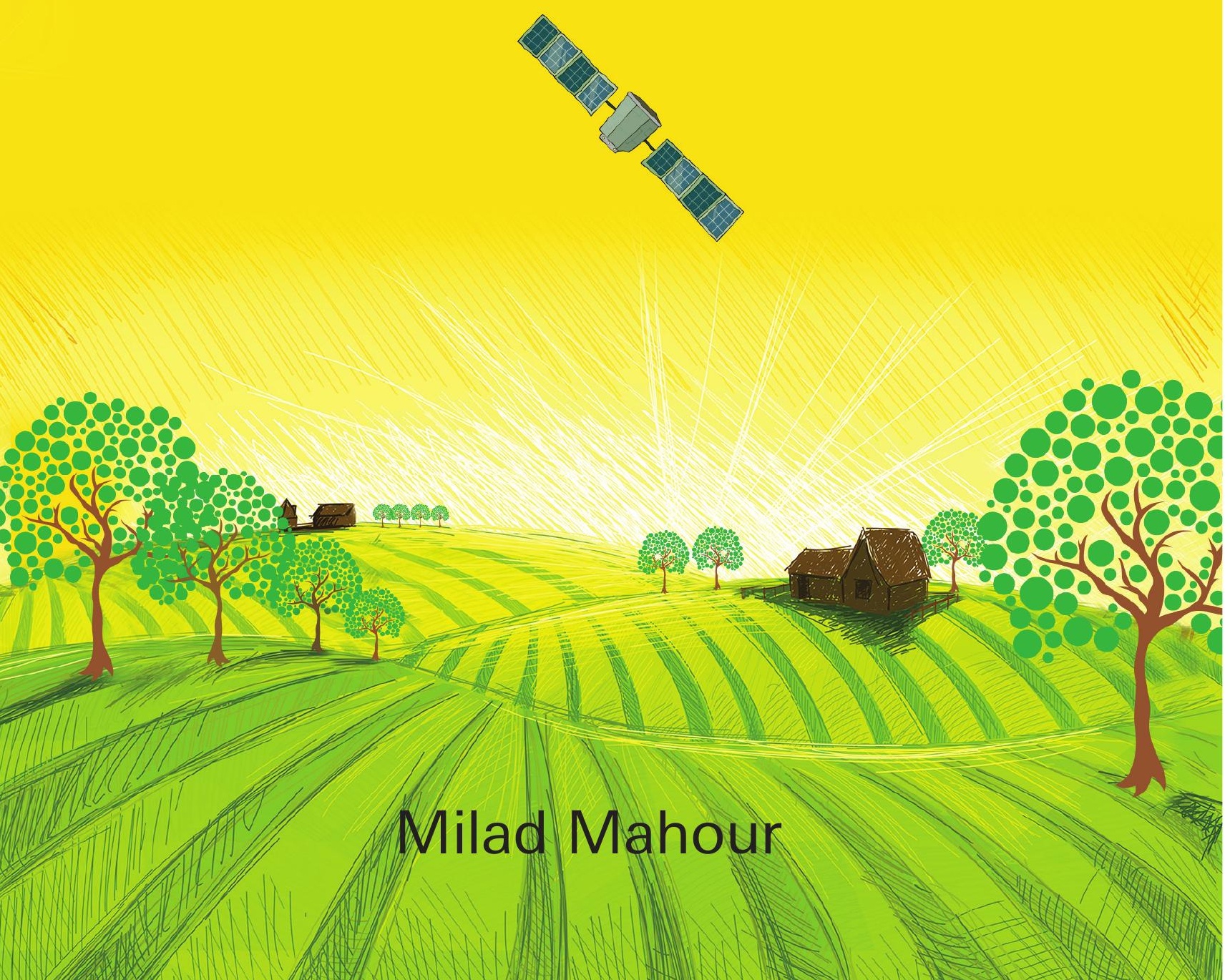


\section{SCALING OF REMOTE SENSING INFORMATION FOR ORCHARD MANAGEMENT}


Graduation committee:

\section{Chairman/Secretary}

Prof.dr.ir. A. Veldkamp University of Twente

\section{Supervisor}

Prof.dr.ir. A. Stein University of Twente

\section{Co-supervisor}

Dr. V.A. Tolpekin University of Twente

\section{Members}

Prof.dr. A.D. Nelson

University of Twente

Prof.dr. R. Zurita-Milla

University of Twente

Prof.dr. M.F. Goodchild

University of Washington

Prof.dr. J. Molenaar

University of Wageningen

ITC dissertation number 337

ITC, P.O. Box 217, 7500 AE Enschede, The Netherlands

ISBN 978-90-365-4689-8

DOI $10.3990 / 1.9789036546898$

Cover designed by Germancreative Printed by ITC Printing Department

Copyright (c) 2018 by Milad Mahour 


\title{
SCALING OF REMOTE SENSING INFORMATION FOR ORCHARD MANAGEMENT
}

\author{
DISSERTATION
}

to obtain

the degree of doctor at the University of Twente, on the authority of the rector magnificus, prof.dr. T.T.M. Palstra, on account of the decision of the graduation committee, to be publicly defended

on Wednesday, December $5^{\text {th }}, 2018$ at $12: 45$ hrs

by

\section{Milad Mahour}

born on September $14^{\text {th }}, 1986$

in Tehran, Iran 
This thesis has been approved by

Prof. dr.ir. A. Stein, supervisor

Dr. V.A. Tolpekin, co-supervisor 
To my family 



\section{Summary}

Precision orchard management as a specific form of precision agriculture aims at supporting decision makers and farm managers by providing strategies to optimize crop production. Multiple information sources are used. In this thesis, the use of remote sensing images is explored for that purpose. In the past, an orchard was the smallest management scale to deal with it, whereas nowadays it concerns individual trees and leaves. This research explored downscaling methods for satellite images, bridging the gap between the tree patterns and detailed geographical information of trees on the ground. It focused on using both coarse and very high resolution satellite images with the aim of providing meaningful information at different level of scales.

First, downscaling cokriging was carried out to match the spatial resolutions when obtaining Land Surface Temperature (LST) and Actual EvapoTranspiration (AET) from remote sensing images. We first applied it to a $1000 \mathrm{~m}$ resolution MODIS LST product. We also downscaled a coarse AET map to a $250 \mathrm{~m}$ resolution. For both procedures, the $250 \mathrm{~m}$ resolution MODIS NDVI product was the co-variable. The two procedures were applied to an agricultural area with a traditional irrigation network in Iran. The study showed that AET values obtained with the two downscaling procedures were similar to each other, but that AET showed a higher spatial variability if obtained with downscaled LST. We concluded that LST had a large effect on producing AET maps from Remote Sensing (RS) images and that downscaling cokriging was helpful to provide daily AET maps at medium spatial resolution.

Second, super resolution mapping (SRM) was applied to a high resolution GeoEye image of a vineyard in Iran with the aim to determine the Actual EvapoTranspiration (AET) and Potential EvapoTranspiration (PET). The Surface Energy Balance System (SEBS) applied for that purpose requires the use of a thermal band, provided by a Landsat TM image of a $30 \mathrm{~m}$ resolution. Image fusion downscaled this information to the 0.5 by $0.5 \mathrm{~m}^{2}$ scale level. Grape trees in the vineyard planted in rows allowed us to distinguish three levels: field, rows of trees and individual trees. The study concluded that modern satellite derived information in combination with recently developed image analysis methods is able to provide reliable AET values at the row level, but not yet for every individual tree.

Third, a framework based upon scale-space theory for detecting and delineating individual trees was developed. The study focused on extracting reliable and detailed information from very High Resolution (VHR) satellite images for the detection of individual trees. The images contain detailed information on spectral and geometrical properties of trees. Individual trees were modeled using a bell shaped spectral profile. Gaussian scale-space theory 
was applied to search for extrema in the scale-space domain. The procedures were tested on two orchards with different tree types, tree sizes and tree observation patterns. Local extrema of the determinant of the Hessian corresponded well to the geographical coordinates and the size of individual trees. False detections arising from a slight asymmetry of trees were distinguished from multiple detections of the same tree with different extents. The study demonstrated how the suggested framework can be used for image segmentation for orchards with different types of trees. It concluded that Gaussian scale-space theory can be applied to extract information from VHR satellite images for individual tree detection. This may lead to improved decision making for irrigation and crop water requirement purposes in future studies.

Fourth, a refined tree crown model based upon Gaussian scale-space theory was developed from very high resolution satellite images. It focused on investigating the use of scale-space theory to detect individual trees in orchards. Trees were characterized by blobs, e.g., bell shaped surfaces. Their modelling required the identification of local maxima, whereas location of the maxima in the scale direction provided information about the tree size. The study presents a two-step procedure to relate the detected blobs to tree objects in the field. A Gaussian blob model identified tree crowns and an improved tree crown model was applied by modifying this model in the scale direction. Three representative cases were evaluated: an area with isolated vitellaria trees, an orchard with walnut trees and one with oil palm trees. Results showed that the refined Gaussian blob model improves upon the traditional Gaussian blob model by discriminating well between false and correct detections and accurately identifying size and position of trees. We concluded that the presented two-step modeling procedure is useful to automatically detect individual trees from VHR satellite images for at least three representative cases.

To summarize, this research focused on satellite based methods at different levels of scales for orchard management. It improved the monitoring of trees, the detection of changes, mapping of tree health and determination of crop water requirement. 


\section{Samenvatting}

Precisiebeheer van boomgaarden is een specifieke vorm van precisielandbouw die bedoeld is om beslissers en bedrijfsmanagers te ondersteunen door strategieën te bieden voor het optimaliseren van de gewasproductie. Hiervoor worden meerdere informatiebronnen gebruikt. In dit proefschrift wordt het gebruik van satelliet-beelden onderzocht voor dat doel. In het verleden was een boomgaard de kleinste beheersschaal, terwijl het tegenwoordig om individuele bomen en bladeren gaat. Dit onderzoek onderzocht neerschalingsmethoden voor satellietbeelden, om de kloof tussen het patroon van bomen en gedetailleerde geografische informatie van bomen op de grond te overbruggen. Het richtte zich op het gebruik van zowel lage als zeer hoge resolutie satellietbeelden met als doel zinvolle informatie op verschillende schaalniveau's te bieden.

De eerste studie beschrijft hoe neerschalend cokriging is uitgevoerd om ruimtelijke resoluties aan te passen bij het verkrijgen van Land Oppervlakte Temperatuur (LST) en Actuele EvapoTranspiratie (AET) informatie van satellietbeelden. We hebben het toegepast op een MODIS LST-product met een resolutie van $1000 \mathrm{~m}$. We hebben ook een ruwe AET-kaart neergeschaald naar een resolutie van $250 \mathrm{~m}$. Voor beide procedures was het MODIS NDVI-product met een resolutie van $250 \mathrm{~m}$ de co-variabele. De twee procedures zijn toegepast op een landbouwgebied met een traditioneel irrigatienetwerk in Iran. De studie toonde aan dat AET-waarden verkregen met de twee neerschalingsprocedures vergelijkbaar waren met elkaar, maar dat AET een hogere ruimtelijke variabiliteit vertoonde als het is verkregen met neergeschaalde LST. We concludeerden dat LST een sterk effect had op het produceren van AET-kaarten van satellietbeelden en dat de techniek neerschalend cokriging nuttig was om dagelijkse AET-kaarten te genereren met een gemiddelde ruimtelijke resolutie.

De tweede studie past superresolutie kartering (SRM) toe op een hoge resolutie GeoEye-beeld van een wijngaard in Iran met als doel de actuele EvapoTranspiratie (AET) en potentiële EvapoTranspiratie (PET) te bepalen. Het Surface Energy Balance System (SEBS) dat voor dat doel wordt toegepast, vereist het gebruik van een thermische band, geleverd door een Landsat TMbeeld met een resolutie van $30 \mathrm{~m}$. Fusie van beelden verkleinde deze informatie naar het schaalniveau van $0,5 \mathrm{bij} 0,5 \mathrm{~m}^{2}$. Druivenbomen in de wijngaard, geplant in rijen, hebben ons in staat gesteld om drie niveaus te onderscheiden: veld, rijen bomen en individuele bomen. De studie concludeerde dat moderne informatie afgeleid van satellietbeelden in combinatie met recent ontwikkelde beeldanalysemethoden in staat is om betrouwbare AET-waarden te leveren op het niveau van een individuele rij, maar nog niet voor elke afzonderlijke boom. 
De derde studie presenteert een kader dat gebaseerd is op schaal-ruimte theorie voor het detecteren en afbakenen van individuele bomen. De studie richtte zich op het extraheren van betrouwbare en gedetailleerde informatie van zeer hoge resolutie (VHR) satellietbeelden voor de detectie van individuele bomen. De beelden bevatten gedetailleerde informatie over spectrale en geometrische eigenschappen van bomen. Individuele bomen zijn gemodelleerd met behulp van een klokvormig spectraal profiel. Gaussische schaal-ruimte methoden zijn toegepast om extremen in het schaal-ruimte domein te zoeken. De procedures zijn getest op twee boomgaarden met verschillende boomsoorten, boomgroottes en observatiepatronen. Lokale extremen van de determinant van de Hessiaan kwamen goed overeen met de geografische coördinaten en de grootte van individuele bomen. Verkeerde detecties als gevolg van een lichte asymmetrie van bomen hebben we onderscheiden van meerdere detecties van dezelfde boom met een verschillende omvang. De studie toonde aan hoe het voorgestelde kader kan worden gebruikt voor beeldsegmentatie voor boomgaarden met verschillende soorten bomen. Het concludeerde dat de Gaussische schaal-ruimte theorie kan worden toegepast om informatie uit VHR-satellietbeelden te extraheren voor de detectie van individuele bomen. Dit kan leiden tot verbeterde besluitvorming voor irrigatie en gewaswatervereisten in toekomstige studies.

De vierde studie toont een verfijnd boomkroonmodel dat is ontwikkeld gebaseerd op Gaussische schaal-ruimte theorie uit zeer hoge resolutie satellietbeelden. Het richtte zich op het onderzoeken van het gebruik van schaal-ruimte theorie om individuele bomen in boomgaarden op te sporen. Bomen zijn gekenmerkt door 'blobs' (klodders), bijvoorbeeld klokvormige oppervlakken. Hun modellering vereiste de identificatie van lokale maxima, terwijl de locatie van de maxima in de schaalrichting informatie verschafte over omvang van een boom. De studie presenteert een tweestaps procedure om de gedetecteerde blobs te relateren aan boomobjecten in het veld. Een Gaussisch blobmodel identificeerde boomkronen en een verbeterd boomkroonmodel is toegepast door dit model in de schaalrichting aan te passen. Drie representatieve gevallen zijn geëvalueerd: een gebied met geïsoleerde vitellaria-bomen, een boomgaard met notenbomen en een boomgaard met oliepalmen. De resultaten toonden aan dat het verfijnde Gaussische blobmodel het traditionele Gaussische blobmodel verbeterde door een goed onderscheid te maken tussen verkeerde en correcte detecties en de grootte en positie van bomen nauwkeurig te identificeren. We concludeerden dat de gepresenteerde tweestaps procedure waardevol was om individuele bomen van VHRsatellietbeelden automatisch te detecteren voor ten minste drie representatieve gevallen.

Samenvattend, dit onderzoek concentreerde zich op satelliet gebaseerde methoden op verschillende schaalniveaus voor het beheer van boomgaarden. 
Het verbeterde het monitoren van bomen, de detectie van veranderingen, het in kaart brengen van de gezondheid van bomen en het vaststellen van het vereiste water. 


\section{Acknowledgements}

After an exciting period of working and doing research at ITC Faculty, today is the day: writing this note of appreciation is the finishing touch on my PhD research. It has been a time of profound learning for me, not only in the scientific arena but also on a personal level. Doing this research has had a significant impact on me. I would like to deliberate on the people who have helped and encouraged me so much throughout this period.

I would first like to express my special appreciations to my promoter Prof. Alfred Stein for his advice, support and continuous encouragements have contributed significantly to the completion of this research. I would remarkably like to single out my supervisor Dr. Valentyn Tolpekin: I want to thank you for your excellent assistance and for all of the opportunities I was given to conduct my research. I would like to extend my appreciation to Dr. Ali Sharifi for his support, advice and critical comments.

I would also like to thank my family for the love of my life my loving mother Fariba, my father Jamshid, my brothers Mohamadamin and Amirali, and my lovely grandma, thank you for giving me a stable mind to think and work for science. I am thankful to you for all what you have done for me. Because of you, I am standing here.

Finally, there are my friends Amir Zarghan, Danial Naghib, Parya Pasha, Tonny Boeve, Frank Osei, Carla Gerritsen, and Adish Khezri. We were not only able to encourage each other by deliberating over our problems but also gladly by talking about things other than just academia.

Thank you very much, everyone!

Milad Mahour 


\section{Table of Contents}

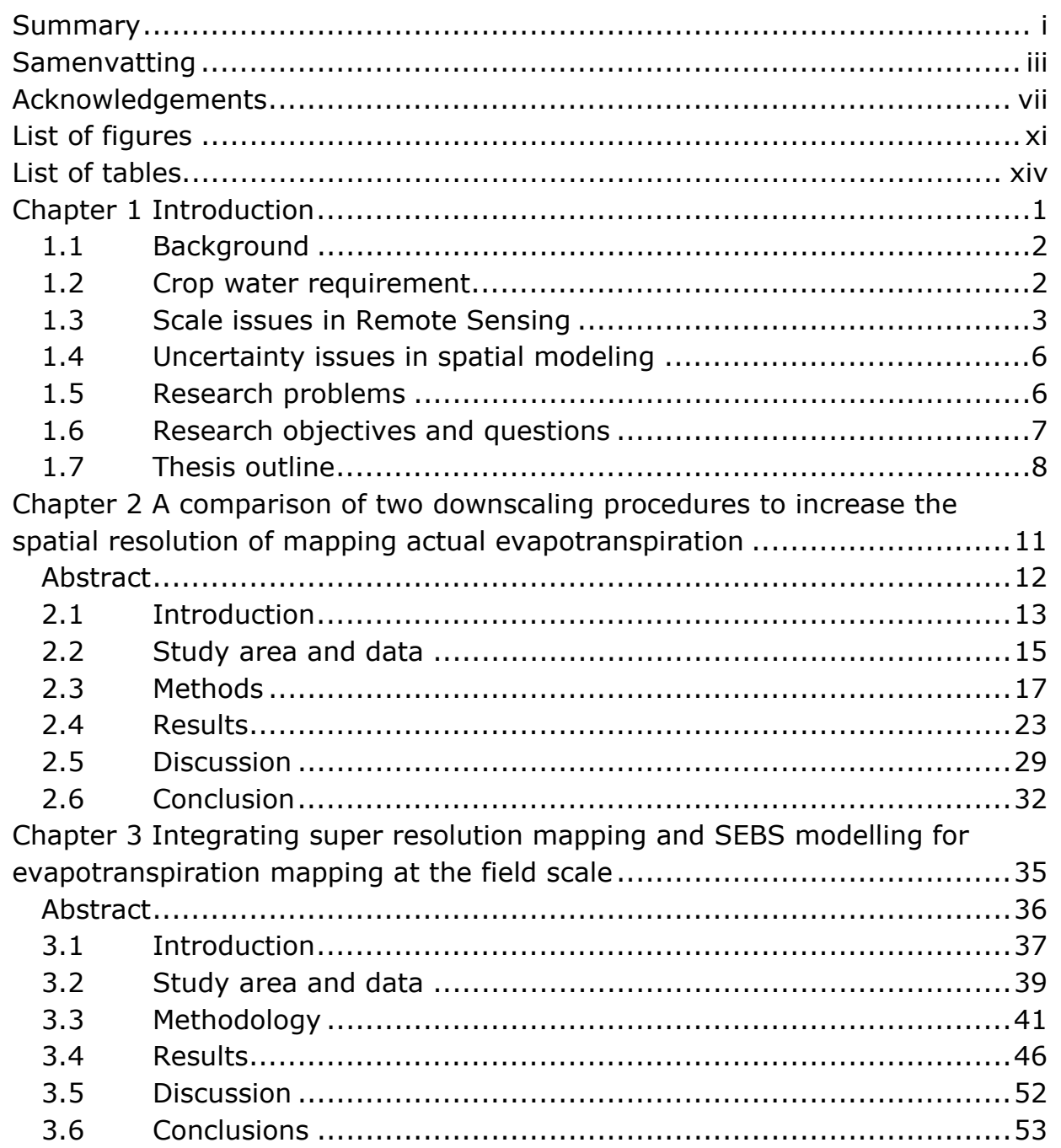

Chapter 4 Tree detection in orchards from VHR satellite images using scale-

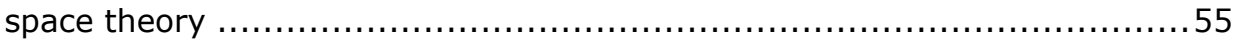

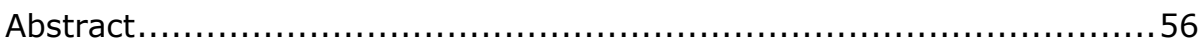

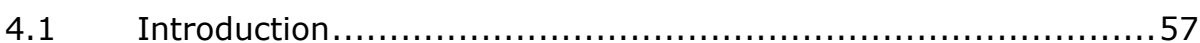

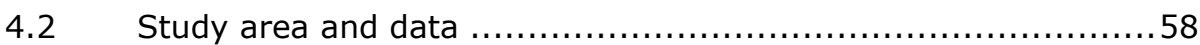

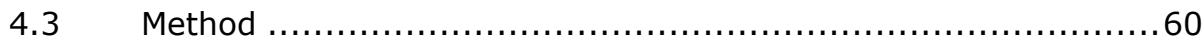

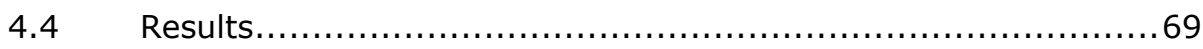

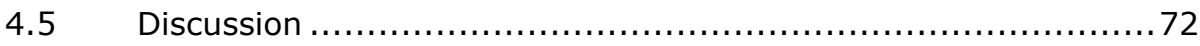

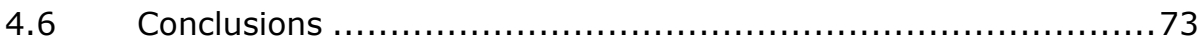

Chapter 5 Refining blob model in scale-space for tree detection from VHR

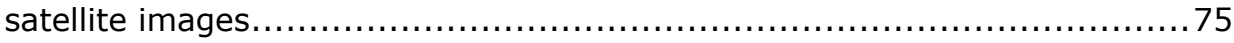




\begin{tabular}{|c|c|}
\hline \multicolumn{2}{|c|}{ Abstract } \\
\hline 5.1 & Introduction...$\ldots \ldots \ldots \ldots \ldots$ \\
\hline 5.2 & Scale-space blob detection... \\
\hline 5.3 & Modeling tree crown in the scale direction $\ldots \ldots \ldots \ldots \ldots \ldots \ldots \ldots \ldots \ldots \ldots \ldots \ldots \ldots \ldots \ldots$ \\
\hline 5.4 & 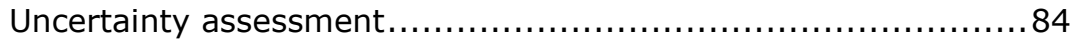 \\
\hline 5.5 & 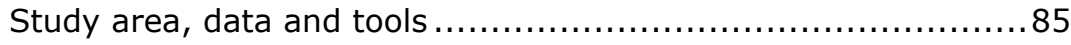 \\
\hline 5.6 & Results.......................... \\
\hline 5.7 & Discussion... \\
\hline 5.8 & Conclusions ....... \\
\hline Chapte & Synthesis .. \\
\hline 6.1 & Research findings and conclusions................. \\
\hline 6.2 & Precision tree management from different methods .............. 103 \\
\hline 6.3 & Reflections \\
\hline 6.4 & Future work \\
\hline
\end{tabular}




\section{List of figures}

FIGURE 1.1: THE CONCEPT OF DOWNSCALING BY DECREASING AND UPSCALING BY INCREASING THE PIXEL SUPPORT.

FIGURE 2.1:THE STUDY AREA LOCATED AT PART OF THE IRRIGATION NETWORK IN QAZVIN, IRAN, INCLUDING THE L1 (RIGHT) AND L2 (LEFT) LATERAL CANALS THAT ARE CLEARLY VISIBLE IN THE NWSE DIRECTIONS. CIRCLES SHOW GATES AT THE BEGINNING OF EACH SUB-LATERAL CANALS (SOURCE: GOOGLE EARTH).

Figure 2.2: SATELLITE RS DATA IMAgERY. A THE LST PRODUCt OF MODIS AT $1000 \mathrm{M}$ SPATIAL RESOLUTION, B THE NDVI PRODUCT OF MODIS AT 250 M SPATIAL RESOLUTION AND C THE LANDSAT 8 IMAGE AT $30 \mathrm{M}$ SPATIAL RESOLUTION (RGB)

FIGURE 2.3: SCHEMATIC DIAGRAM OF THE GENERAL METHODOLOGY.

FIGURE 2.4: CONCEPT OF CHANGING SUPPORT FROM A PIXEL SUPPORT TO B POINT SUPPORT, THEN AVERAGING POINTS TO C FINER PIXEL SUPPORT

FIGURE 2.5: SCATTER PLOT AND HISTOGRAM OF NDVI BETWEEN LST AND ET AT 250 M SPATIAL RESOLUTION

FIGURE 2.6: EXPERIMENTAL VARIOGRAM OF LST AND NDVI IMAGES AT $1000 \mathrm{M}$ AND $250 \mathrm{M}$ SPATIAL RESOLUTION AND CROSS-VARIOGRAM BETWEEN THEM IN FOUR GEOGRAPHICAL DIRECTIONS ......24

FIGURE 2.7: EXPERIMENTAL VARIOGRAM OF ET AND NDVI IMAGES AT $1000 \mathrm{M}$ AND $250 \mathrm{M}$ SPATIAL RESOLUTION AND CROSS-VARIOGRAM BETWEEN THEM IN FOUR GEOGRAPHICAL DIRECTIONS .......25

FIGURE 2.8: RESULT OF DOWNSCALING COKRIGING OF A LST AND B ET USING NDVI AS CO-VARIABLE AT 250 M SPATIAL RESOLUTION.

FIGURE 2.9: AET AT 250 M SPATIAL RESOLUTION USING DOWNSCALED LST AS INPUT FOR THE SEBS . 26

FIGURE 2.10: ESTIMATED LST FROM LANDSAT 8 USING THE SW ALGORITHM AT 30 M SPATIAL RESOLUTION

FIGURE 2.11: A ERROR MAP AND B CLASSIFIED ERROR MAP BETWEEN DOWNSCALED LST AND REFERENCE LST FROM LANDSAT 8 AT $250 \mathrm{M}$ SPATIAL RESOLUTION .

FIGURE 2.12: SCATTER PLOT BETWEEN DOWNSCALED LST AND REFERENCE LST FROM LANDSAT $8, \mathrm{R}=$ 0.48 .

FIGURE 2.13: SCATTER PLOT BETWEEN DOWNSCALED ACTUAL ET AND REFERENCE ACTUAL ET FROM LANDSAT 8 AT $250 \mathrm{M}$ SPATIAL RESOLUTION, R $=0.49$

FIGURE 2.14: COMPARISON BETWEEN AET AND LST FROM A MODIS AT $1000 \mathrm{M}(\mathrm{R}=-0.95)$ AND B LANDSAT 8 AT $250 \mathrm{M}$ SPATIAL RESOLUTION $(R=-0.94)$. AET AND LST ESTABLISH A NEGATIVE RELATIONSHIP IF THE SEMI-ARID REGION SUFFERS FROM WATER SHORTAGE.

FIGURE 2.15: RESIDUAL MAP, ERROR MAP AND RELATIVE ERROR MAP (\%) BETWEEN REFERENCE AND DOWNSCALED AET

Figure 3.1: The STUdy AREA LOCATEd IN THE NORTHERN PART OF IRAN. (A) THE GEOEYE SATELLITE IMAGE AT 2 M MULTISPECTRAL AND A 0.5 M PANCHROMATIC RESOLUTION, (B) THE LANDSAT 5 TM IMAGE AT 30 M RESOLUTION, (c) THE UlTRACAM DIGITAL AERIAL PHOTO AT 14 CM RESOLUTION

Figure 3.2: IDENTIFICATION OF THREE INDIVIDUAL PLANTS AS THE SUBSET $P$ : (A) FROM THE GEOEYE PANCHROMATIC IMAGE AND (B) AS REFERENCE POLYGONS FROM THE AERIAL PHOTO .41

FIGURE 3.3: THE RESULT OF SRM BASED MRF FOR SUBSET R WITH USING THE STARTING PARAMETERS $S=4 T 0=3$ AND $\eta=0.9$ AND THE OPTIMIZED PARAMETERS $\Lambda=0.9$ AND $\lambda$ pa $n=0.4 ;$ RED POLYGONS ARE REFERENCE DATA . 
FiguRE 3.4: RESULT OF SRM BASED MRF FOR THE THREE ROWS IN SUBSET R INDIVIDUALLY: (A) $R 15$,

(B) $R 16$ AND (C) $R 17$; RED POLYGONS ARE REFERENCE DATA

FIGURE 3.5: THE INITIAL (LEFT) AND THE OPTIMIZED (RIGHT) SRM RESULTS FOR INDIVIDUAL PLANTS OF SUBSET $P$ LOCATED IN $R 16$ : (A)P1, (B) $P 2$, (c) $P 3$. IN THE OPTIMIZED RESULTS A MORE COHERENT PATTERN IS OBSERVED THAT BETTER CORRESPONDS WITH THE RED POLYGONS AS REFERENCE DATA

Figure 3.6: RETRIEVAL DAILY AET VALUES AT A 30 M RESOLUTION BASED ON THE SEBS MODEL OVERLAID WITH THE WHOLE FIELD F

FigURE 3.7: THE HIGH RESOLUTION NDVI IMAGE (A), THE AET IMAGE OBTAINED FROM SEBS (B) AND THE RESULT AFTER IMAGE FUSION (C) USING THE GS METHOD....

FIGURE 3.8: COMBINATION OF SRM RESULT WITH THE ACTUAL ET (A) FOR SUBSET $R$ AND (B) ZOOMING IN AT SUBSET $P$

FIGURE 4.1: INFORMATION OF TREE POSITION AND CROWN RADIUS, DISTANCE BETWEEN ROWS AND INDIVIDUAL PLANTS.

FIGURE 4.2: STUDY AREA WITH A. ORCHARD 1 PLANTED WITH PEACH AND B. ORCHARD 2 PLANTED WITH WALNUT TAKEN FROM AN ULTRACAM DIGITAL AERIAL PHOTO (TRUE COLOR), RED POLYGONS ARE DERIVED REFERENCE TREE CROWN BOUNDARY

FIGURE 4.3: SCHEMATIC DIAGRAM FOR TREE DETECTION AND ITS UNCERTAINTY ASSESSMENT ............61

FigURE 4.4: ILLUSTRATION OF THE GREY-LEVEL BLOB ALONG THE YELLOW LINE, A. ON THE ROW OF TREES OF THE NDVI IMAGE OF ORCHARD 2, B. GREY-LEVEL BLOB WITH LOCAL MAXIMA AND LOCAL MINIMA. THIS FIGURE SHOWS BRIGHT BLOBS ON A DARK BACKGROUND OF THE ORCHARD IMAGE 63

FIGURE 4.5: HISTOGRAM OF THE PANCHROMATIC IMAGE OF ORCHARD 1 AND ORCHARD 2 AND THE NDVI IMAGE OF ORCHARD 2, BLUE DASH LINE INDICATES SEPARATION BETWEEN TREES AND NONTREE ON THE PANCHROMATIC AND THE NDVI IMAGES.

FIGURE 4.6: A SET OF SMOOTHED IMAGES FROM A SUBSET FROM NDVI IMAGE OF ORCHARD 2, A. ORIGINAL IMAGE AT ZERO SCALE, B. 3D PLOT OF IMAGE AT SCALE 0 (ORIGINAL IMAGE), C. SMOOTHED IMAGE AT SCALE 7.5, D. 3D PLOT OF IMAGE AT SCALE 7.5, E. SMOOTHED IMAGE AT SCALE 50, F. 3D PLOT OF IMAGE AT SCALE 50

FIGURE 4.7: OVER-ESTIMATE AND UNDER-ESTIMATE BETWEEN REFERENCE $R_{1}$ AND ESTIMATED $D_{1}$ TREE OBJECTS

FIGURE 4.8: THE MATCHED OBJECTS ARE ACCEPTED WHEN EACH CENTER FALLS WITHIN EACH OTHER. A) CORRECTLY MATCHED, B) FALSE POSITIVES AND C) FALSE NEGATIVES

FiguRE 4.9: RESULTS OF THE SCALE-SPACE BLOB ON A. THE PANCHROMATIC IMAGE AT ORCHARD 1, B. ERROR MAP

FiguRE 4.10: RESULTS OF THE SCALE-SPACE BLOB ON A. THE NDVI IMAGE AT ORCHARD 2, B. ERROR MAP.

FIGURE 5.1: THE INTENSITY PROFILE OF A) A CONIFEROUS TREE WITH A SINGLE MAXIMUM, B) A BROADLEAVED TREE WITH SEVERAL LOCAL MAXIMA AND C) A NOISY BACKGROUND. D) REPRESENTS THE FITTED GAUSSIAN FUNCTIONS AFTER REGION GROWING BETWEEN TWO INTERLOCKED TREES, COLORED BLUE AND RED. THE GREY CURVE IS OBTAINED IF THE GAUSSIAN FUNCTION IS FITTED TO ALL POINTS, WHEREAS THE BLACK CURVES ARE OBTAINED IF REGION GROWING IS APPLIED ON THE TWO SEPARATE TREE OBJECTS.

FigURE 5.2: THE SPECTRAL PROFILE OF TREE CROWNS ON A) THE NDVI IMAGE OF WV-2 (2.0 M) AND B) THE NDVI IMAGE OF WV-2 AT 0.5 M SPATIAL RESOLUTION. 
FIGURE 5.3: SCHEMATIC DIAGRAM OF THE SCALE-SPACE FOR BLOB DETECTION FROM THE TWODIMENSIONAL SAMPLED GAUSSIAN KERNEL, INDEXED BY $u$, AND THE TWO-DIMENSIONAL DISCRETE GAUSSIAN KERNEL, INDEXED BY $v$. THE DETECTED RED AND BLUE BLOB OBJECTS ARE FROM THE SAMPLED AND DISCRETE GAUSSIAN KERNELS, RESPECTIVELY.

FigURE 5.4: THE BLOB VOLUME $b$ VOLUME AND THE BLOB LIFETIME $b$ LIFE. A BLOB VOLUME IS THE AREA BELOW THE FITTED MODEL $f 3 s$ AT SCALE DIRECTION PROFILES $h s$. THE VERTICAL DASHED LINE INDICATES THE LOCATION OF THE MAXIMUM $t 0$ FROM MODEL $f 3 s$ (DASHED LINE RED COLOR). CLOSED BLUE SYMBOLS SHOW THE RANGE SMIN, $S$ MAX.

FIGURE 5.5: SCALE DIRECTION PROFILE $h S$ FOR A REAL TREE. GREEN, BLACK, BLUE AND RED LINES REPRESENT MODELS $f 1 s, f 2 s, f 3 s$ AND $f 4 s$, RESPECTIVELY. THE RED AND BLACK CURVE ARE INVISIBLE BECAUSE THEIR VALUES ARE NEARLY IDENTICAL TO THE BLUE AND GREEN CURVES, RESPECTIVELY. GREEN, BLACK, BLUE AND RED VERTICAL DASHED LINES INDICATE THE LOCATION OF THE $S k$ FOR ALL FOUR MODELS, WHEREAS CLOSED SYMBOLS SHOW THE OBTAINED RANGE $S M I N, S M A X$.

FIGURE 5.6: RESULTS OF THE DISCRETE GAUSSIAN SCALE-SPACE WITH MODIFIED TREE SIZE MEASUREMENT USING MODEL $f 3 s$; A) REFERENCE DATA FROM AN ULTRACAM IMAGE B) WALNUT ORCHARD WITH DETECTED BLOBS AND C) THE ERROR MAP.

FIGURE 5.7: RESULTS OF THE DISCRETE GAUSSIAN SCALE-SPACE WITH MODIFIED TREE SIZE MEASUREMENT USING MODEL $f 3 s$; A) REFERENCE DATA FROM A PANCHROMATIC IMAGE, B) THE OIL PALM ORCHARD WITH DETECTED BLOBS AND C) THE ERROR MAP.

FIGURE 5.8: RESULTS OF THE DISCRETE GAUSSIAN SCALE-SPACE WITH MODIFIED TREE SIZE MEASUREMENT USING MODEL $f 3 s$; A) REFERENCE DATA FROM A PANCHROMATIC IMAGE, B) VITELLARIA TREES WITH DETECTED BLOBS AND C) THE ERROR MAP.

FIGURE 5.9: DIFFERENCES BETWEEN SAMPLED AND DISCRETE GAUSSIAN SCALE-SPACE BLOB DETECTION FOR THE WALNUT ORCHARD.

FIGURE 5.10: DIFFERENCES BETWEEN SAMPLED AND DISCRETE GAUSSIAN SCALE-SPACE BLOB DETECTION FOR THE OIL PALM ORCHARD.

FIGURE 5.11: DIFFERENCES BETWEEN SAMPLED AND DISCRETE GAUSSIAN SCALE-SPACE BLOB DETECTION FOR VITELLARIA TREES.

FIGURE 5.12: DISTRIBUTIONS OF PARAMETER $\delta$ FOR DIFFERENT TREES TYPES OBTAINED WITH MODEL $f 3 s$. 


\section{List of tables}

TABLE 2.1: THE GROUND METEOROLOGICAL AT THE LOCAL WEATHER STATION IN QAZVIN. TIME OF RECORDING INFORMATION IS AT 6 AM GMT.

TABLE 2.2: COMPARISON BETWEEN DOWNSCALED LST FROM MODIS AND REFERENCE LST FROM

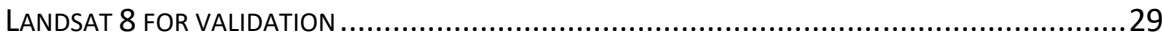

TABLE 2.3: Comparison BETWEen DOWNSCALEd AET ANd RefERENCE AET .................................29

TABLE 3.1: THE gROUND METEOROLOGICAL DATA (AT tHE QAZVIN WEATHER STATION). TIME OF

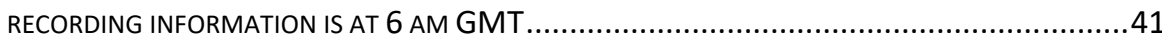

TABLE 3.2: MEAN AET VALUES AND THEIR STANDARD DEVIATION FOR SUBAREAS $R$ AND $P$.................51

TABLE 4.1: GEOMETRICAL AND PHYSICAL CHARACTERISTICS OF ORCHARDS ..................................59

TABLE 4.2: SPATIAL AND SPECTRAL CHARACTERISTICS OF RS IMAGES ........................................59

TABLE 4.3: TREE CROWN POSITIONAL ACCURACY, MEAN AREA DIFFERENCE AND TOTAL DETECTION ERROR IN ORCHARD 1 VS. ORCHARD 2

TABLE 4.4: TREE CROWN POSITIONAL ACCURACY, MEAN AREA DIFFERENCE AND TOTAL DETECTION ERROR IN ORCHARD 1 VS. ORCHARD 2

TABLE 5.1: DETECTED TREE OBJECTS BASED ON THE DISCRETE SCALE-SPACE AND USING THE $f 3 s$ MODEL.

TABLE 5.2: POSITIONAL INACCURACY, OVERESTIMATION AND UNDERESTIMATION METRICS BASED UPON THE MODIFIED TREE SIZE MEASUREMENT AT $s 0$ USING THE $f 3 s$ MODEL. 
Chapter 1 Introduction 


\subsection{Background}

Precision orchard management as a specific form of precision agriculture supports decision makers and farm managers with suggestions and recommendations for monitoring individual trees. It provides an optimal management strategy from multiple sources to optimize crop production, and deals with variation at different levels of detail (Pierce and Nowak, 1999). For instance, important in this respect is irrigation water requirement if water scarcity prevails. Efficient use of water is then needed to provide optimal yields to contribute positively to issues of food security. Water availability and supply at the right level affect the possibility of irrigating, and may even influence the security of investments in an agricultural area. Precision agriculture aims at providing integration of advanced geomatical technologies such as a Global Positioning System (GPS), a geospatial information system (GIS) and Remote Sensing products in supporting agricultural activities.

Use of Remote Sensing (RS) technologies in irrigation management applications provides an opportunity for farmers and decision makers to manage their products at maximized cost-benefit ratio concerning the field variation comparing to the use of traditional techniques (Brisco et al., 2014). RS technologies acquire data processes on the Earth in a variety of types and at different spatio-temporal resolutions. Satellite data can be divided into three levels of resolutions: high ( $<50 \mathrm{~cm}$ ), coarse $(>1 \mathrm{~km}$ ) and medium (for instance $250 \mathrm{~m}$ ). Many coarse spatial resolution products are publicly available and are widely used, for example in monitoring water deficit in agricultural area that is used in turn to retrieve EvapoTranspiration (ET), water content, and other products that are necessary for precision orchard management.

\subsection{Crop water requirement}

There is a need for estimating remote sensing-based high resolution ET maps and improve estimation of Crop Water Requirement (CWR) in orchard management ( $\mathrm{Ha}$ et al., 2012a). The absence of access to higher spatial resolution of ET maps has been a challenge because of coarser resolution thermal bands from satellite sensors ( $\mathrm{Ha}$ et al., 2012b). To overcome this issue, disaggregation methods are needed to increase the spatial resolution of ET images and thermal bands of satellite sensors.

Determining the water supply for various crops types based upon their requirement for consumption is an important management decision (Wu et al., 2012). Water deficit, defined as the difference between supply and requirement, is increasingly the result of improper water resource management. An important variable in this respect is the crop ET. In fact, the ET refers to two simultaneous processes related to plant - moisture interaction: evaporation, being the loss of water from the soil surface, and transpiration 
the removal of water from wet vegetation through the atmosphere (Allen et al., 1998). Actual ET (AET) is defined as the actual elimination of water from the surface, and Potential ET (PET) as the capability of the atmosphere to remove the water from the surface as a consequence of evaporation and transpiration. In agricultural irrigation management systems, the amount of water that is needed to maximize crop productivity, the so-called Crop Water Requirement (CWR), equals the difference between AET and PET:

$\mathrm{CWR}=\mathrm{PET}-\mathrm{AET}$

The CWR is thus the deficit, or the water stress of the crop and water supplement is required if CWR $>0$.

\subsection{Scale issues in Remote Sensing}

Scale of RS data and scale of management are usually not matching. There is a need to improve applicability of RS data in precision orchard management one needs to change the support of RS data. The change of support could be either upscaling or downscaling. In traditional agriculture, a field was the smallest scale for management. In modern precision orchard management, however, the management scale is rows of trees, individual trees or even leaves. From the Remote Sensing point of view, scale means the spatial resolution, or the support of the data and scale transfer is change in support. Support is the largest area of an object of interest (Bierkens et al., 2000) where refers to the ground resolution cell size as it represents the pixel size of the image. To achieve a finer scale level, the pixel size needs to be divided into smaller pixels. Downscaling aims at dividing coarse resolution pixels to obtain finer spatial resolutions. Downscaling is equivalent to decreasing the support of the image and is a disaggregation method. Disaggregation methods can be classified into scale-based (downscaling) and image fusion methods (Ha et al., $2012 b)$. Both methods aim to enhance spectral and spatial resolution of images. Downscaling methods convert a coarse resolution image into an image of a finer spatial resolution. Downscaling methods do not change radiometric properties of the image (Luo et al., 2008). In contrast, image fusion uses two or more images from different or the same sensors (Aiazzi et al., 2002) to obtain both a higher spatial resolution and a finer spectral resolution image. Fusion is carried out to produce a relevant RS product using high, medium and low resolution images. Adversely, there also could be a demand of aggregating fine spatial resolution pixels to a coarse spatial resolution. Aggregation is referred to upscaling by increasing the support of the research area (Bierkens et al., 2000). Figure 1.1 illustrates the downscaling and upscaling concepts. 


\section{Downscaling}
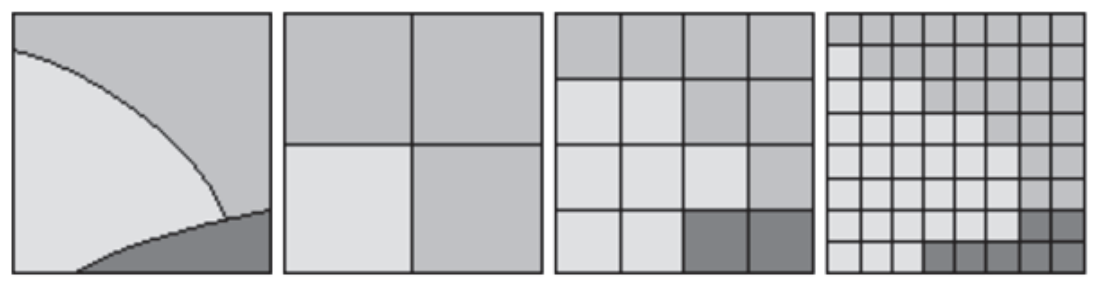

\section{Upscaling}

Figure 1.1: The concept of downscaling by decreasing and upscaling by increasing the pixel support

\section{The field scale}

In an agricultural system, fields as traditional management units, are observable from RS images that may show spatial variation within each field. Improved measurement facilities and location specific conditions of soils and crops at any given time are playing a crucial role in modern precision orchard management (Bouma, 2007). In this way, timely, updated and localized information are vital for various management actions such as control of irrigation water. Timely information means real time observations and per day decision making. Such information should be available at the scale of management. For instance, farmers require information regarding crop water requirement and soil moisture conditions during the growing season. Decision making, however, can also be considered at different levels such as that of the national government, the local government, agro-industrial complexes, and farmers. It is important to know the scale of RS data and compare that at the scale at which decision making needs to be applied for the agricultural purposes (Bierkens et al., 2000). Definition of scale implies spatial and temporal variability. The scale level should therefore be considered in relation to the scale level that is required for the decision makers in agricultural management systems.

Bouma (2007) pointed out that management decisions by farmers and decision makers can be divided into three dimensions: the strategic dimension, the tactical dimension, and operational decisions. The strategic dimension covers major decisions about the future of farm. The choice of crop type or level of scale further belongs to a tactical dimension. As operational decisions, and with respect to the context of precision orchard management it is for example important to know where and how much water should be given to each field or specific parts of the fields, e.g. rows, or in orchard to the particular tree. Therefore, it is important to obtain correct and reliable information at an 
operational scale. In particular, Remote Sensing techniques should be applied at the required level of scale.

Use RS images of a coarse spatial resolution and a high temporal and spectral resolution in the field management are problematic to be used for precision orchard management, as their large pixel size is not useful for management at the field level. This problem can be solved by means of downscaling and fusion methods. To produce the timely and localized end products, downscaling techniques could provide the high spatial resolution satellite data to produce proper information, e.g., timely crop water requirement at the required scale which is useful for different levels of precision orchard management.

\section{The plant scale}

In traditional agricultural management system, the field was the smallest unit. Nowadays, the management scale is finer, namely the rows of tree in orchard, or even individual trees. In that sense, RS observation and management scale practices do not fully coincide yet. High spatial resolution satellite images can be used to identify groups of trees and study their spatial characteristics, but the spatial resolution still is too coarse to count and detect individual trees precisely. Therefore, the pixel size of the image on the ground is too coarse to distinguish trees in a row. Nowadays most trees and rows of trees, are irrigated using drip irrigation method. This method drips water slowly to optimize water use. The drippers could be closed for several reasons, such as the presence of sediment causing water shortage, which leads to low production and eventually dying of trees. To avoid this problem, individual trees need to be inspected during the growing season. This will create a possibility to irrigate each tree based upon its actual water needs. To achieve this, the spatial location of each individual tree is needed as well as its crop water requirement. Water supply can be measured through soil moisture, whereas the CWR in orchards is not always fixed and stable because of the temporal variation in various type of the orchards and yearly weather changes. The water stress at individual trees shows variation and characterization depending on temporal, spatial and weather-related categories. In many production situations, such as a vineyard, only one type of crop is cultivated. Even here, there is a variation in temperature, solar radiation and humidity.

High spatial resolution satellite images provide fine spatial details on the ground. Rows of trees can be distinguished and can be enumerated using the high resolution panchromatic band. Trees with different canopy crown structures and shapes are covered in an RS image by several pixels. Downscaling methods divide those pixels into smaller ones in order to obtain finer spatial resolution by means of achieving more details of extracting individual trees. 


\subsection{Uncertainty issues in spatial modeling}

Spatial data quality is a key issue in GeoInformation science. It allows to identify sources of uncertainty and thus to make better decisions. Fisher (1997) pointed out three forms of uncertainty during the process of deriving spatial data set from the real world: error, vagueness and ambiguity. Error is the difference between object measured with unknown error and the same object measured without error. Vagueness or fuzziness is uncertainty in the definition of an object or its position on the ground. It can often be identified with respect to the extent of an object. Ambiguity arises due to disagreement on objects and the way they are defined in a spatial data set (Fisher, 1997). To investigate the uncertainty, a reference data set is indispensable. A reliable reference data set should specify how it was collected and how it relates to the data set used for the analysis. Van Oort (2006) defined 11 elements for spatial data quality. In this research, we consider positional accuracy, variation in quality and resolution. Uncertainty can be assessed using statistical models and spatial models for the purpose of

- Disaggregation of thermal remote sensing images from coarse to fine spatial resolution.

- Disaggregation of ET maps from coarse to fine spatial resolution.

- Presence of spatial extent and location for detecting individual trees.

For precision orchard management, uncertainty assessment is useful to validate a tree crown boundary by the presence and the spatial extent of individual trees. Accuracy indicators with respect to the spatial extent of the tree objects include: true positives where a tree is present both on the image and in the reference data; false positives where a tree is present on the image but absent at the reference data; and false negatives where there a tree is absent on the image but present in the reference data (Schuenemeyer and Drew, 2010). In the context of field data to validate information obtained from remote sensing images, uncertainty should be evaluated with respect to the another source of data e.g., in-situ data or the use of better satellite images, i.e. images of a finer resolution, with at least the same spectral bands and collected at the same time.

\subsection{Research problems}

This thesis addresses various problems in orchard management. Low water productivity and inappropriate water allocation due to losses of water in the agricultural irrigation networks may cause low water use efficiency in orchards. Because of accurate and precise CWR estimation, there is an essential need for optimal water allocation to support irrigation management in time and space. Water should be supplied as much as tree in an orchard need with the precise allocation and based on CWR. An important variable regarding water supply is 
estimation of crop ET. The CWR can be determined using Actual ET (AET) and Potential ET (PET) based on satellite RS products.

Lack of high resolution daily AET maps needs to be addressed for water resource management at the orchard scale. The absence of coarse spatial resolution of thermal band at publicly available RS satellite data and in Very High Resolution (VHR) satellite data encounter technical problem to generate the high spatial resolution daily AET maps considering uncertainty issues.

For orchard management, trees are the objects of interest, in particular when it concerns their water supply. Detection of individual trees and delineation of the vegetated crown boundaries are therefore predominant, e.g., for efficient decision making on the CWR. In irrigation orchard management, estimation of CWR depends upon the tree species, tree locations, and tree sizes where the amount of water supply relies on vegetated tree cover fraction. Moreover, individual trees have a spatial pattern at both coarse and fine remotely sensed imageries. These patterns address different parameters related to the tree crown such as tree species and tree sizes with increasingly showing more detail and texture at finer spatial resolution. Detection of individual trees from RS images requires sufficient spectral and geometrical details, in particular Very High Resolution (VHR) satellite images are adequate among current RS images. This scale level of detail is however insufficient for detecting individual trees, where adjacent tree canopies interlocks, especially during the growing season.

\subsection{Research objectives and questions}

The main objective of this research is to assess uncertainty of disaggregation methods supporting precision agriculture management in the field and the plant scales. This includes the following sub-objectives:

First objective: To generate high resolution daily AET maps and consider uncertainties of downscaling in both data and methods.

In this objective the following research questions are addressed:

- How to generate medium spatial resolution AET maps using thermal band of coarse spatial resolution of RS satellite image?

- What method is most convenient to scale ET maps with the thermal band of RS satellite images?

- How to carry out an uncertainty analysis for downscaling methods at finer spatial resolution AET maps?

Second objective: To disaggregate from the field scale to the rows and individual plants for AET estimation integrating SRM and image fusion.

In this objective the following research questions are addressed: 
- How to extract information of individual plants of vineyard with SRM?

- What could be the role of SRM at plant scale information for vineyard?

- How to validate the result of SRM?

- How to integrate the results of SEBS and SRM?

Third objective: To investigate the application of scale-space methods for individual tree detection from VHR remote sensing imageries.

In this objective the following research questions are addressed:

- What kind of information do we need in the scale-space methods?

- Can scale-space be used accurately to detect individual trees in VHR satellite images?

- How to validate the result of the scale-space for individual tree detection?

Fourth objective: To improve automatic detection of individual tree crowns from VHR satellite images by refining a Gaussian blob model in Gaussian scalespace.

In this objective the following research questions are addressed:

- How to refine the tree crown modeling in the scale-space methods?

- How to validate the results of improved tree crown modeling?

- What are the differences between discrete and sampled Gaussian scalespace in resulting detection of individual trees?

- How important is the shape of individual trees in the scale-space methods?

\subsection{Thesis outline}

This thesis consists of six chapters. Chapters 1 and 6 correspond to the introduction and synthesis. Chapters 2-5 present the four technical articles based on ISI journal and conference articles that are published or currently under review for the publication.

Chapter 1. Gives the general introduction to the needs of optimal water allocation on the field and the plant scale levels by introducing the research objectives and research question.

Chapter 2. Proposes the comparison of two downscaling procedures to increase the spatial resolution of mapping actual evapotranspiration.

Chapter 3. Proposes the integration and implementation of detecting rows of plants and mapping daily evapotranspiration for individual trees.

Chapter 4. Describes the implementation of detecting individual trees using the scale-space methods focusing on the presence and spatial extent of the detected individual tree crown results. 
Chapter 5. Proposes and improves the tree crown modeling by refining the Gaussian blob model over the scale direction focusing on decreasing the uncertainty on the final results concerning the spatial extent and location of individual trees.

Chapter 6. Summarizes the conclusions of this research study by answering the research questions and addressing the directions of the future works. 


\section{Chapter 2 A comparison of two downscaling procedures to increase the spatial resolution of mapping actual evapotranspiration ${ }^{1}$}

\footnotetext{
${ }^{1}$ This chapter is based on the published paper:

Mahour, M., Tolpekin, V. A., Stein, A., \& Sharifi, M. A. (2017). A comparison of two downscaling procedures to increase the spatial resolution of mapping actual evapotranspiration. ISPRS journal of photogrammetry and remote sensing, 126, 56-67. DOI: $10.1016 /$ j.isprsjprs.2017.02.004
} 


\begin{abstract}
This research addressed the effects of downscaling cokriging Land Surface Temperature (LST) on estimation of Actual Evapotranspiration (AET) from remote sensing images. Two procedures were followed. We first applied downscaling cokriging to a coarse resolution LST product of MODIS at $1000 \mathrm{~m}$. With its outcome, daily AET of a medium spatial resolution $(250 \mathrm{~m})$ was obtained using the Surface Energy Balance System (SEBS). Second, we downscaled a coarse AET map to medium spatial resolution $(250 \mathrm{~m})$. For both procedures, the $250 \mathrm{~m}$ resolution MODIS NDVI product was used as a covariable. Validation was carried out using Landsat 8 images, from which LST was derived from the thermal bands. The two procedures were applied to an agricultural area with a traditional irrigation network in Iran. We obtained an average LST value of $305.8 \mathrm{~K}$ as compared to a downscaled LST value of 307.0 $\mathrm{K}$. Reference AET estimated with SEBS using Landsat 8 data was equal to 5.756 $\mathrm{mm}$ day $^{-1}$, as compared with a downscaled AET value of $5.571 \mathrm{~mm}^{\text {day }}{ }^{-1}$. The RMSE between reference AET and downscaled AET was equal to $1.26 \mathrm{~mm}^{-1}{ }^{-}$ ${ }^{1}(r=0.49)$ and between reference and downscaled LST to $3.67 \mathrm{~K}(r=0.48)$. The study showed that AET values obtained with the two downscaling procedures were similar to each other, but that AET showed a higher spatial variability if obtained with downscaled LST. We concluded that LST had a large effect on producing AET maps from Remote Sensing (RS) images, and that downscaling cokriging was helpful to provide daily AET maps at medium spatial resolution.
\end{abstract}




\subsection{Introduction}

Precision irrigation as a component of Precision Agriculture (PA) aims at supporting decision makers and farm managers with suggestions and recommendations to meet Crop Water Requirement (CWR) and hence to improve water productivity. It provides a management strategy from multiple sources to optimize crop production, dealing with variation at diverse levels of detail (Pierce and Nowak, 1999). Irrigation Water Requirement (IWR) is particularly challenging if water scarcity prevails. Efficient use of water is needed to provide optimal yields and contribute positively to issues of water scarcity and food security. Use of Remote Sensing (RS) technology in irrigation management applications provides an opportunity for farmers and decision makers to manage their farms by maximizing the cost-benefit ratio in terms of field variation as compared to traditional techniques (Brisco et al., 2014). RS technology acquires data from physical processes that are taking place on the Earth in a variety of types, and at various spatio-temporal resolutions. Satellite products are commonly divided into coarse (low), medium and fine (high) spatial resolution images. Many coarse and medium spatial resolution images of a high temporal resolution are publicly available and accessible to potential users, whereas high spatial resolution images have a too low temporal resolution or are only commercially available. In addition, such images commonly miss several of the required spectral bands, e.g. the middle infrared and thermal bands, thus limiting their applicability in modeling of natural processes like EvapoTranspiration (ET). PA requires detailed information on processes that are taking place on small segments of individual farms, hence requiring high spatial resolution products. In short, high spatial and temporal resolution images are required to provide ET maps that are useful for CWR and IWR to support irrigation management (Ha et al., 2012a) at the farm level.

Producing daily ET maps of a high spatial resolution has been a challenge as only coarse resolution thermal bands from satellite sensors are operationally available at the required temporal resolution (Ha et al., 2012b). Downscaling methods are potentially useful to increase the spatial resolution of ET maps and thermal bands of various satellite sensors.

Obtaining ET information is a key component in estimating the water balance in soil, vegetation and surface energy (Yang et al., 2006). It simultaneously comprises water evaporation by means of land and water surfaces and transpiration from vegetation (Gowda et al., 2007); (Allen et al., 1998). Two types of ET are distinguished: AET is the actual elimination of water from the vegetated area and the soil and potential ET (PET) is the capability of the atmosphere to remove water from the surface as consequence of evaporation and transpiration process if crop is severe water shortage. 
Several methods exist to estimate ET. First, ET can be measured within the field. To do so, field measurements can be used in the eddy covariance technique (EC), the Bowen ratio-energy balance (BREB), or soil water balance techniques, such as surface renewal (SR) or lysimeter methods (Ha et al., 2012a). Second, ET can be spatially estimated by means of the surface energy balance, which combines information from different sources, such as RS images, ground meteorological data. This study considers ET as a spatial variable and hence it is important to know its spatial distribution at diverse spatial scales. The distribution is likely to also change in time. Field-based techniques are based upon point-based measurements and hence can only partly provide this distribution for a large area. RS-based ET models estimate ET from the field scale to the regional scale (Gowda et al., 2007) at different spatial and temporal resolutions. In this context, several models have been developed such as METRIC (Allen et al., 2007; Gowda et al., 2007), the Surface Energy Balance Algorithm for Land (SEBAL); (Bastiaanssen, 2000), the Simplified Surface energy Balance (SSEBS) (Senay et al., 2007), and the Surface Energy Balance System (SEBS) (Su, 2002). All these models require data from the thermal bands of satellite sensors. Daily ET maps estimated from available and accessible RS data are too coarse to be used in precision farm management, as the pixel sizes are commonly too large to well present spatial variability within individual fields, thus causing substantial errors (Braswell et al., 2003). Such errors are therefore caused by pixels that have diverse land cover and various vegetation types, roughness conditions and soil moisture contents (Kustas et al., 2004). Clearly, there is a gap between available and needed spatial and temporal scales (Wu and $\mathrm{Li}, 2009$ ) for optimal water allocation in an irrigation network. Recently, high spatial resolution images provide a tool to identify more accurate detail and variation in space, whereas high temporal resolution images help us to understand variation of ET across time at different field scales.

In geostatistics, scale is equivalent to the support size, and scale transfer means change of support. Support for RS images is equivalent to the pixel footprint. Support is the largest area for the property of interest that does not include its variation. Downscaling decreases the support size of the pixel area, thus increasing the spatial resolution of an image (Tang et al., 2015); this is also called disaggregation. Disaggregation methods are classified into two groups, traditional scale-based downscaling methods and image fusion methods ( $\mathrm{Ha}$ et al., 2012a), both aiming to enhance spectral properties and spatial resolution of images. Downscaling methods convert a coarse spatial resolution image to a finer spatial resolution image using geostatistical models. They preserve the radiometric properties of the image. Image fusion, in contrast, uses two or more images (Aiazzi et al., 2002) to obtain both high spatial and spectral resolution images at the same time (Ha et al., 2012b). Early examples are downscaling the Landsat 7 thermal band using NDVI as a 
co-variable (Rodriguez-Galiano et al., 2012), and integrating super resolution mapping for ET estimation at the field scale using image fusion (Mahour et al., 2015a). The basis for downscaling LST, however, is the inverse relationship between LST and NDVI as has been studied well in literature (e.g. W. P. Kustas et al. 2003). In this research geostatistical downscaling is used to increase the spatial resolution thermal band of RS images for PA purposes. Moreover, the SEBS model is used to estimate AET using satellite image data and weather information.

The objective of this research was to study the effect of downscaling LST using cokriging on estimation of AET applying SEBS. Medium resolution daily AET maps were generated to quantify the uncertainties encountered during downscaling.

\subsection{Study area and data}

Iran is a water scarce country with limited rainfall in a semi-arid region, being a relatively dry country with limited water resources. The study area is a part of an irrigation network located in a semi-arid region in the Qazvin province, in the North of Iran. Qazvin is near Tehran and suffers from water shortage in the agricultural sector. The Qazvin irrigation network contains two main lateral canals (L1 and L2) and is one of the oldest and most advanced systems in the country. The study area and its related network are used as a pilot area for this study. The irrigation network is located between $36^{\circ} 01^{\prime} 05^{\prime \prime}$ to $36^{\circ} 13^{\prime} 09^{\prime \prime}$ $\mathrm{N}$ and $50^{\circ} 14^{\prime} 34^{\prime \prime}$ to $50^{\circ} 29^{\prime} 31^{\prime \prime} \mathrm{E}$ (Figure 2.1), near the city of Qazvin and covers an area of approximately $400 \mathrm{~km}^{2}$. The network structures and methods to determine CWR are old, causing substantial water loss, low water efficiency and poor crop productivity.

The irrigated area consists of fallow farms and a wide diversity of crop types such as wheat, corn, barley, canola, potato, sugar beet, lentil, pea, bean, tomato, orchard and grape garden (vineyard). The irrigation network is defined from the smallest level e.g., the field, to the largest level, e.g. the whole area. A field (parcel) is the unit with a single crop type, and each farm includes one or more fields. Figure 1 illustrates the irrigation network with the canals L1 and L2 and the gates at the delivery points of water from the water utility system. Each gate supplies water to several farms, e.g. each farm is irrigated via a single gate. 


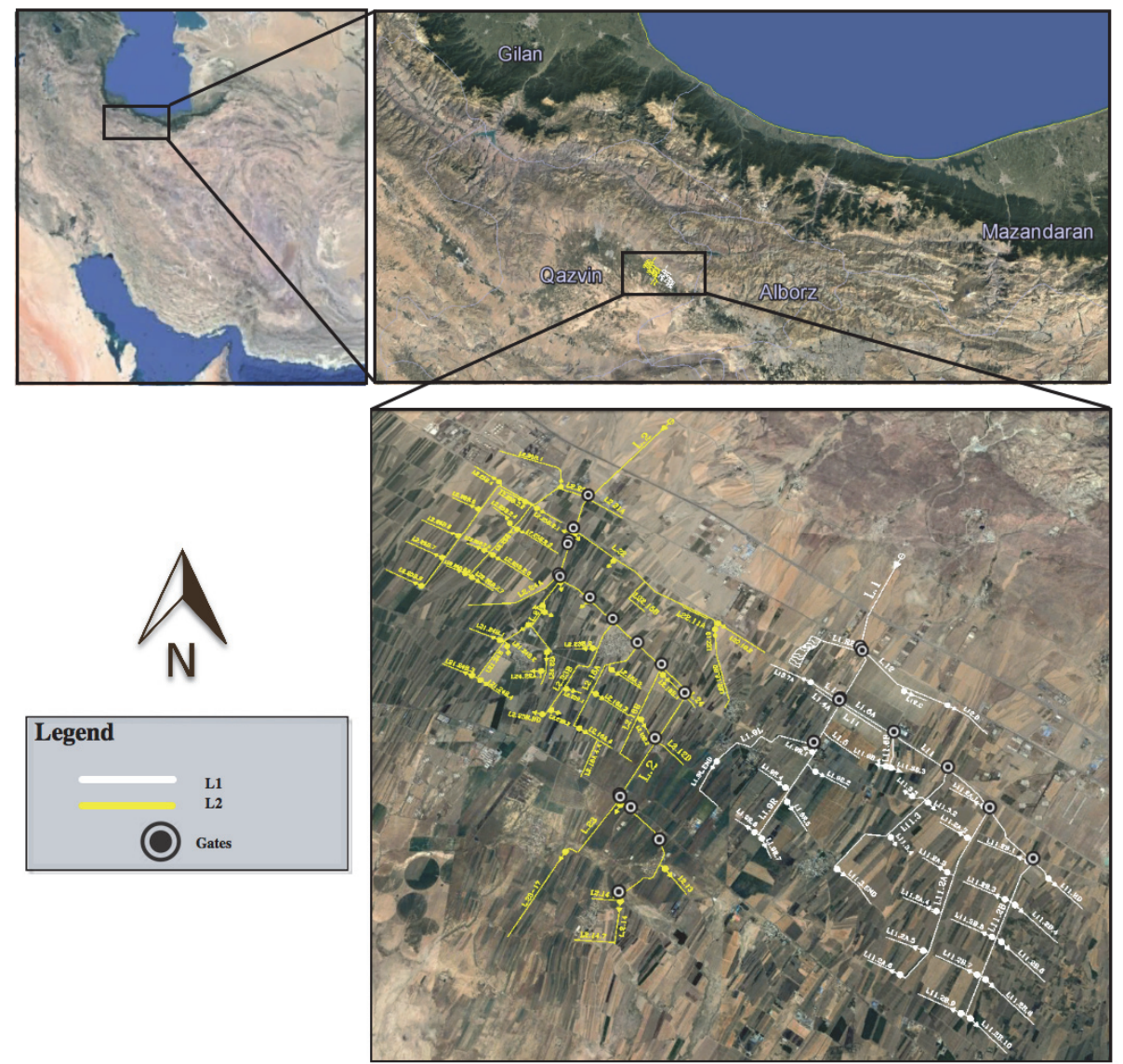

Figure 2.1:The study area located at part of the irrigation network in Qazvin, Iran, including the L1 (right) and L2 (left) lateral canals that are clearly visible in the NW-SE directions. Circles show gates at the beginning of each sub-lateral canals (Source: Google Earth).

\section{Remote sensing imagery}

The Moderate-resolution Imaging Spectroradiometer (MODIS) is an RS instrument installed in two Terra and Aqua satellites. It captures data at diverse spatial resolutions from $250 \mathrm{~m}$ to $1000 \mathrm{~m}$ for different bands. MODIS with two satellites is able to provide data every one or two days. In addition, it has several derived products such as the Land Surface Temperature (LST) and the Normalized Difference Vegetation Index (NDVI) to be used in this study. The more recent Landsat Data Continuity Mission (LDCM) has a sensor of a finer spatial resolution sensor in the thermal channels. Landsat 8 provides multispectral sensor images at $30 \mathrm{~m}$ spatial resolution, panchromatic sensor image at $15 \mathrm{~m}$ spatial resolution and two thermal channels of $30 \mathrm{~m}$ spatial resolution. Image data from Landsat 8 are available every 16 days.

In this study, three RS images were acquired: an LST (MOD11A2) and an NDVI (MOD13Q1) MODIS product, and a Landsat 8 satellite image (Figure 2.2). The 
daily LST product has a $1000 \mathrm{~m}$ spatial resolution and the 16 days NDVI product has a $250 \mathrm{~m}$ spatial resolution. The LST product was collected on June 6, 2014 whereas the NDVI product was taken on June 10, 2014. The period covered by the NDVI product included the date of the LST product. The Landsat 8 image was taken on June 6, 2014 at 7:13 AM (GMT).

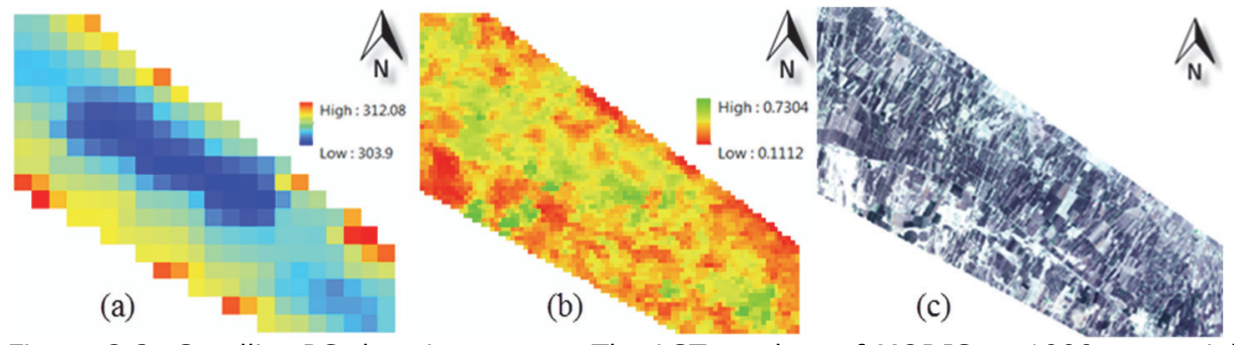

Figure 2.2: Satellite RS data imagery. a The LST product of MODIS at $1000 \mathrm{~m}$ spatial resolution, $\mathbf{b}$ The NDVI product of MODIS at $250 \mathrm{~m}$ spatial resolution and $\mathbf{c}$ The Landsat 8 image at $30 \mathrm{~m}$ spatial resolution (RGB)

\section{Meteorological data}

Major input for the SEBS model are the local weather data that were available from the local Qazvin weather station on June 6, 2014. This weather station, located in Qazvin city, has coordinates 36 $15^{\prime} 00^{\prime \prime} \mathrm{N}, 50^{\circ} 30^{\prime} 00^{\prime \prime} \mathrm{E}$. It is $23 \mathrm{~km}$ and $33 \mathrm{~km}$ away from canals L1 and L2, respectively. Table 2.1 shows the weather data, including maximum and minimum air temperature, air pressure, wind speed, humidity, ET of grass as reference and sunshine hours every three hours.

Table 2.1: The ground meteorological at the local weather station in Qazvin. Time of recording information is at 6 am GMT.

\begin{tabular}{cccccccc}
\hline & $\begin{array}{c}\text { Wind } \\
\text { speed } \\
\left(\mathrm{m}_{\mathrm{s}}^{-1}\right)\end{array}$ & $\begin{array}{c}\text { Max } \\
\text { Temp } \\
\left({ }^{\circ} \mathrm{C}\right)\end{array}$ & $\begin{array}{c}\text { Min } \\
\text { Temp } \\
\left({ }^{\circ} \mathrm{C}\right)\end{array}$ & $\begin{array}{c}\text { Sunshine } \\
(\mathrm{h})\end{array}$ & $\begin{array}{c}\text { Humidity } \\
(\%)\end{array}$ & $\begin{array}{c}\text { Air } \\
\text { pressure } \\
(\mathrm{mbar})\end{array}$ & $\begin{array}{c}\mathrm{ET} \\
(\mathrm{mm} / \mathrm{day})\end{array}$ \\
\hline $2014-$ & 2 & 32.1 & 10.7 & 10 & 21 & 870.2 & 7 \\
$06-06$ & & & & & & & 7 \\
\hline
\end{tabular}

\subsection{Methods}

The methods applied in this research consist of three steps (Figure 2.3). The first step is to apply downscaling cokriging on a coarse resolution MODIS LST product image to estimate daily medium resolution AET using the SEBS. The second step is to downscale coarse resolution AET at $250 \mathrm{~m}$ spatial resolution. The MODIS NDVI product is used as a co-variable in both steps. The third step carries out validation using derived LST and AET from Landsat 8 images. 


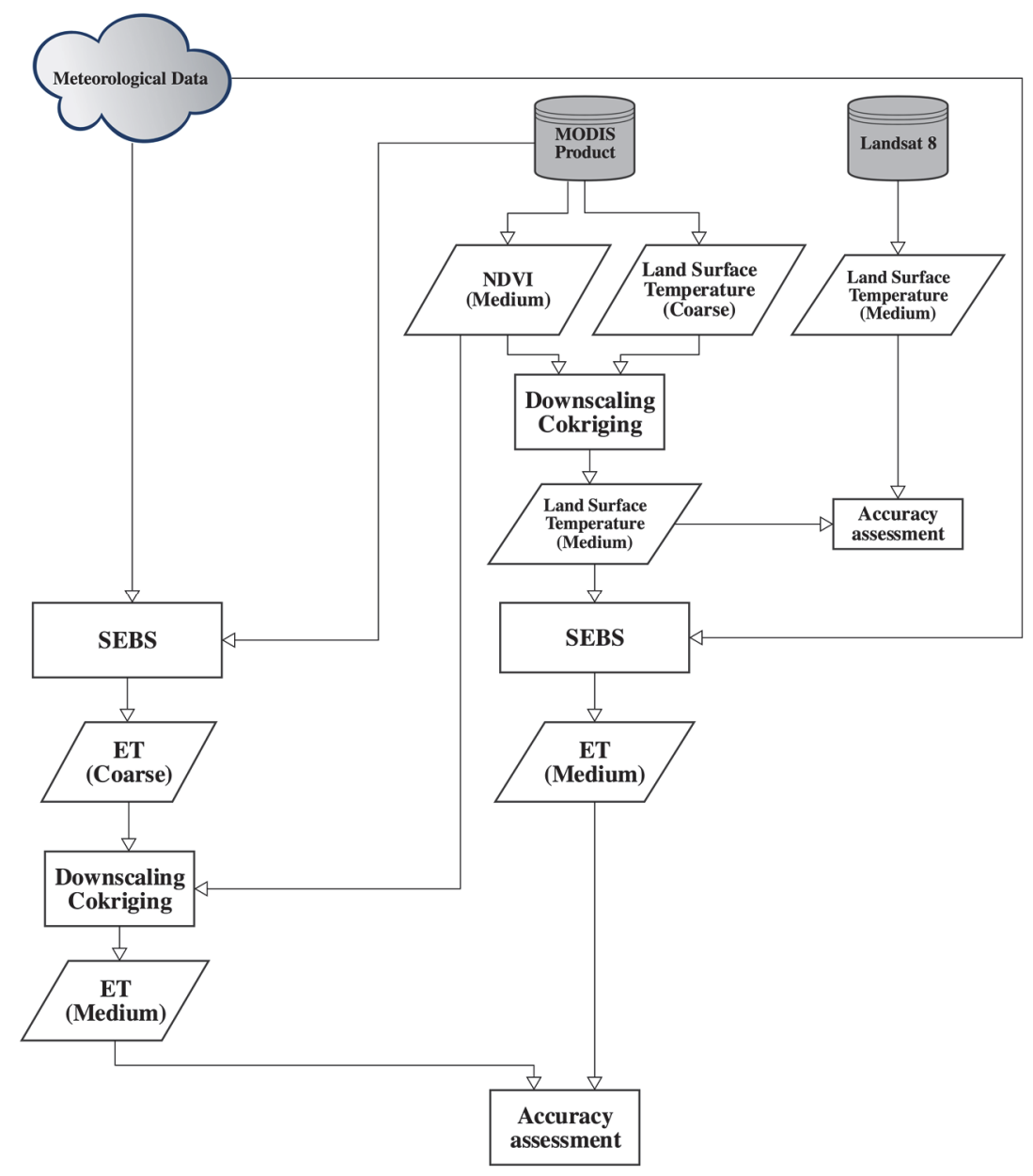

Figure 2.3: Schematic diagram of the general methodology

\section{Downscaling cokriging}

Downscaling cokriging aims at merging two spatial datasets with different spatial resolutions, using the spatial structure inherent in those datasets (Rodriguez-Galiano et al., 2012; Stein and Corsten, 1991). We consider a fine spatial resolution cokriged image written as:

$\widehat{\mathrm{Z}}_{u_{0}}^{k_{0}}\left(s_{0}\right)=\sum_{i=1}^{M} \alpha_{i} \mathrm{Z}_{v}^{k}\left(s_{i}\right)+\sum_{j=1}^{N} \beta_{j} \mathrm{Z}_{V}^{l}\left(s_{j}\right)$

where

- $\quad \hat{\mathrm{Z}}_{u_{0}}^{k_{0}}\left(s_{0}\right)$ is a downscaled cokriged predictor random variable (RV) which represents the pixel value at centroid location $s_{0}$ with support $u_{0}$ and spectral band $k_{0}$. 
- $\quad \mathrm{Z}_{v}^{k}\left(s_{i}\right)$ is a $\mathrm{RV}$ at pixels with support $v$ of coarse spatial resolution image and spectral band $k . N$ pixels are used. For instance, summation over $N$ pixels could be included a square $3 \times 3,5 \times 5,7 \times 7$ and or $9 \times 9$ window of nearest pixels; $\alpha_{i}$ is a weight assigned to the RV of the pixel $i$.

- $\quad \mathrm{Z}_{V}^{l}\left(s_{j}\right)$ is a RV at pixels with support $V$ of fine spatial resolution image and spectral band $l$. $M$ pixels are used. For instance, summation over $M$ pixels could be a square $3 \times 3,5 \times 5,7 \times 7$ and or $9 \times 9$ window of pixels; $\beta_{j}$ is a weight assigned to the RV of the pixel $j$.

Further, $u_{0}, v$ and $V$ are identified as pixel size or geostatistical support (Rodriguez-Galiano et al., 2012). Pixels from the coarse resolution image LST product of MODIS are used as the RV that is being downscaled using cokriged predictor. Then, $k_{0}$ indicates the downscaled LST image with support $u_{0}$ equals $250 \mathrm{~m}, k$ indicates a coarse resolution MODIS LST product with support $v$ equals $1000 \mathrm{~m}$ and $l$ indicates the high spatial resolution MODIS NDVI product with support $V$ equals $250 \mathrm{~m}$. The parameters $\alpha_{i}$ and $\beta_{j}$ are estimated as two optimal sets of weights with minimum prediction error variance $E\left\{\left[\hat{\mathrm{Z}}_{u_{0}}^{k_{0}}\left(s_{0}\right)-\right.\right.$ $\left.\left.\mathrm{Z}_{v}^{k}\left(s_{i}\right)\right]^{2}\right\}$. These weights are obtained by solving the cokriging system to estimate the pixel value of $\hat{\mathrm{Z}}_{u_{0}}^{k_{0}}\left(s_{0}\right)$ in order to give an unbiased predictor $\mathrm{E}\left\{\hat{\mathrm{Z}}_{u_{0}}^{k_{0}}\left(s_{0}\right)-\mathrm{Z}_{V}^{l}\left(s_{j}\right)\right\}=0$.

The cokriging system is represented by the following matrix equation:

$\mathrm{CX}=\mathrm{B}$

$\mathrm{C}=\left[\begin{array}{cccc}\mathrm{C}_{v v}^{k k}\left(h_{M M}\right) & \mathrm{C}_{v V}^{k l}\left(h_{M N}\right) & 1 & 0 \\ \mathrm{C}_{V v}^{l k}\left(h_{N M}\right) & \mathrm{C}_{V V}^{k l}\left(h_{N N}\right) & 0 & 1 \\ 1 & 0 & 0 & 0 \\ 0 & 1 & 0 & 0\end{array}\right]$

$\mathrm{B}=\left[\begin{array}{c}\mathrm{C}_{u_{0} v}^{k_{0} k}\left(h_{01}\right) \\ \vdots \\ \mathrm{C}_{u_{0} v}^{k_{0} k}\left(h_{0 M}\right) \\ \mathrm{C}_{u_{0} V}^{k_{0} l}\left(h_{01}\right) \\ \vdots \\ \mathrm{C}_{u_{0} V}^{k_{0} l}\left(h_{0 N}\right) \\ 1 \\ 0\end{array}\right]$

$\mathrm{X}=\left[\begin{array}{c}\alpha_{1} \\ \vdots \\ \alpha_{M} \\ \beta_{1} \\ \vdots \\ \beta_{N}\end{array}\right]$ 
The weights are obtained as:

$\mathrm{X}=C^{-1} B$

where the inverse matrix $C$ represents the variograms and cross variograms between two RVs in the right hand side of Equation 2.1, being variograms of low $\mathrm{Z}_{v}^{k}$ and high $\mathrm{Z}_{V}^{l}$ spatial images and cross variograms between them. The variograms of the low and high spatial resolution images are denoted by $\mathrm{C}_{v v}^{k k}$ and $C_{V V}^{l l}$, respectively. $C_{V v}^{l k}$ is the cross variogram between $\mathrm{Z}_{v}^{k}(s)$ and $\mathrm{Z}_{V}^{l}(s)$, where $h$ is as of the spatial Euclidean distance between centroid of $s$ and $s$ of two pixels (Atkinson et al., 2008). The variogram represents the spatial variation of that $\mathrm{RV}$ as a function of $h$ distance which is given by:

$\mathrm{C}_{v v}^{k k}(h)=\frac{1}{2} E\left\{\left[\mathrm{Z}_{v}^{k}\left(s_{i}\right)-\mathrm{Z}_{v}^{k}\left(s_{i}+h\right)\right]^{2}\right\}$

Similarly for $V$ the variogram is $\mathrm{C}_{V V}^{l l}(h)$ including the expected squared differences in $V$. The cross variogram between two low and high spatial images is defined as:

$\mathrm{C}_{V v}^{l k}(h)=\frac{1}{2} E\left\{\left[\mathrm{Z}_{v}^{k}\left(s_{i}\right)-\mathrm{Z}_{v}^{k}\left(s_{i}+h\right)\right]\right\}\left\{\left[\mathrm{Z}_{V}^{l}\left(s_{i}\right)-\mathrm{Z}_{V}^{l}\left(s_{i}+h\right)\right]\right\}$

The cross variogram describes the spatial variation between two high and low spatial resolution images.

There are two variograms and one cross variogram functions in Equation 2.4 that are not empirically available because, $\hat{\mathrm{Z}}_{u_{0}}^{k_{0}}(s)$ is unknown and is to be predicted. In fact, the two variograms $\mathrm{C}_{u_{0} v}^{k_{0} k}(h)$ and $\mathrm{C}_{u_{0} V}^{k_{0} l}(h)$ can be obtained using linear system theory (Papoulis and Pillai, 2002), which is known as integration or averaging points inside a pixel (Figure 2.4). The linear system theory in geostatistics is referred as regularization by Matheron (1963). It can be written as:

$\mathrm{Z}_{u_{0}}^{k_{0}}\left(s_{0}\right)=\frac{1}{\left|u_{0}\left(s_{0}\right)\right|} \int_{u_{0}\left(s_{0}\right)} \mathrm{z}_{\bullet}^{k_{0}}(y) d y$

where $\mathrm{Z}_{\bullet}^{k_{0}}$ is random function (RF) of spectral band $k_{0}$ at centroid coordinate $y$ at point support •

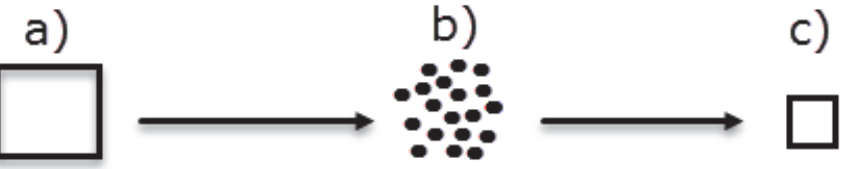

Figure 2.4: Concept of changing support from a pixel support to $\mathbf{b}$ point support, then averaging points to $\mathbf{c}$ finer pixel support 
Equation 2.9 can be defined for each $\mathrm{Z}_{v}^{k}\left(s_{0}\right)$ and $\mathrm{Z}_{V}^{l}\left(s_{0}\right)$ by changing supports from $u_{0}$ to $v$ and $V$, respectively. Averaging or integration in Equation 2.9 can be formulated as a convolution that concerns a point support of the RF and the point spread function (PSF) inside that pixel. This is the so-called impulse response $\mathrm{I}_{u_{0}}(y)$ (Pardo-Igúzquiza et al., 2006), written as:

$\mathrm{I}_{u_{0}}(y)=\left\{\begin{aligned} \frac{1}{u_{0}\left(s_{0}\right)}, & y \in u_{0}\left(s_{0}\right) \\ 0, & \text { otherwise }\end{aligned}\right.$

$\mathrm{I}_{u_{0}}(y)$ as the impulse response function can be constant or non-constant. We use constant function where the PSF can be applied to that pixel of image with support $v$ and $V$, by means of $\mathrm{I}_{u_{0}}(y)$.

The point support variogram $\mathrm{C}_{\bullet \bullet}^{k_{0} k}(h)$ and the cross variogram $\mathrm{C}_{\bullet \bullet}^{k_{0} l}(h)$ can be calculated using convolution and the impulse response function (Matheron, 1963; Papoulis and Pillai, 2002), given by:

$\mathrm{C}_{u_{0} v}^{k_{0} k}=\mathrm{C}_{\bullet \bullet}^{k_{0} k}(h) * \mathrm{I}_{u_{0}}(h) * \mathrm{I}_{v}(h)$

$\mathrm{C}_{u_{0} V}^{k_{0} l}=\mathrm{C}_{\bullet \bullet}^{k_{0} l}(h) * \mathrm{I}_{u_{0}}(h) * \mathrm{I}_{V}(h)$

where $*$ indicates the convolution operator.

\section{LST retrieval from Landsat 8 thermal channels using split window algorithm}

LST is retrieved from thermal channels of Landsat 8 using split window algorithm. e SW algorithm proposed by Sobrino et al. (2007) uses two thermal bands in the atmospheric window between 10 and $12 \mu \mathrm{m}$. LST is then retrieved using (Jimenez-Munoz and Sobrino, 2008):

$T_{s}=T_{i}+c_{1}\left(T_{i}-T_{j}\right)+c_{2}\left(T_{i}-T_{j}\right)^{2}+c_{0}+\left(c_{3}+c_{4} w\right)(1-\varepsilon)+\left(c_{5}+c_{6} w\right) \Delta \varepsilon$

where $T_{i}$ and $T_{j}$ are at-sensor brightness temperatures at Landsat 8 thermal band 10 and band 11 (Kelvin), respectively, $\varepsilon$ is the mean emissivity at the two thermal bands and $\Delta \varepsilon$ is the emissivity difference between band 10 and band 11 . Emissivity $(\varepsilon)$ is estimated following an NDVI threshold method pointed out by $\mathrm{Yu}$ et al. (2014). The SW coefficients $c_{0}$ to $c_{6}$ were extracted from simulated data by Jimenez-Munoz et al. (2014). Atmospheric water vapor content $(w)$ was calculated for moderated and moist atmosphere using ratio technique proposed by Ren et al. (2014). 


\section{Surface energy balance system}

The Surface Energy Balance System (SEBS) was developed for assessing of atmospheric turbulent fluxes and daily ET per pixel using remote sensing data (Su, 2002). The surface energy balance is written as:

$R_{n}=H+\lambda E+G_{0}$

where the net radiation flux $R_{n}$ is expressed as the sum of the sensible heat flux $H$ which is the heat transferred between the air and surface by turbulence, the latent heat flux $\lambda E$ and the soil surface heat flux $G_{0}$ that is the energy for warming the subsurface of the earth, each expressed in $\mathrm{W} \mathrm{m}^{-2}$. SEBS requires three sets of input data:

1. Land surface emissivity (LSE), albedo, temperature and the Normalized Difference Vegetation Index (NDVI) derived from remote sensing images. LSE and albedo are also available at $1000 \mathrm{~m}$ spatial resolution every day and every 16 days, respectively. SEBS can use Landsat and MODIS images with a combination of ground meteorological data as input for calculating the surface energy balance, but is not applicable to Very High Resolution (VHR) images, as these do not have a thermal band.

2. Air pressure, humidity, temperature and wind speed at reference height, obtained from meteorological data.

3. Downward shortwave radiation and downward longwave radiation that can be measured directly or can be obtained from a radiation model.

The output AET from SEBS model is based on the spatial resolution of the thermal band of an image (Su, 2002).

\section{Validation}

We validated the downscaling cokriging results of LST and AET using the Landsat 8 satellite image. A reference LST was estimated from Landsat 8 thermal channels at $30 \mathrm{~m}$ spatial resolution, whereas SEBS was used to determine AET from Landsat 8 images at $30 \mathrm{~m}$ spatial resolution. The accuracy of downscaled AET data was evaluated by comparing these data with LST and AET from Landsat 8 that were upscaled to a $250 \mathrm{~m}$ spatial resolution. This process is approximate only, as the data used for the quality assessment were derived using the same model at the fine resolution that is also used at the coarser resolution. However, the derived values are better data, and hence may serve as a closer approximation of the truth. 


\subsection{Results}

\section{Downscaling LST and ET using NDVI as co-variable}

The mean value of the original LST was equal to $307.0 \mathrm{~K}$ ranging between $303.9 \mathrm{~K}$ to $313.5 \mathrm{~K}(\mathrm{SD}=1.68)$, and the mean of coarse resolution daily $\mathrm{ET}$ was equal to $5.56 \mathrm{~mm}$ day $^{-1}$ ranging from 3.57 to $6.43(\mathrm{SD}=0.49)$. We first explored the relationship of each LST and ET variables with NDVI as a covariable for downscaling LST and ET. To check the relationship between coarse resolution variables with NDVI, both LST and ET were resampled from $1000 \mathrm{~m}$ to $250 \mathrm{~m}$ resolution. We observed a resampling effect being a repletion of resampled LST and ET values (Figure 2.5). The reason was that data were available at the same resolution of the NDVI variable. Figure 2.5 shows the relationship of NDVI between LST and ET at the $250 \mathrm{~m}$ resolution. A linear negative relationship $(r=-0.77)$ exists between resampled LST and NDVI and a positive relationship between ET and NDVI $(r=0.77)$. As a result, a low LST area is commonly identified as a vegetated area, whereas a high LST area occurs on low NDVI areas, e.g. with less or absent vegetation. Consequently, a high ET area is covered with more vegetation, corresponding with higher NDVI values.
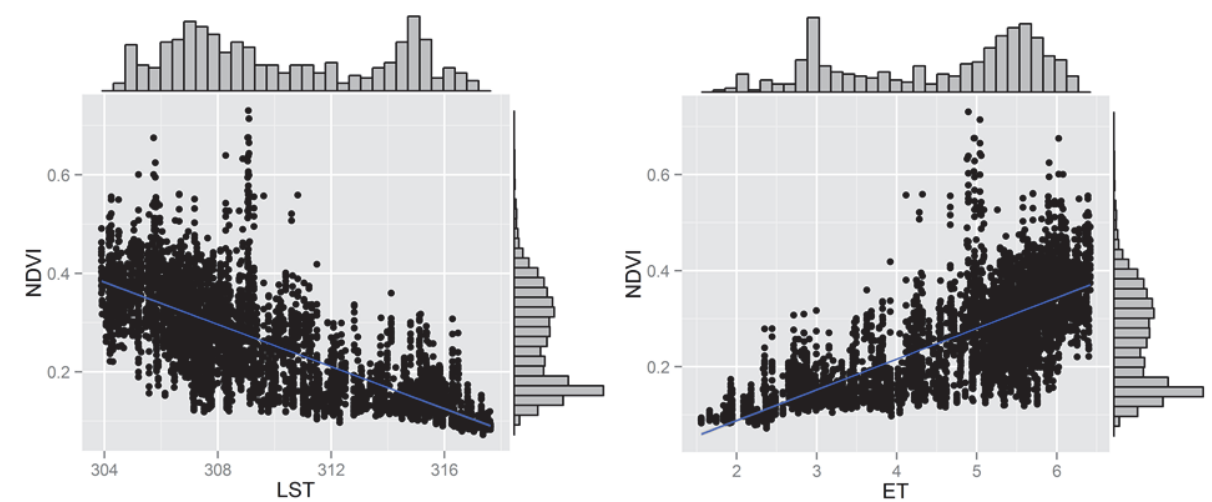

Figure 2.5: Scatter plot and histogram of NDVI between LST and ET at $250 \mathrm{~m}$ spatial resolution 

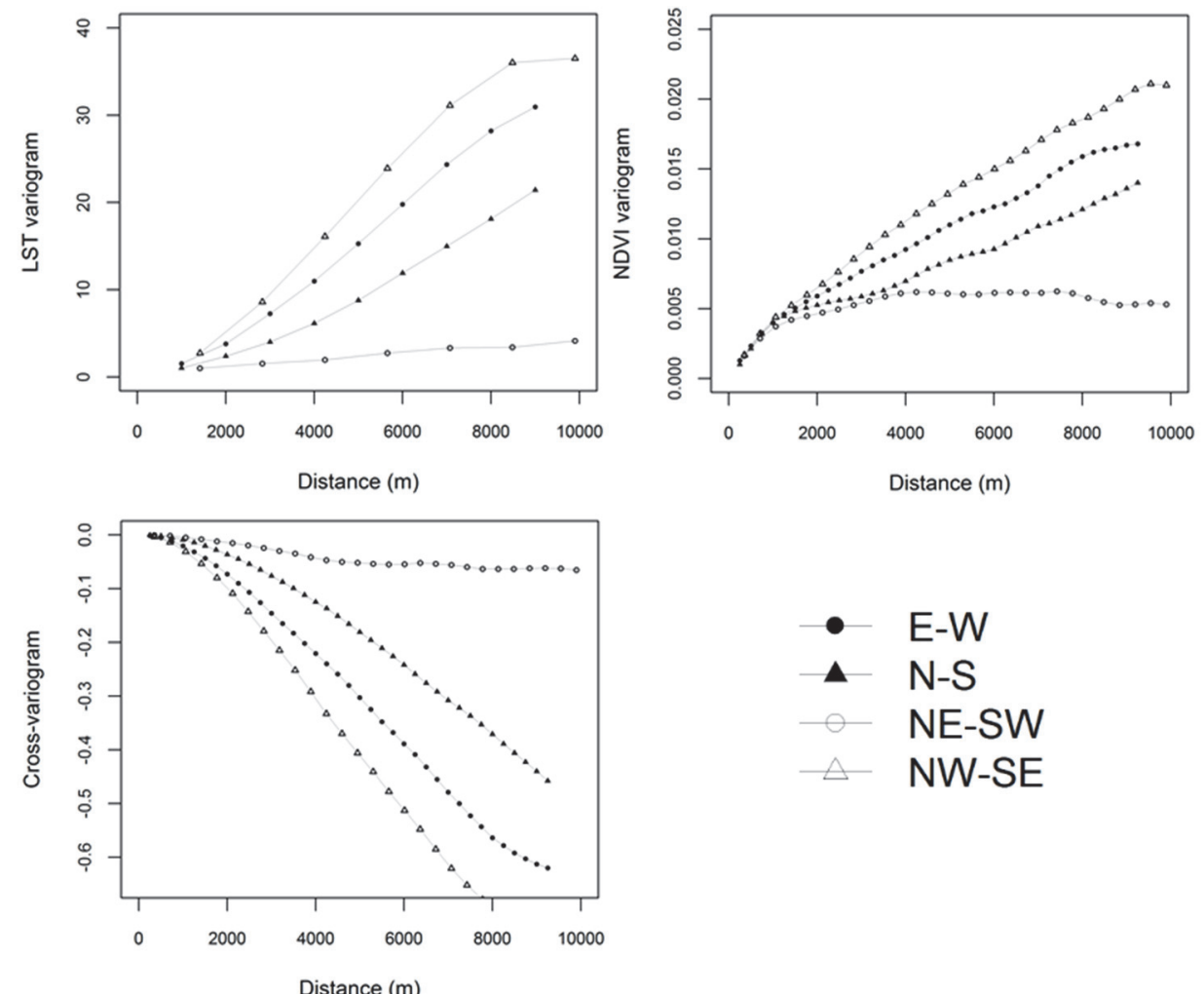

Figure 2.6: Experimental variogram of LST and NDVI images at $1000 \mathrm{~m}$ and $250 \mathrm{~m}$ spatial resolution and cross-variogram between them in four geographical directions 


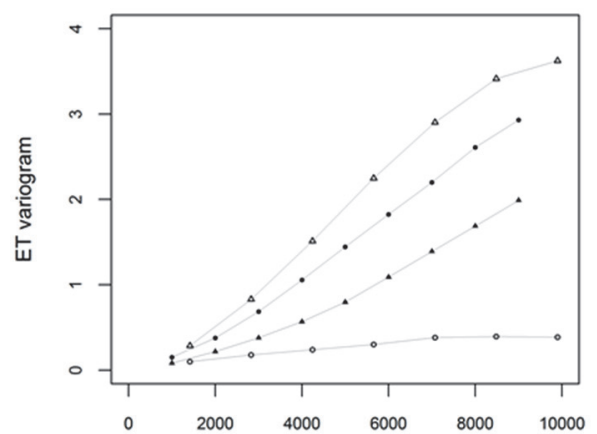

Distance $(m)$

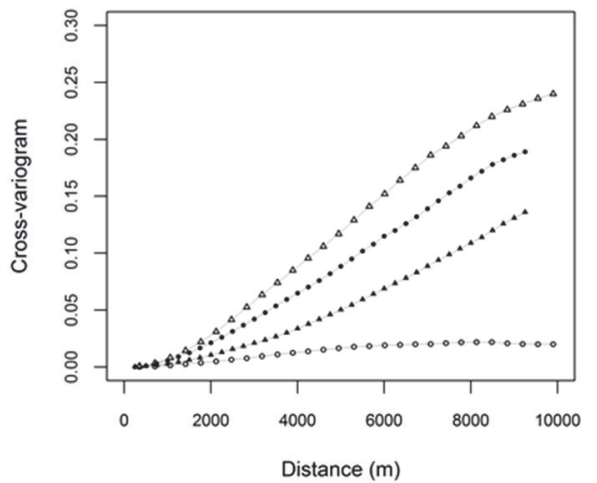

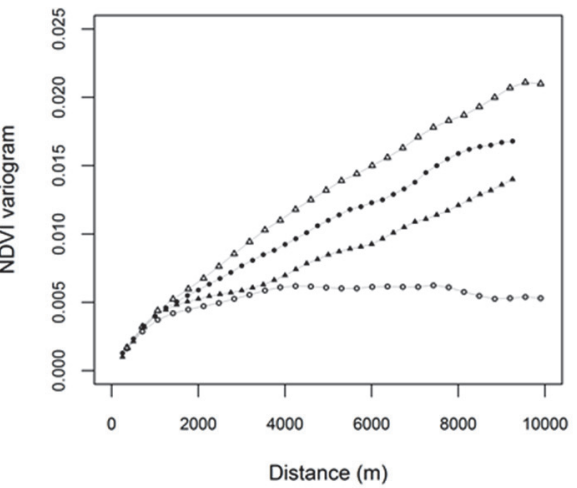

$\rightarrow E-W$

$\triangle \mathrm{N}-\mathrm{S}$

NE-SW

NW-SE

Figure 2.7: Experimental variogram of ET and NDVI images at $1000 \mathrm{~m}$ and $250 \mathrm{~m}$ spatial resolution and cross-variogram between them in four geographical directions

Figure 2.6 shows a negative variance relation between the experimental variograms of LST and NDVI images and the cross-variogram. Figure 7 shows a positive variance between the variograms of AET and NDVI and the crossvariogram. Variograms and cross-variograms showed that the lowest variation occurred in the NE-SW direction, whereas the highest variation was observed in the NW-SE direction for LST, ET and NDVI. These experimental variograms and cross-variogram were used to generate point support variograms and cross-variogram from experimental LST, ET and NDVI images. Following Equation 9, a nested exponential model was fitted with an anisotropy structure. Anisotropy was observed in both range (geometrical) and sill (zonal) in different directional variograms (Figure 2.6 and 2.7). To achieve a common range for all directional variograms to be used in downscaling cokriging, convolution (Equation 2.12 and 2.13) was repeatedly applied by using a cutoff value on the range parameter. In this way, it was possible to find the optimal fitted model of the experimental and induced point support variograms. These point support variograms were employed to obtain weights as low and high pass filters for applying at original LST, ET and NDVI images. 

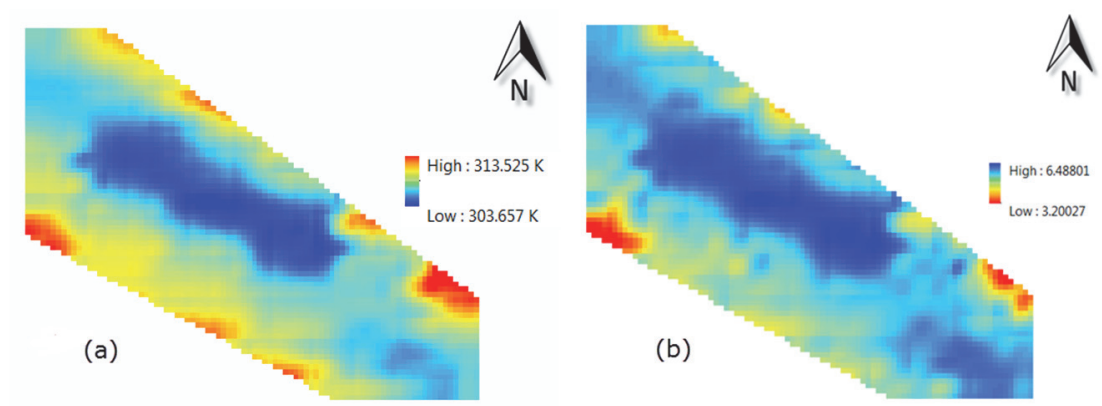

Figure 2.8: Result of downscaling cokriging of $\mathbf{a}$ LST and $\mathbf{b}$ ET using NDVI as co-variable at $250 \mathrm{~m}$ spatial resolution

Figure 2.8 shows downscaled LST and ET using NDVI as a co-variable. To check the consistency of applying downscaling cokriging, we resampled downscaled LST and ET images to the original resolution, and the observed standard deviation of downscaled LST slightly changed from 1.68 to 1.65 , and for AET from 0.51 to $0.52 \mathrm{~mm}$ day $^{-1}$ which means that the downscaled images are similar to the original data in terms of their variability.

Figure 2.9 shows the result of AET using downscaled LST as input for SEBS. As compared with downscaled AET, we note similarity, but more variation was observed for AET using downscaled LST (Figure 2.9). The results indicate that the AET map derived with downscaled LST (Figure 2.9) was largely changed with respect to the areas of the mixed pixels containing both soil and vegetation. Highly vegetated areas with a low LST changed only slightly in comparison with other downscaled method (Figure 2.8b).

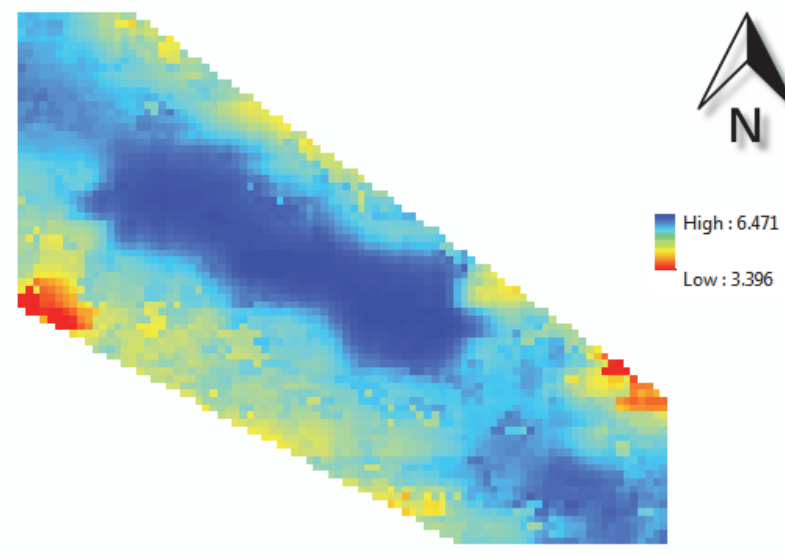

Figure 2.9: AET at $250 \mathrm{~m}$ spatial resolution using downscaled LST as input for the SEBS

Comparing result of downscaled LST and ET with reference data from Landsat 8 image data 
For validating result of downscaled LST and ET, we used the LST data that were retrieved from Landsat 8 at the same date as the MODIS LST product. Figure 2.10 shows LST retrieval at $30 \mathrm{~m}$ spatial resolution from Landsat 8 using the SW algorithm.

Comparing LST estimated from thermal bands of Landsat 8 as reference data with downscaled LST using cokriging, we upscaled the spatial resolution of reference LST from $30 \mathrm{~m}$ to $250 \mathrm{~m}$. Figure 2.11 illustrates the residual map, showing the differences between measured LST (downscaled) and reference LST. The classified error map (Figure 2.11b) shows white color pixels with $2 \mathrm{~K}$ differences, whereas red and blue colors indicate underestimated and overestimated pixels, respectively. These underestimation and overestimation are due to the spatial differences between downscaled LST and reference LST. Underestimation can be observed in the area where covered by soil and patches with salt marsh. Figure 2.12 shows a scatter plot between measured LST and reference LST ( $r=0.48)$, whereas Figure 2.13 illustrates the scatter plot between measured AET and referenced AET $(r=0.49)$. Table 2.2 indicates descriptive statistical information between downscaled and reference LST. Mean LST at both observed and reference data are similar to each other but their standard deviations are different: for downscaled LST it equals 1.70, whereas for reference LST data it equals 4.42 . This caused by small differences between their range values: for downscaled LST the range is from 303.52 to $313.52 \mathrm{~K}$, whereas for reference LST it ranges from 294.21 to $316.68 \mathrm{~K}$. Figure 2.13 shows a scatterplot between reference AET and downscaled AET. Table 2.3 shows statistical information between the downscaled AET and the reference AET. Downscaled AET ranges between 3.20 and $6.48 \mathrm{~mm}^{-1}$ day $^{-1}$ (SD $=0.51$ ), whereas reference AET ranges between 0.06 and 6.15 (SD = 1.77). Their mean values are close: 5.57 for downscaled AET and 5.75 for reference AET, a difference due to a lower AET with a higher LST from the Landsat 8 sensor. Finally, we found that the RMSE between reference and downscaled AET was equal to $1.26 \mathrm{~mm} \mathrm{day}^{-1}(r=0.49)$ and between reference and downscaled LST to $3.67 \mathrm{~K}(r=0.48)$. 


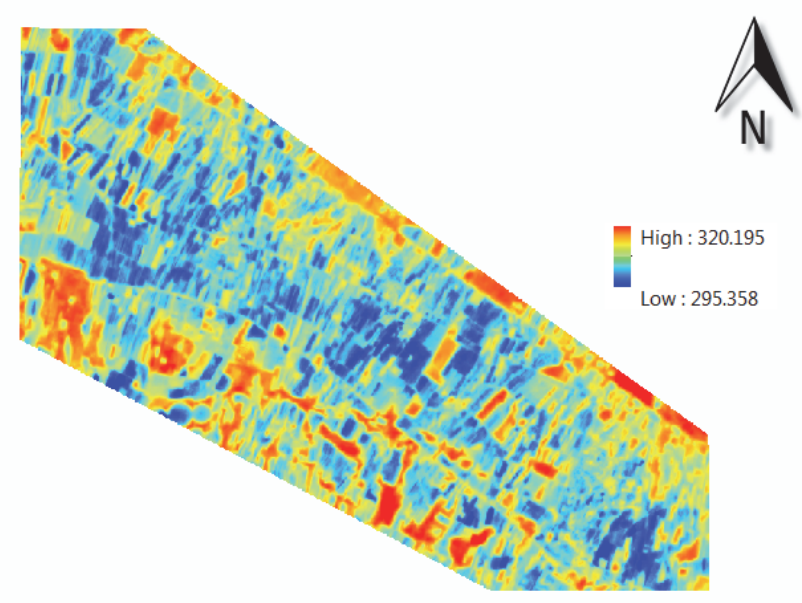

Figure 2.10: Estimated LST from Landsat 8 using the SW algorithm at $30 \mathrm{~m}$ spatial resolution

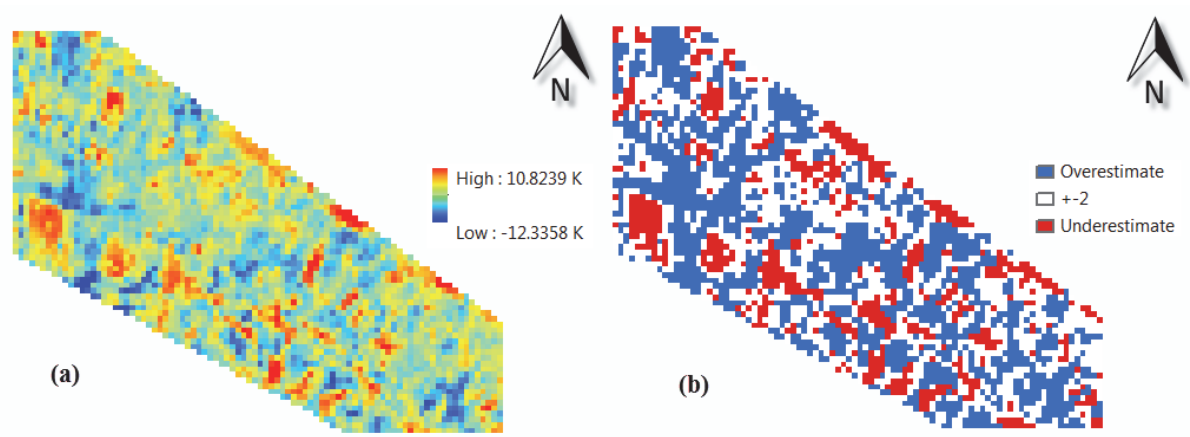

Figure 2.11: a Error map and b classified error map between downscaled LST and reference LST from Landsat 8 at $250 \mathrm{~m}$ spatial resolution

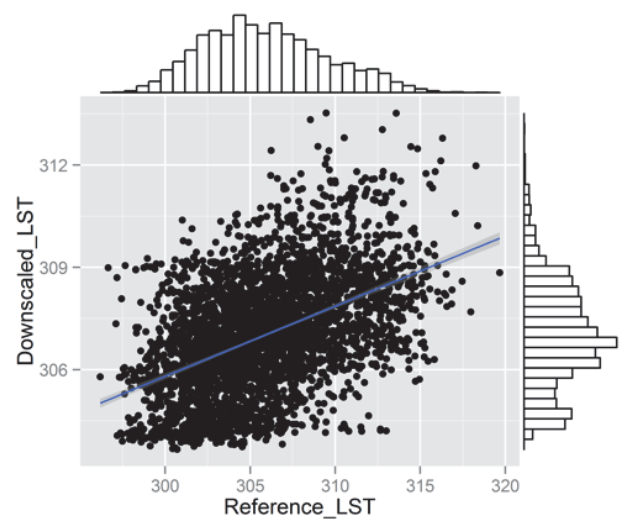

Figure 2.12: Scatter plot between downscaled LST and reference LST from Landsat 8, $r$ $=0.48$ 


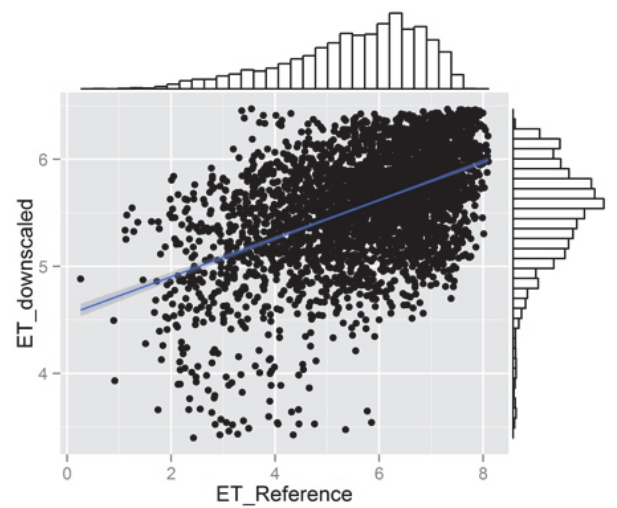

Figure 2.13: Scatter plot between downscaled actual ET and reference actual ET from Landsat 8 at $250 \mathrm{~m}$ spatial resolution, $r=0.49$

Table 2.2: Comparison between downscaled LST from MODIS and Reference LST from Landsat 8 for validation

\begin{tabular}{cccccc}
\hline & Min & Max & Mean & Sd & RMSE \\
\hline $\begin{array}{c}\text { Downscaled } \\
\text { LST } \\
\begin{array}{c}\text { Reference } \\
\text { LST }\end{array}\end{array}$ & 303.52 & 313.52 & 306.98 & 1.70 & 3.67 \\
\hline
\end{tabular}

Table 2.3: Comparison between downscaled AET and Reference AET

\begin{tabular}{cccccc}
\hline & Min & Max & Mean & Sd & RMSE \\
\hline $\begin{array}{c}\text { Downscaled } \\
\text { AET }\end{array}$ & 3.200 & 6.488 & 5.571 & 0.51 & 1.26 \\
$\begin{array}{c}\text { Reference } \\
\text { AET }\end{array}$ & 0.065 & 6.153 & 5.576 & 1.77 & \\
\hline
\end{tabular}

\subsection{Discussion}

\section{Uncertainties related to LST and AET estimation from Landsat 8}

This paper addressed the uncertainty of downscaling LST and AET. Validation was applied between the original LST and AET product available at $1000 \mathrm{~m}$ resolution from MODIS downscsaled to $250 \mathrm{~m}$ resolution, with LST and AET from Landsat 8 data products upscaled to the same resolution. LST and AET scatterplots (Figure 2.14) showed a strong relationship for both MODIS ( $r=$ $0.95)$ and Landsat $8(r=0.94)$. This confirms that LST is strongly related to AET. Upscaling Landsat 8 LST and AET products by means of averaging, however, resulted in uncertainties that we did not further consider due to limitation of reference in situ data. Averaging indicated that the mean values of the downscaled and the reference LST and AET were close to each other: 
304.6 and $306.9 \mathrm{~K}$ for reference and downscaled LST, and 5.571 and 5.756 $\mathrm{mm}$ day $^{-1}$ for downscaled and reference AET, respectively (Tables 2.2, 2.3). Although the uncertainty may have an impact on the results of both products, we did not further study this. However, the outliers in the scatter plots (Figure 2.12 and Figure 2.13) are due to patches that are covered with salt marsh. Removing those outliers means removal of patches that also would remove some agricultural fragments within the same irrigation network. Clearly, its removal has a profound effect, in particular when focusing at the field scale.
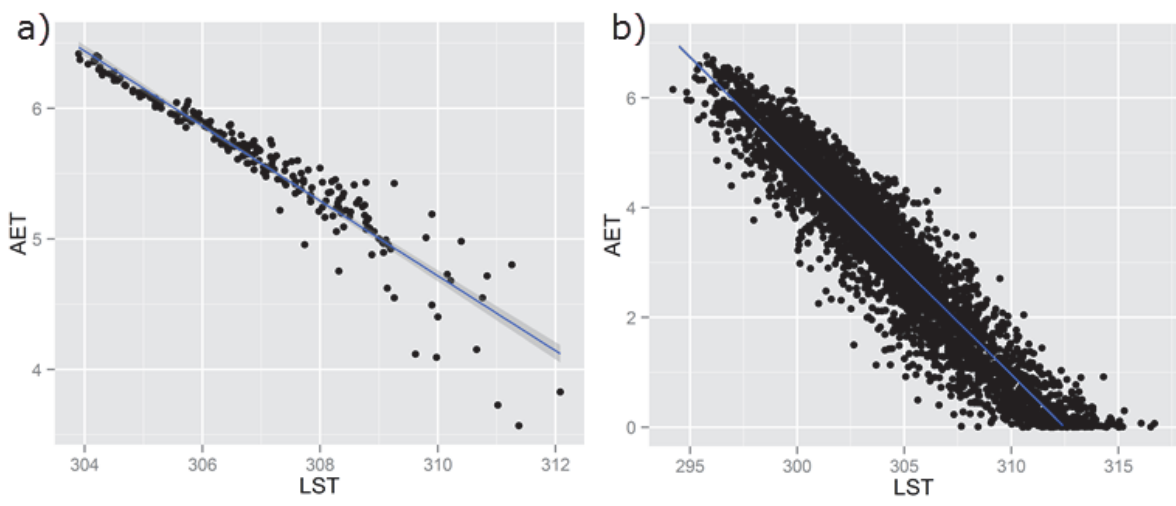

Figure 2.14: Comparison between AET and LST from a MODIS at $1000 \mathrm{~m}(r=-0.95)$ and $\mathbf{b}$ Landsat 8 at $250 \mathrm{~m}$ spatial resolution $(r=-0.94)$. AET and LST establish a negative relationship if the semi-arid region suffers from water shortage.

\section{Anisotropy variograms}

Experimental variograms and cross-variograms indicated that the spatial variation for different distances depends both on the size of pixel (support) and on the cover type. The aim of downscaling cokriging is to change the support to a finer spatial resolution. To do so, the pixel support was changed to the point support. With, in principle, an infinite number of points inside the pixel support, we could aggregate up to any resolution. In addition, point support variograms and cross-variogram were helpful to predict and model spatial variation of coarser pixel to finer pixel, i.e. we could model spatial variation of coarser pixels and predict that to finer pixel resolution.

Anisotropy is observed in both range (geometrical) and sill (zonal) in different directional variograms (Figure 2.6 and 2.7). This combination of anisotropy leads to a complex model for downscaling cokriging. We could, however, explain these anisotropies in terms of the physics of the region. Lateral canals of the irrigation network L1 and L2 are in the NE-SW direction. This direction has a relatively low variation, whereas other sub-canals are in the NW-SE direction showing higher variation. Therefore, more sub-canals could be expected in the direction of NW-SE with lower LST and higher ET variation, 
whereas only the two lateral L1 and L2 canals are in the NE-SW direction with higher LST and lower ET variation. In this agricultural area, therefore, the anisotropy is caused by irrigation, resulting in different variation in LST and ET. This, in turn, resulted in different directional variograms. Because of applying downscaling cokriging, we set the cut-off on the range parameter for solving the geometrical anisotropy. This resulted in weights at low and high pass filters. The maximum range for obtaining those weights was approximately $1500 \mathrm{~m}$, relevant for weights of different window sizes as e.g. $3 \times 3$ and $5 \times 5$ in the low and high pass filters. A cut-off range of $6000 \mathrm{~m}$ was applied, resulting in pixel values that become independent for distances larger than $6000 \mathrm{~m}$. This resulted in total variances equal to $36.5,3.6$ and 0.02 for LST, AET and NDVI, respectively, and equal to -0.75 and 0.25 for their crossvariograms.

\section{Management issues in application of irrigation system}

The main practical question to be addressed will be to determine when and how much water is to be applied to a crop, which does not seriously suffer a water shortage. To answer this question, CWR and IWR are to be estimated at a high accuracy. This means that the quality of the CWR and IWR estimates is good enough for an operational application. In actual management, IWR is to be estimated on a daily, weekly, monthly and yearly basis, whereas CWR can be measured on daily basis. Hence, IWR can be measured on a weekly basis, by means of aggregating daily CWR. From the experience (Sharifi, 2013) at Qazvin irrigation network, crop has shown a resistance against water shortage. On this basis, the recommendation is to irrigate when the available amount of water is reaching as low as $50 \%$ water capacity of soil. That means that threshold here is based on weekly aggregated CWR equals to weekly IWR, and an allowable range that crop can tolerate water shortage without a serious effect on its production. This range is between $10 \%$ and $20 \%$ of CWR (Sharifi, 2013). If the threshold is set at $20 \%$ of the CWR, the required accuracy of AET (Table 2.3) equals 0.5 to $1 \mathrm{~mm} \mathrm{day}^{-1}$ during the peak in the water consumption season. Taking PET equal to $6.5 \mathrm{~mm} \mathrm{day}^{-1}$ as maximum value of AET (Table 2.3), however, and at the average of $5 \mathrm{~mm} \mathrm{day}^{-1}$ (Table 2.3), the required accuracy of AET equals $1 \mathrm{~mm}^{\text {day }}{ }^{-1}$. On this basis, we may assume that the

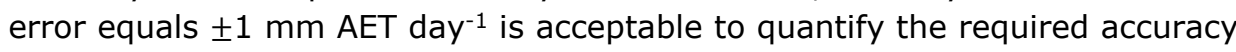
for daily CWR for this agricultural area (Figure 2.15). That means the daily AET estimation should have an accuracy of approximately $1 \mathrm{~mm} \mathrm{day}^{-1}$. 


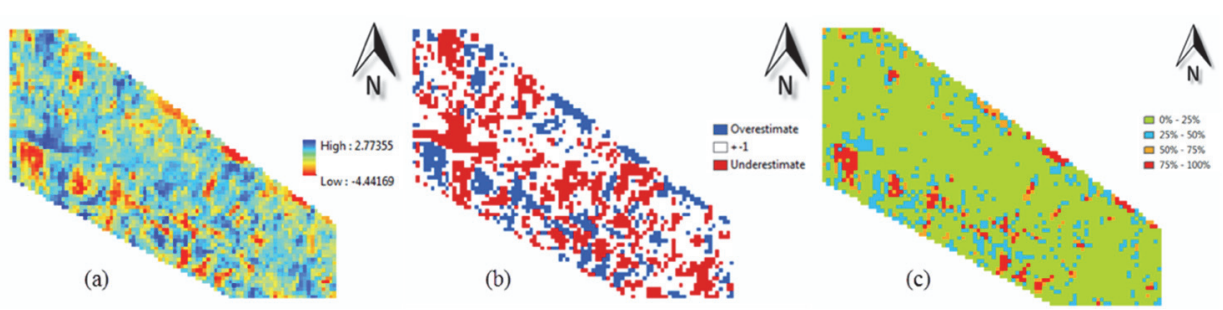

Figure 2.15: Residual map, error map and relative error map (\%) between reference and downscaled AET

\section{Practical aspect of allocation and distribution of water within the canals and gates}

In an agricultural system, fields are the common management units for farmers and water board decision makers. The basis of calculating IWR is CWR at the field scale, whereas the main issue concerns the point for the delivery of water, i.e. the gates, specifying the volume of water for individual farms. This means that AET estimation should be good for IWR estimation at the gate level but not necessarily at the field level. The L1 canal has 10 gates and the L2 canal has 17 gates, each gate delivering water towards several farms (Figure 2.1). To manage the input of water within the canals and gates, daily medium AET maps can provide relevant information for each gate to supply farms as delivery point of water, but not to supply every field individually. This is because of large spatial variation at some farms with different fields as of crop type whereas, each farm cannot be sum of its fields and or a weighing of all fields. Exploring the water supply at each individual fields can be carried out through the probabilistic models where water can be supplied based on the crop type, area and spatial variation of that field.

In precision irrigation, timely, updated and localized information is important for various management actions such as controlling gates and canals. Such information relates to determining the number of observations day ${ }^{-1}$ to make a decision based on an updated ET value. Such information should be delivered as an appropriate spatial distribution at the field scale to answer when, where and how much water the crop needs for its cultivation.

\subsection{Conclusion}

The aim of this research was to generate daily medium resolution AET maps with respect to the impact of different spatial resolution of input LST RS data on the AET determination. The following conclusion were derived:

- Downscaling cokriging was successfully applied on MODIS images. It provided a smooth LST map that was affected by relatively smooth NDVI information. The procedure is applicable as well on other satellite image products where a strong relationship exists between a predictive variable and a co-variable. 
- Both the downscaled AET map and LST were in good agreement with the reference Landsat $8 \mathrm{AET}$ and LST products, even though those were obtained from another sensor and were acquired at slightly different times.

- Further improvements are needed for management purposes to determine daily AET maps at finer spatial resolutions to be available every day. 


\section{Chapter 3 Integrating super resolution mapping and SEBS modelling for evapotranspiration mapping at the field scale ${ }^{2}$}

2 This chapter is based on the published paper:

Mahour, M., Stein, A., Sharifi, M. A., \& Tolpekin, V. A. (2015). Integrating super resolution mapping and SEBS modeling for evapotranspiration mapping at the field scale. Precision agriculture, 16(5), 571-586. DOI: 10.1007/s11119-015-9395-8 


\section{Abstract}

This study addressed the use of Super Resolution Mapping (SRM) for precision agriculture. SRM was applied to a high resolution GeoEye image of a vineyard in Iran with the aim to determine the Actual EvapoTranspiration (AET) and Potential EvapoTranspiration (PET). The Surface Energy Balance System (SEBS) applied for that purpose requires the use of a thermal band, provided by a Landsat TM image of a $30 \mathrm{~m}$ resolution. Image fusion downscaled that information towards the 0.5 by $0.5 \mathrm{~m}^{2}$ scale level. The geometry was validated with an UltraCam aerial photo. Grape trees in the vineyard were planted in rows and three levels were distinguished: the field, rows and individual trees. AET values thus obtained ranged within rows from 5.32 ( $s d=0.26$ ) to 5.39 $(s d=0.24)$, whereas values for individual plants ranged from 5.29 ( $s d=0.22$ ) through 5.33 ( $\mathrm{sd}=0.39$ ) to 5.36 ( $\mathrm{sd}=0.23$ ). The study showed that AET values were obtained close to $5.71 \mathrm{~mm}^{-1}{ }^{-1}$ derived by standard calculations at the field scale, but spatial variability was clearly present. The study concluded that modern satellite derived information in combination with recently developed image analysis methods is able to provide reliable AET values at the row level, but not yet for every individual grape tree. 


\subsection{Introduction}

Precision Agriculture (PA) is a relatively new and advanced form of agriculture that emerged as a concept in the nineteen nineties (Bouma, 2007). It allows farmers to manage their crops by maximizing the cost-benefit ratio in terms of field variation (Brisco et al., 2014). Good management depends upon collecting timely and precise information about the status of crops and resources. Remote sensing tools can be useful in this respect. In particular, PA benefits from integrating advanced geomatical technologies such as a Global Positioning System (GPS), a Geospatial Information System (GIS) and Remote Sensing (RS) products in supporting agricultural activities. PA aims at providing the optimal management strategy with multiple sources to support farm managers and decision makers such as crop water requirement related to the adoption of a proper policy on available agricultural area. Crop water requirements are to be assessed, evaluated and managed on the basis of modeling, and in this way it is affected by uncertainty (Zhang et al., 2002).

Nowadays, the management system scale is much more precise than before. The smallest unit is the plant scale or even the scale of individual leaves in contrast to traditional agriculture management system scales where the field was the smallest unit.

Determining the amount of water to be supplied to various crop types is an important management decision (Wu et al., 2012). Water deficit, defined as the difference between supply and requirement is increasingly the result of improper water resource management. An important variable in this respect is crop EvapoTranspiration (ET). Water will be lost from the crop and soil due to ET, depending upon crop type, vegetation cover and weather factors. In agricultural irrigation systems, enough water is used to compensate for crop ET; the so-called actual crop water requirement. Two types of ET can be distinguished, Potential EvapoTranspiration (PET) and Actual EvapoTranspiration (AET). AET is defined as the actual elimination of water from the soil surface and the plant, whereas PET is atmospheric capability to remove the water from the surface as a consequence of evaporation and transpiration (Pidwirny, 2006) if crop is not faced with any water shortage.

Remotely sensed data are useful to supply crop information from satellite data. With spatial resolutions down to $0.5 \mathrm{~m}$, more and more information becomes available at a very high resolution. This scale level, however, is still too coarse to be of much value at the plant scale of many crops. In this study Super Resolution Mapping (SRM) is used to partition pixels into smaller sub-pixels in order to achieve a high spatial resolution image from a coarser resolution image (Ardila et al., 2011; Atkinson, 2009). SRM creates hard classification maps at a finer resolution by increasing the spatial resolution of input imagery 
using a spatial optimization method (Atkinson, 2009). SRM takes the spatial dependency into account between neighboring pixels based on spatial distance. SRM has been proposed using diverse algorithms.

Tatem et al. (2001) developed SRM with a Hopfield neural network. Verhoeye and De Wulf (2002) proposed the application of linear optimization techniques for sub-pixel mapping. Mertens et al. (2003) applied genetic algorithms in SRM. Boucher and Kyriakidis (2006) implemented indicator kriging in SRM to evaluate the spatial variability of classes. Kasetkasem et al. (2005) introduced SRM based on Markov Random Field (MRF). Tolpekin and Stein (2009) adapted SRM based MRF to variation in class separability. Lopez (2011) proposed MRF based SRM for identification of urban trees in very high resolution images on the basis of an energy function, spatial smoothness, and prior and conditional probability.

This study considers the Surface Energy Balance System (SEBS) to use remote sensing information in precision agriculture. SEBS estimates atmospheric turbulent fluxes, evaporative fraction and actual ET using satellite image data and meteorological information (Su, 2002). It includes a toolbox for determining physical parameters of land surface such as albedo, land surface emissivity and land surface temperature from spectral radiance and reflectance measurements of satellite earth observation data.

Precision agriculture in Iran is in its infancy, and possibly much can be gained from further development and applications. An interesting crop is the grape tree. It is grown in the Northern part of Iran, close to the Caspian Sea. In that area water is scarce and optimal water application is required to maintain and possibly increase productivity. Water application is commonly done at the field scale. Grape trees, however, are planted in rows and the question was raised whether precision agriculture can benefit from RS imagery at the row level, or even at the individual plant level. In this way, the scarce water could be applied at those locations where it was maximally beneficial.

Remotely sensed observations and management scale practices do not fully coincide yet. High spatial resolution satellite images can be used to identify the contours of relatively large individual plants and study their spatial characteristics, but the spatial resolution is still too coarse to extract information that is relevant for PA. In this study we explore location and spectral information of individual plants at it was extracted by Super Resolution Mapping (SRM) based on Markov Random Field (MRF) of a very high resolution image. We focused on obtaining crop water requirement, and applied SEBS at coarse resolution images to retrieve the actual information. 
The objective of this research was to investigate to which degree current remote sensing images can be of help in precision agriculture. The aim is to obtain high resolution information on the basis of rows and individual plants of vineyard from images of coarse spatial and spectral resolution.

\subsection{Study area and data}

The study area is a vineyard with geographical coordinates $36^{\circ} 11^{\prime} 21^{\prime \prime} \mathrm{N}$, $50^{\circ} 13^{\prime} 19^{\prime \prime} \mathrm{E}$, located close to the city of Sharifabad, in the center of the Qazvin province North-western Iran. In this region, water is scarce and ground water level is lowering every year by approximately $80 \mathrm{~cm}$. The area is an open homogeneous land planted with grape trees and is also referred to as an industrial type agricultural field (Figure 3.1). Gardens and agricultural fields like vineyards are abundant in this region. The main reason of focusing on grape trees is the economic importance of grape fruit and potential capacity of RS based information in assessing the crop water requirement at row and possibly at plant levels. The selected field consists of grape trees planted in 22 rows. The length of each row is $40 \mathrm{~m}$ and there are 16 plants per row, the distance between trees in a row is $2 \mathrm{~m}$, whereas the plant diameter is approximately $60 \mathrm{~cm}$. The growing season of grape trees takes place between spring and leaf fall in autumn. That means the growing season starts from April until October for both traditional and industrial grape trees. The study period is selected such that grape trees are in the mid-season of growing and that interlocks between canopy covers in rows can be observed.

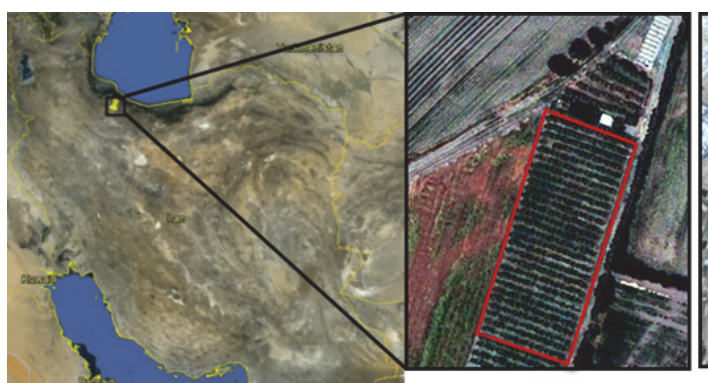

(a)

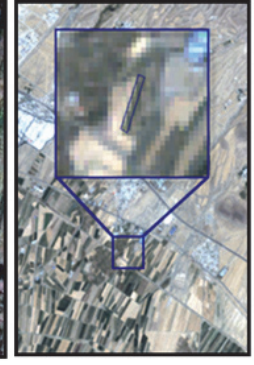

(b)

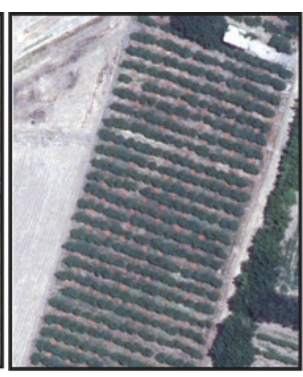

(c)

Figure 3.1: The study area located in the Northern part of Iran. (a) the GeoEye satellite image at $2 \mathrm{~m}$ multispectral and a $0.5 \mathrm{~m}$ panchromatic resolution, (b) the Landsat 5 TM image at $30 \mathrm{~m}$ resolution, (c) the UltraCam digital aerial photo at $14 \mathrm{~cm}$ resolution

\section{Remote sensing imagery}

Three types of images were obtained from this field: a GeoEye satellite image, an UltraCam digital aerial photo and a Landsat 5 TM satellite image (Figure 3.1). GeoEye-1 is a high resolution satellite image of a $0.41 \mathrm{~m}$ spatial resolution in panchromatic mode and $1.65 \mathrm{~m}$ in multispectral mode. The GeoEye image provides both image products as panchromatic images and multispectral images separately as well as simultaneously as a panchromatic 
and multispectral (pan-sharpened) product. A four band pan-sharpened, multispectral image and a panchromatic GeoEye image were collected for the study area on June 19, 2011. Images were projected in Universal Transfer Mercator (UTM) with the standard spheroidal reference surface WGS 84. A panchromatic image and multispectral images of GeoEye are very well coregistered. A Landsat 5 TM image was taken on August 1, 2011 (Figure 3.1) which has seven multispectral bands such as the visible (from $0.45 \mu \mathrm{m}$ to 0.69 $\mu \mathrm{m}$ ), near infrared (from $0.76 \mu \mathrm{m}$ to $0.90 \mu \mathrm{m}$ ), middle infrared (from $1.55 \mu \mathrm{m}$ to $1.75 \mu \mathrm{m}$ and $2.08 \mu \mathrm{m}$ to $2.35 \mu \mathrm{m}$ ) and a resampled thermal band (from $10.40 \mu \mathrm{m}$ to $12.5 \mu \mathrm{m})$, all at a $30 \mathrm{~m}$ spatial resolution. For atmospheric correction of the Landsat image, the Simplified Method in the Atmospheric Correction (SMAC) is used (Rahman and Dedieu, 1994). An UltraCam digital aerial photo was taken on July 17,2012 at $0.14 \mathrm{~m}$ ground resolution in the visible and near infrared multispectral range. The digital photo was taken by a high resolution multichannel RGBI sensor on an airborne platform at a $6 \mu \mathrm{m}$ physical pixel size. The digital aerial photo was orthorectified to eliminate camera tilt, lens distortion and topographic correction. To overlay the aerial photo with the GeoEye satellite image, it was georeferenced using ground control points (GCPs) extracted from the GeoEye satellite image, using the GeoEye image as the master image for geo-registration (Figure 3.1).

\section{Meteorological data}

A main issue in PA is to indicate the water stress with respect to the ET. For this purpose the SEBS model presented below has been used at rows and individual pixels in the field. Variability of ET depends upon crop-, soil-, water, management and weather-related variables. Weather data were collected by the Qazvin weather station during a day of August 1, 2011. The weather station with coordinates $36^{\circ} 15^{\prime} 00^{\prime \prime} \mathrm{N}, 50^{\circ} 30^{\prime} 00^{\prime \prime} \mathrm{E}$ is located at approximately $17 \mathrm{~km}$ north of the city of Qazvin (Table 3.1). Recorded weather data include the maximum and minimum temperature, wind speed, sunshine hours, air pressure and humidity.

\section{Field data}

For the field data, we considered a field, denoted by $F$, of $3040 \mathrm{~m}^{2}$. In this field, grape trees were planted in 22 rows, labeled as $R_{1}, \ldots, R_{22}$, each row containing 16 plants. This field was selected as it had regularly spaced grape trees, and had a shared coverage in both GeoEye satellite image and UltraCam photo. Visual interpretation was based on the UltraCam image, whereas the Geoeye panchromatic image was applied to delineate individual plants and create reference data for validation (Figure 3.2). Delineating plants was not possible for some rows and plants because several plants were not pruned, resulting in an interlock between them. To study the effects of SRM in more detail a subset $R=\left\{R_{15}, R_{16}, R_{17}\right\}$ of three rows was identified with relatively little interlock. Within $R_{16}$ we defined the subset $P=\left\{P_{1}, P_{2}, P_{3}\right\}$ consisting of three individual 
plants that had relatively low coverage, so that only a few interlocks occurred between canopies of the plants.

Table 3.1: The ground meteorological data (at the Qazvin weather station). Time of recording information is at 6 am GMT

\begin{tabular}{ccccccc}
\hline & $\begin{array}{c}\text { Wind speed } \\
{\left[\mathrm{m} \cdot \mathrm{s}^{-1}\right]}\end{array}$ & $\begin{array}{c}\text { Max } \\
\text { Temp }\left[{ }^{\circ} \mathrm{C}\right]\end{array}$ & $\begin{array}{c}\text { Min } \\
\text { Temp }\left[{ }^{\circ} \mathrm{C}\right]\end{array}$ & $\begin{array}{c}\text { Sunshine } \\
\text { hours }\end{array}$ & $\begin{array}{c}\text { Humidity } \\
{[\%]}\end{array}$ & $\begin{array}{c}\text { Air pressure } \\
{[\mathrm{mbar}]}\end{array}$ \\
\hline $2011-08-01$ & 2.6 & 37.14 & 17 & 12.7 & 14.4 & 868.8 \\
\hline
\end{tabular}

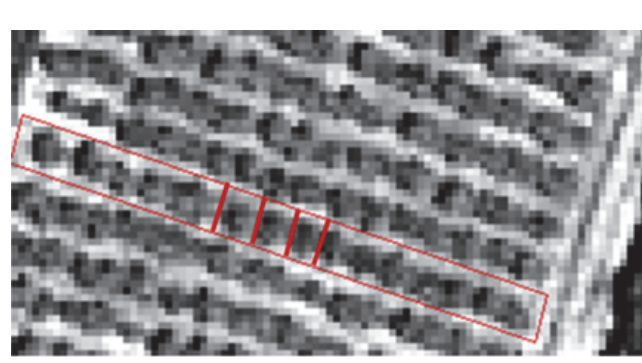

(a)
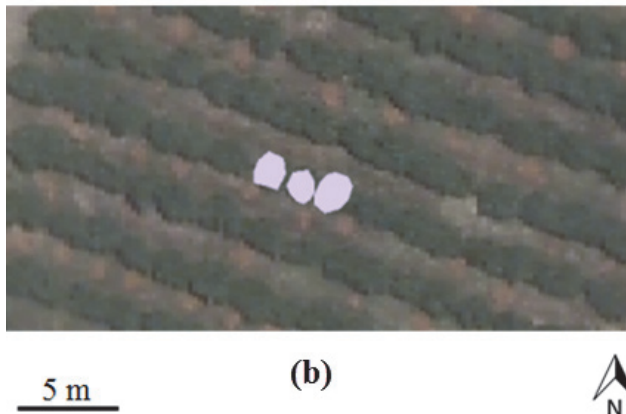

(b)

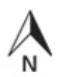

Figure 3.2: Identification of three individual plants as the subset $P$ : (a) from the GeoEye panchromatic image and (b) as reference polygons from the aerial photo

\subsection{Methodology}

The methodology of this research is divided into three stages. The first step uses MRF based SRM to detect rows and plants within rows. The second step uses SEBS to determine the ET at a rather coarse level (30 $\mathrm{m}$ resolution). The third step applies image fusion to integrate the results from SEBS and SRM to assess the ET at row and plant levels to support precision agriculture.

\section{Super resolution mapping based on Markov Random Field}

We consider a coarse resolution multispectral image $y$ of $M \times N$ pixels and a fine resolution multispectral image $x . S$ is the scale factor between $y$ and $x$ as ratio of pixel size where pixel is modeled with square footprint whereas the pixel size is the side of the square. If $S$ is integer, then each pixel $y$ contains $S^{2}$ pixels from $x$, whereas if $S$ is non-integer that number may vary. It is 
assumed that $x$ only contains pure pixels whereas $y$ also contains mixed pixels. A pixel in $y$ is represented as $b_{i}$ (i.e., $i \in\{1, \ldots, M \times N\}$ ) and a pixel in $x$ as $a_{i \mid j}$, where the notation $i \mid j$ indicates that the center of the pixel is inside the footprint of pixel $b_{i}$. If the footprint of $b_{i}$ contains $W\left(b_{i}\right)$ centroids of $a_{i \mid j}$ then a general equation expressing the relation between $x$ and $y$ is represented as a weighted average with weights $\theta_{j}$ equals:

$y\left(b_{i}\right)=\frac{1}{W\left(b_{i}\right)} \sum_{j=1}^{W\left(b_{i}\right)} \theta_{j} x\left(a_{i \mid j}\right)$

For integer valued $S$ and aligned grids of $a$ and $b, W\left(b_{i}\right)=S^{2}$ pixels $a_{i \mid j}$ compose $b_{i}$, whereas for non-integer valued $S$, fractions of $a_{i \mid j}$ compose $b_{i}$ and $W\left(b_{i}\right)$ can have various values between $[S]^{2}$ and $([S]+1)^{2}$, with $[S]$ denoting the integer part of $S$. It is convenient to choose a grid of $a$ to match the direction of rows in $\mathrm{R}$, whereas in practice grid $b$ is not aligned with the rows in $\mathrm{R}$. To deal with misaligned grids we use geographic coordinates to relate $b_{i}$ and $a_{i \mid j}$. For each pixel $b_{i}$, thus all pixels $a_{i \mid j}$ with centroid in $b_{i}$ are identified.

In (1) we do not further explore weighing of the sub-pixels, and take $\theta_{j}=$ 1throughout. MRF as a contextual classification method uses the spatial dependence between finer scale pixels $(a)$ to assign class label $c\left(a_{i \mid j}\right)$ to each $a_{i \mid j}$ at the finer scale image. The label set is denoted by $L$ whereas $c$ is a superresolution map. In MRF, a context is prior information that is used when constructing the global energy in a Bayesian way. MRF can be specified by means of a Gibbs Random Field (GRF) (Li, 2009). For super-resolution map $c$, the prior probability density function in a GRF is written as:

$P(c)=\frac{1}{Z} \exp \left[-\frac{U(c)}{T}\right]$

where $U(c)$ is the prior energy function of $c, T$ is a constant termed of the temperature and $Z$ is a partition function, ensuring normalization of $P(c)$.

Let $U\left(c\left(a_{i \mid j}\right) \mid c\left(D\left(a_{i \mid j}\right)\right)\right)$ be the local prior energy of pixel in $a_{i \mid j}$ and let $D\left(a_{i \mid j}\right)$ be the neighborhood of pixel $a_{i \mid j}$. This can be expressed as $U\left(c\left(a_{i \mid j}\right) \mid c\left(D\left(a_{i \mid j}\right)\right)\right)$ following Tolpekin and Stein (2009). This energy function takes the value zero if all neighbor pixels are assigned to the same class, whereas it takes larger value for heterogeneous class labels in $\left(a_{i \mid j}\right)$. Further, let $U\left(x_{i} \mid c_{i}\right)$ be the local conditional energy of pixel $a$ and $U\left(c_{i} \mid x_{i}\right)$ the local posterior energy of the pixel $a$. The following equation expresses the posterior energy applying Bayes formula to a single pixel $a_{i \mid j}$ :

$U\left(c\left(a_{i \mid j}\right) \mid x\left(a_{i \mid j}\right), c\left(D\left(a_{i \mid j}\right)\right)\right)=U\left(x\left(a_{i \mid j}\right) \mid c\left(a_{i \mid j}\right)\right)+U\left(c\left(a_{i \mid j}\right) \mid c\left(D\left(a_{i \mid j}\right)\right)\right)$ 
Further, let $\lambda(0 \leq \lambda<1)$ be an MRF parameter that balances the prior and conditional energy functions and let $\lambda_{\text {pan }}\left(0 \leq \lambda_{\text {pan }}<1\right)$ be the likelihood energy parameter that balances the conditional energies of the multispectral and panchromatic GeoEye images. The energy function with respect to coarse resolution image $y$ and panchromatic image $q$ is then written following Ardila et al. (2011):

$$
\begin{aligned}
& U\left(c\left(a_{i \mid j}\right) \mid c\left(D\left(a_{i \mid j}\right)\right), y\left(b_{i}\right), q\left(a_{i \mid j}\right)\right)=\lambda U\left(c\left(a_{i \mid j}\right) \mid c\left(D\left(a_{i \mid j}\right)\right)\right)+(1- \\
& \lambda)\left(\lambda_{\text {pan }} U\left(q\left(a_{i \mid j}\right) \mid c\left(a_{i \mid j}\right)\right)+\left(1-\lambda_{\text {pan }}\right) U\left(y\left(b_{i}\right) \mid c\left(a_{i \mid j}\right)\right)\right)
\end{aligned}
$$

The global posterior energy function is then obtained as:

$U(c \mid y, q)=\sum_{i, j} U\left(c\left(a_{i \mid j}\right) \mid c\left(D\left(a_{i \mid j}\right)\right), y\left(b_{i}\right), q\left(a_{i \mid j}\right)\right)$

The equations can be interpreted as follows. First, $x$ is not observed and we only have $y$ and $q$. The solution of MRF based SRM is then found by finding the super-resolution map $c$ that leads to the minimum of the global posterior energy function (3.5). To apply SRM based MRF, the posterior energy (3.5) is optimized in terms of smoothness parameters $\left(\lambda, \lambda_{\text {pan }}\right)$. Our finding with the values of smoothness parameter agrees with the values of other studies Tolpekin and Stein (2009) and Ardila et al. (2011) for the same scale factor and class separability. A maximum a posteriori (MAP) estimated is then obtained by applying Simulated Annealing (SA). In order to minimize the posterior energy for estimating MAP, a convenient class label is defined for each pixel. SA reaches the highest classification accuracy and the lowest energy as compared to other algorithms (Tso and Mather, 2009). It is a stochastic algorithm that includes as the annealing parameters the initial temperature $T_{0}$ and the cooling rate $n<1$ controls the temperature reduction rate. The temperature is decreased as $T_{k+1}=T_{k} \times \eta$. A high temperature corresponds to large randomness and thus increases the probability of labeling pixels by replacing classes with a new class of a higher energy. We set $T_{0}=3$ after testing values between 0 and 3 , and $\eta=0.9$, as taking a larger $\eta$ value resulted in a high increase of the number of iterations to reach convergence for assigning class labels. Those experimentally determined values agreed with those from Tolpekin and Stein (2009). We defined two classes as canopy and soil and estimated the mean and covariance matrices of these classes. The scale factor value was set equal to 4 , resulting in each pixel at the SRM map having a $0.5 \mathrm{~m}$ spatial resolution, thus allowing a good integration of SEBS and the SRM based map.

After optimizing the smoothness parameters and the posterior energy, the appropriate class label is defined for each pixel. The application of MAP criterion 
ensures that the obtained SRM is optimal both with respect to the image data and with respect to the spatial configuration of land cover classes.

\section{Evapotranspiration}

EvapoTranspiration (ET) refers to two simultaneous processes related to plant - atmosphere interaction: evaporation, being the loss of water from the soil surface, and transpiration the removal of water from wet vegetation through the atmosphere (Allen et al., 1998). Commonly, actual ET (AET) is distinguished from potential ET (PET), where AET is the actual elimination of water from the surface, and PET is the capability of the atmosphere to remove the water from the surface as a consequence of evaporation and transpiration (Pidwirny, 2006) when a crop is not faced with any water shortage. In agricultural irrigation management systems, the amount of water that is needed to maximize crop productivity, is equal to PET, and the so-called Crop Water Stress (CWS), equals the difference between AET and PET (Pidwirny, 2006):

$\mathrm{CWS}=\mathrm{PET}-\mathrm{AET}$

CWS is thus the deficit, which in principle has to be supplied to crop if CWS $>0$.

The Surface Energy Balance System (SEBS) was developed for the assessing of atmospheric turbulent fluxes and daily ET per pixel using remote sensing data (Su, 2002). The surface energy balance is written as:

$R_{n}=H+\lambda^{*} E+G_{0}$

The net radiation flux $R_{n}$ is thus the sum of the sensible heat flux $H$ which is the heat transferred between the air and surface by turbulence, the latent heat flux $\lambda^{*} E$ where $\lambda^{*}$ is the latent heat of vaporization and $E$ is the actual EvapoTranspiration. $G_{0}$ is the soil surface heat flux that is the energy for warming the subsurface of the earth, each expressed in $\mathrm{Wm}^{-2}$. SEBS requires three sets of input data:

1. Land surface emissivity, albedo, temperature and the Normalized Difference Vegetation Index (NDVI) data derived from remotely sensed images. Land Surface Emissivity (LSE) is estimated from the visible and near infrared bands of Landsat 5 TM following Sobrino (2004). Su (2002) assumed a linear relationship between soil heat flux and net radiation. Sensible heat flux $(H)$ is modeled by Monin-Obukhov Similarity (Brutsaert, 1982). Finally the daily actual ET ( $\mathrm{ET}_{\text {daily }}, \mathrm{mm} \mathrm{day}^{-1}$ ) is estimated as ( $\left.\mathrm{Su}, 2002\right)$ : 
$\mathrm{ET}_{\text {daily }}=8.64 \times 10^{7} \times \Lambda_{\text {daily }} \times \frac{\overline{R_{n}}-\overline{G_{0}}}{\lambda^{*} \rho_{w}}$

Here $\overline{R_{n}}$ is the daily net radiation $\left(\mathrm{J} \mathrm{m}^{-2} \mathrm{day}^{-1}\right), \lambda^{*}$ is the latent heat of vaporization $\left(\lambda^{*}=\left(2.501-0.00237 \times T_{\text {air }}\right) \times 10^{6}\right)\left(\mathrm{J} \mathrm{kg}^{-1}\right)$, ^daily is the daily average evaporative fraction that can be found in Su (2002) and $\rho_{w}$ is the density of water $\left(1000 \mathrm{~kg} \mathrm{~m}^{-3}\right)$. In addition, the soil heat flux $\overline{G_{0}}$ during 24 hours is assumed to be small, and therefore was neglected. Further, LST is taken from the thermal band using the method by Sobrino et al. (2004), whereas the surface albedo for shortwave radiation $(\alpha)$ is derived from narrowband to broadband conversion by Liang (2001). SEBS can use Landsat images with a combination of ground meteorological data as input for calculating the surface energy balance, but is not applicable to GeoEye or Ultracam images, as they do not have a thermal band.

2. Air pressure, humidity, temperature and wind speed data at reference height, obtained from weather stations.

3. Downward shortwave radiation and downward longwave radiation data that can be measured directly or can be obtained from a radiation model. The net radiation flux $\left(R_{n}\right)$ is estimated by incorporating the retrieved surface emissivity, the land surface temperature (LST) and $\alpha$ from the Landsat 5 TM data and by the use of the downward longwave and solar radiation.

The output of SEBS is provided at spatial resolution of the thermal band of the input image (Su, 2002). In this research, SEBS is applied to estimate AET and PET on a daily basis, whereas SRM is used to detect the rows or the individual plants. To do so, the raw data of each image band is converted first to radiance and reflectance.

\section{Image fusion for integration of actual ET and NDVI}

In this research, the result of AET from SEBS from the $30 \mathrm{~m}$ lower coarse resolution image was fused with the NDVI image extracted from the GeoEye satellite image. To do so, it was assumed that the NDVI at the fine resolution image includes both vegetation with a high AET and soil with a low daily AET. The Gram-Schmidt (GS) spectral sharpening (Laben and Brower, 2000) was applied for image fusion of the fine scaled GeoEye image with the coarse scale Landsat image. GS consists of four steps. Step 1 simulates a coarse spatial resolution image of AET maps at $30 \mathrm{~m}$ spatial resolution. Step 2 performs a GS transformation on the simulated coarser resolution image. Step 3 adjusts the statistical information at the finer spatial resolution image of NDVI at $0.5 \mathrm{~m}$ spatial resolution and compares it with statistical information of the first transform GS providing an adapted finer resolution image. Step 4 applies the inverse GS transformation and provides the enhanced spatial resolution image. 
All processes were carried out following ( $\mathrm{Ha}$ et al., 2012b) in ENVI (Environment for Visualizing Image) software, developed by ITT ${ }^{\circledR}$.

\section{Comparison with existing methods}

We validated the SRM results from each row and individual plants using the UltraCam photo and the panchromatic image of the GeoEye satellite image respectively.

SRM is performed both at subset $R$, and for the three individual plants in $P$. A reference map displaying the rows and individual plants was created from the UltraCam digital aerial photo and the panchromatic image of GeoEye satellite image. In this process, selected rows and individual plants were presented as a red polygon (Figure 3.2). The number of pixels classified inside a polygon served as a reference for the total number of classified pixels. Accuracy of SRM results was assessed using Cohen's kappa statistics (Richards, 2013).

The quality and accuracy of estimated AET determined through SEBS should be assessed in comparison with field measurements (Su, 2002). However, due to the absence of in-situ data, we followed a standard FAO-56 method, i.e. the FAO Penman-Monteith methodology (Allen et al., 1998) of determining daily PET and to validate the result of ET obtained from SEBS. In this process ET is estimated as follows:

$\mathrm{ET}_{\mathrm{c}}=\mathrm{ET}_{0} \times \mathrm{K}_{\mathrm{c}}$

where $\mathrm{ET}_{\mathrm{c}}$ is the potential crop evapotranspiration under standard conditions, $\mathrm{ET}_{0}$ is the ET of grass as the reference crop and $\mathrm{K}_{\mathrm{c}}$ is the coefficient factor for the well-watered crop under optimal agronomic conditions. The $\mathrm{K}_{\mathrm{c}}$ is a single crop coefficient for the grape tree was chosen at the mid-season stage of crop development. PET was determined as well from meteorological data using (3.9) that was then compared to the assumed maximum value of AET from SEBS.

\subsection{Results}

\section{SRM from GeoEye satellite image}

We begin by considering optimization of the smoothness parameters for applying SRM based MRF, $\lambda$ and $\lambda_{\text {pan }}$. For subset R, values equal to $\lambda=0.9$ and $\lambda_{\text {pan }}=0.4$ resulted in the highest accuracy for row detection. The optimized SRM showed a much more coherent pattern of the three rows. Convergence was reached after 70 iterations, when the total energy after a reduction with more than $50 \%$ did not decrease any further (Figure 3.3). 

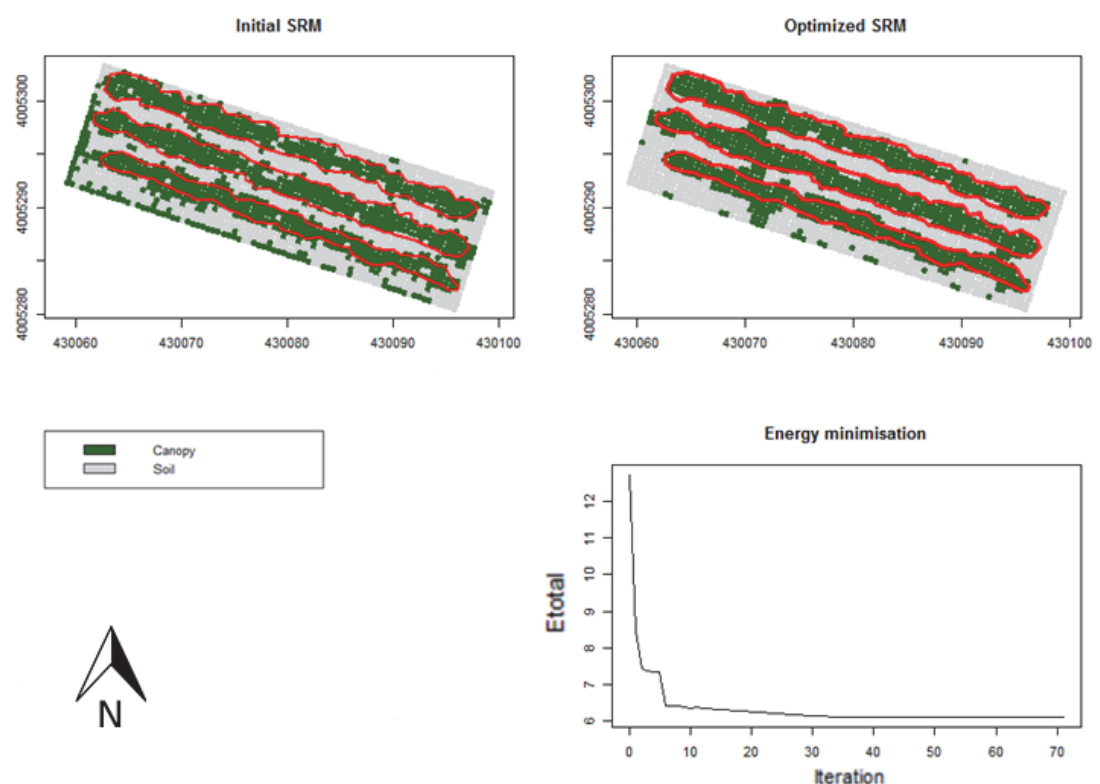

Figure 3.3: The result of SRM based MRF for subset $\mathrm{R}$ with using the starting parameters $\mathrm{S}=4 T_{0}=3$ and $\eta=0.9$ and the optimized parameters $\lambda=0.9$ and $\lambda_{\text {pan }}=0.4$; red polygons are reference data

Using a $\eta=0.95$ value, we observed the highest quality of agreement $(\kappa=$ 0.72 ), whereas the total energy included a local and global minimum values. This value needed 174 iterations to converge. Choosing $\eta=0.9$ updated the pixels and changed their classes during 63 iterations. The curve shows that the energy minimization values converged from a local minimum value equal to 7.2 to a global minimum value of 6.5. Optimization was repeated for each of the three rows individually (Figure 3.4), observing slightly different structures for the rows of plants. 


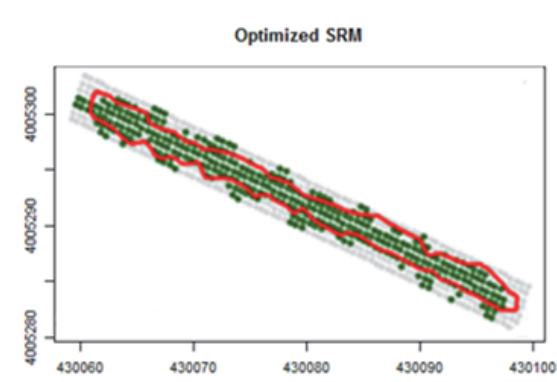

(a)

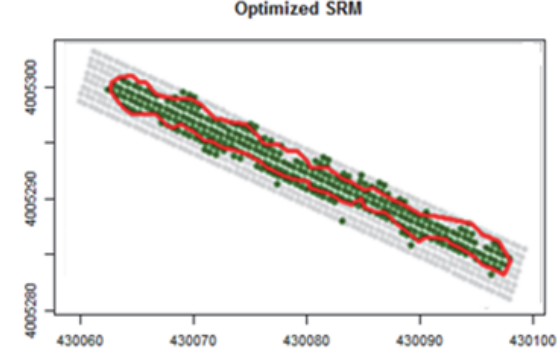

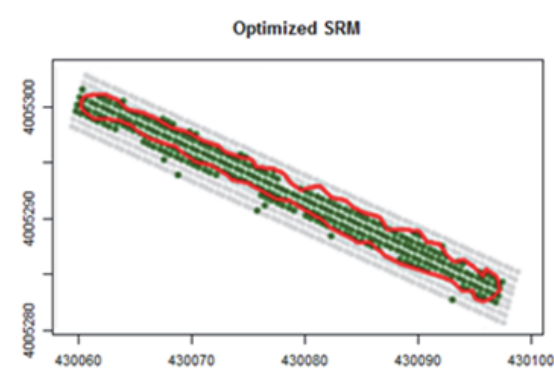

(b)

(c)

Figure 3.4: Result of SRM based MRF for the three rows in subset R individually: (a) $R_{15}$, (b) $R_{16}$ and (c) $R_{17}$; red polygons are reference data

Figure 3.5 displays the result of initial and optimized SRM for the subset P. Values of $\kappa$ were equal to $0.64,0.60$ and 0.71 respectively. Plant $P_{1}$, was covered by 18 pixels as canopy class after the initial SRM, whereas by the optimal SRM it was covered by 9 pixels. For plants $P_{2}$ and $P_{3}$ the original coverage of 22 and 17 reduced to 17 to 12 , respectively. 

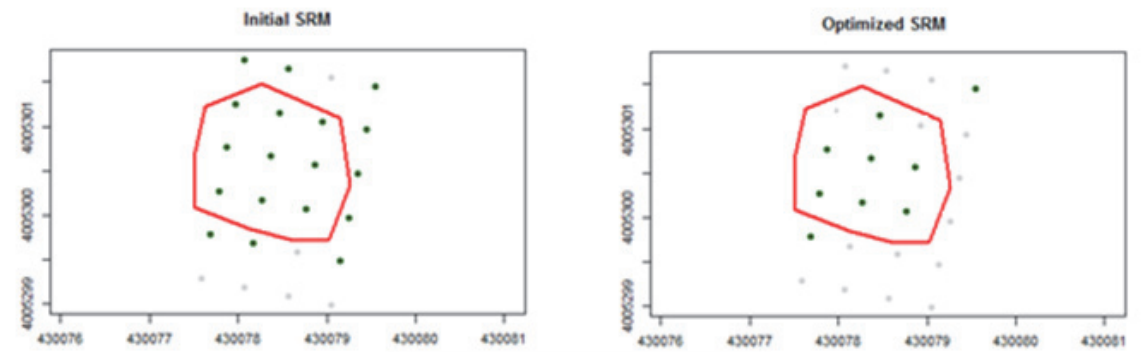

(a)
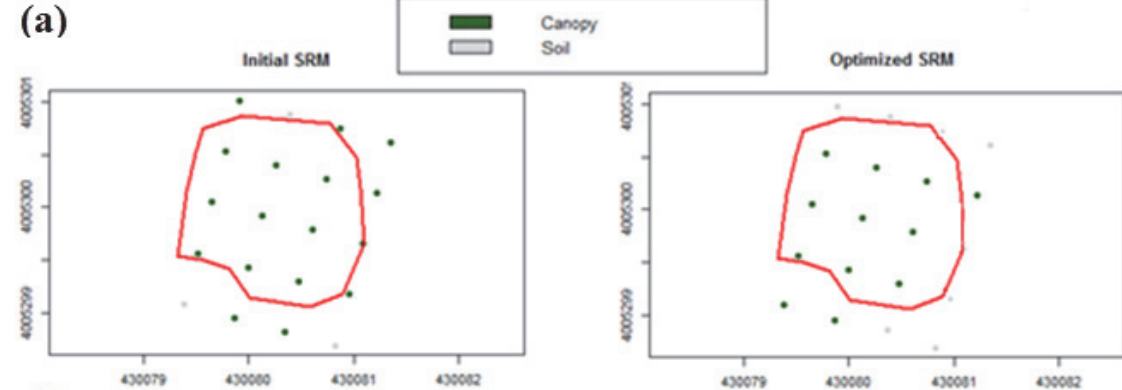

(b)

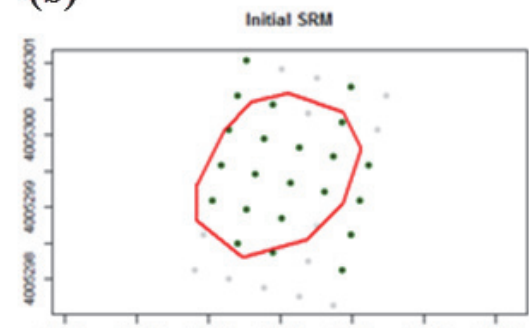

(c)

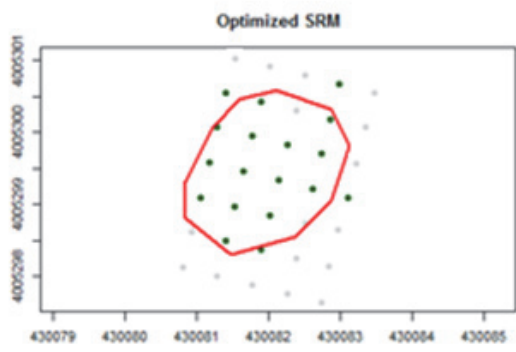

Figure 3.5: The initial (left) and the optimized (right) SRM results for individual plants of subset $P$ located in $R_{16}$ : (a) $P_{1}$, (b) $P_{2}$, (c) $P_{3}$. In the optimized results a more coherent pattern is observed that better corresponds with the red polygons as reference data

\section{Daily ET from the Landsat 5 TM satellite image}

AET values around the field $F$ with its 22 rows obtained using the RS data and the weather data in SEBS is presented in Figure 3.6. Daily AET values in this field ranged from $4.50 \mathrm{~mm} \mathrm{day}^{-1}$ up to $5.76 \mathrm{~mm}^{-1}$ day $^{-1}$. The AET value of 5.76 $\mathrm{mm}_{\text {day }}{ }^{-1}$ was taken as the PET value. This value is comparable to the PET derived with the FAO Penman-Monteith methodology, equal to $5.71 \mathrm{~mm} \mathrm{day}^{-1}$. Comparison of these two values shows a small difference, confirming the acceptability of SEBS. We observed that there was a lower AET variation along the top of the vineyard as compared to the bottom side. 


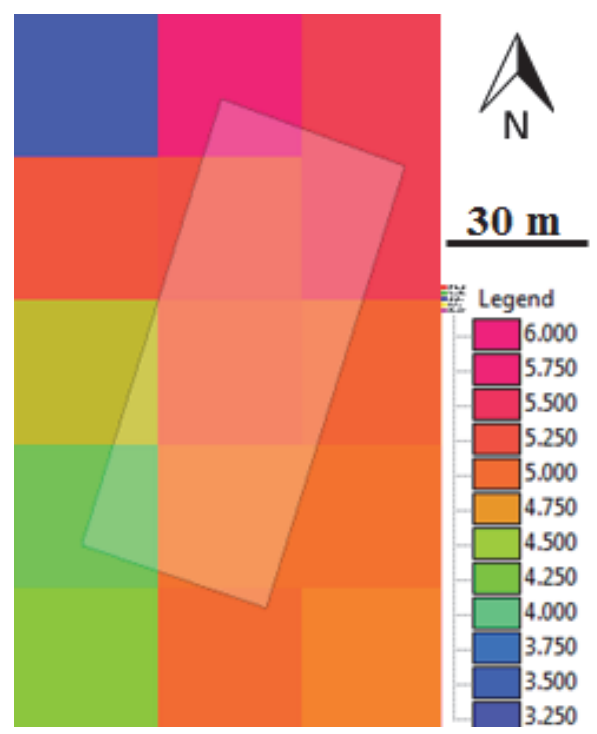

Figure 3.6: Retrieval daily AET values at a $30 \mathrm{~m}$ resolution based on the SEBS model overlaid with the whole field $\mathrm{F}$

\section{Image fusion of AET and NDVI maps}

After image fusion of the coarse resolution image (Figure 3.7a) and the fine resolution image (Figure 3.7b), Figure 3.7(c) illustrates the resampled coarse resolution image as the AET values (Figure 3.7(b)). High AET values shown as light colors appear within the rows, whereas low values, shown as dark colors, appear between the rows. Therefore, the high AET values correspond with the canopy, whereas low AET values refer to the soil between the rows. Because of the coarse resolution of the Landsat image and the high resolution of the GeoEye image, the observed pattern looks similar to the GeoEye image, whereas the values correspond with the AET values obtained from the Landsat image.

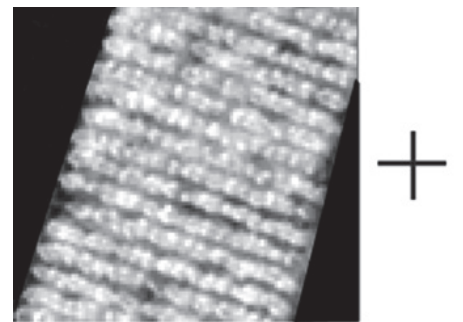

$20 \mathrm{~m}$

$$
\text { (a) }
$$

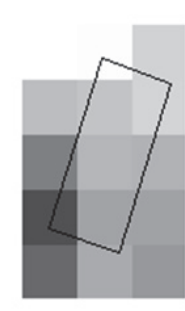

(b)

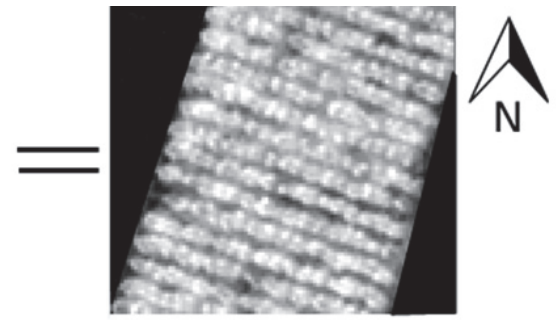

(c)

Figure 3.7: The high resolution NDVI image (a), the AET image obtained from SEBS (b) and the result after image fusion (c) using the GS method 
In this part, the results of applying SRM for the fused image at the $0.5 \mathrm{~m}$ resolution are presented first for rows 15 to 17 and then for three individual plants (Figure 3.8). Rows are clearly identified, whereas individual plants are more difficult to separate.

Table 3.2: Mean AET values and their standard deviation for subareas $R$ and $P$

\begin{tabular}{ccc}
$\begin{array}{c}\text { Rows and individual } \\
\text { plants }\end{array}$ & Mean AET [mm day $\left.{ }^{-1}\right]$ & Standard deviation \\
\hline$R_{15}$ & 5.32 & 0.26 \\
$R_{16}$ & 5.33 & 0.25 \\
$R_{17}$ & 5.39 & 0.24 \\
$P_{1}$ & 5.29 & 0.22 \\
$P_{2}$ & 5.33 & 0.39 \\
$P_{3}$ & 5.36 & 0.23 \\
\hline
\end{tabular}

Table 3.3 indicates the results AET for $R$ and $P$, respectively, where for assigning $A E T$ to each row or individual plant the mean pixel value was taken per row and individual plant. For rows we observe AET values ranging between 5.32 ( $\mathrm{sd}=0.26$ ) and $5.39(\mathrm{sd}=0.24)$, whereas values for individual plants the AET values ranged from $5.29(\mathrm{sd}=0.22)$ for $P_{1}$, through $5.33(\mathrm{sd}=0.39)$ for $\mathrm{P}_{2}$ to 5.36 ( $\mathrm{sd}=0.23$ ) for $\mathrm{P}_{3}$. The standard deviation indicates the amount variation from the mean, i.e. a low sd indicates that AET values are close to the mean AET value. So, we observed that plant $P_{2}$ has the highest sd and $P_{1}$ with has the lowest sd. Furthermore, the AET value of $P_{1}$ is close to the mean AET as compared to the other individual plants and rows. Hence the main difference is, as expected, at the within-plant level. Because, $P_{2}$ is located between $P_{1}$ and $P_{3}$, the effect of extracting individual plants that was based on visual interpretation, resulted in the high sd value for $P_{2}$ as compared to $P_{1}$ and $P_{3}$. For the individual plants $P_{1}, P_{2}, P_{3}$ the AET values slightly below the FAO-56 PET value.

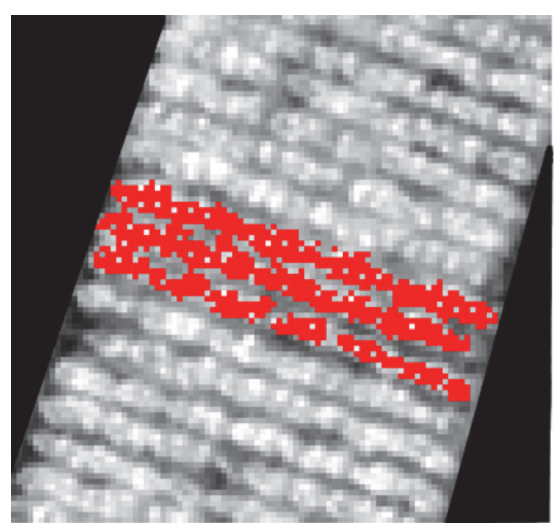

(a)

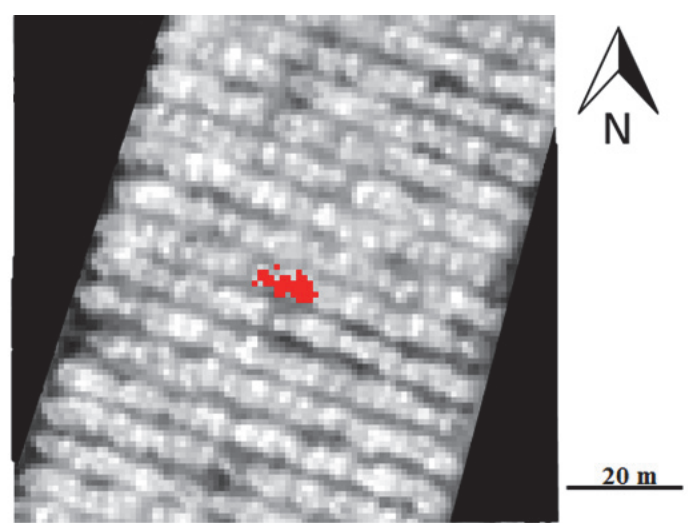

(b)

Figure 3.8: Combination of SRM result with the actual ET (a) for subset $R$ and (b) zooming in at subset $P$ 


\section{Application of SRM and SEBS for precision agriculture}

We found that rows are clearly identified, whereas individual plants are more difficult to separate. Hence, precision agriculture that is based on the satellite with the finest resolution and the use of SEBS should focus on rows rather than on plants. Spatially varying water application should therefore best be done at the row level. Application of SRM may then proceed as follows. First, the relation between the SRM produced map and the actual ET per row and individual plant is constructed. This is followed by the specification of the NDVI map as vegetation index indicates for rows and individual plants.

\subsection{Discussion}

In this part, the results are discussed of applying SRM based MRF for obtaining AET from SEBS as reported in the result section. Further, the applicability of using SRM and the SEBS in a more general setting is discussed in detail to support the crop water requirement in precision agriculture.

An important problem for linking SEBS and SRM results concerns the resolution of the thermal band available from RS images. The Geoeye image has a high spatial resolution, whereas the Landsat 5 TM produces medium spatial resolution images. To overcome this problem, image fusion using the GramSchmidt (GS) method applied to increase the spatial resolution of the actual ET image from $30 \mathrm{~m}$ resolution to $0.5 \mathrm{~m}$ spatial resolution equivalent to the resolution of the SRM result. To apply downscaling, the NDVI image from the pan-sharpened GeoEye image was used. It was further assumed that vegetation in the NDVI map represents a higher AET value than the soil.

For implementing SRM based MRF, the set of training pixels for canopy and soil was chosen from the multispectral and panchromatic bands. There was a limitation for selecting land cover classes in the multispectral GeoEye image, because of the absence of variation between soil and canopy pixels. Therefore, when choosing training pixels from the soil class, we selected an area close to the area of interest. For $\eta$, Kassaye (2006) recommended values between 0.8 and 0.9 as being optimal for simple and complex scenes respectively.

The highest $\kappa$ values, equal to $0.64,0.60$ and 0.71 , were observed for one subset of three individual plants respectively. An important reason that relatively low accuracies are achieved is due to the use of the UltraCam digital aerial photo as reference data. The time of acquisition of the GeoEye image and the aerial photo differs by more than a year. Therefore, changes during the growing season could affect the selection of an appropriate boundary for each row and individual plants. The observed values, though, are well compatible with values of $0.73,0.67,0.68$ and 0.54 , respectively, observed e.g. by Ardila (2012) for four subsets of urban trees. 
The current study is potentially useful for farmers who want to obtain information regarding the health of individual plants. The reason is that NDVI as a vegetation index is informative on general vegetation status that is in turn affected by crop stress. Hence, using SRM at the individual row and plant scale and combining that result at the $0.5 \mathrm{~m}$ pixel resolution results into a $50 \mathrm{~cm}$ resolution NDVI map. Farmers will thus be able to control crop health at that scale level. Precision agriculture aims at providing management strategies from multiple sources to support the decision makers and farm managers with crop production (Oliver, 2010). Using advanced technologies in Geomatic science such as integration RS, GIS and GPS data thus leads to an important and reproducible strategy. In particular in this study, crop water requirement was the main issue for farmers and decision makers. Farmers who want to develop a strategy for managing water supply though irrigation networks of agricultural fields can use crop water requirement derived from RS data using the SEBS model and SRM as shown in this study. Such a product helps farmers and decision makers to decide on the amount of water requirements to maximize the cost benefit ratio of crop productivity. In this study, the target area was a vineyard, and crop water requirement was studied at the plant scale. The AET map can be utilized to assess the water stress at row and plant levels, and develop strategy for irrigation and select those irrigation methods that are appropriate to use. In turn, the NDVI map can be instrumental to make a fertilization plan.

Taking the maximum AET value as the PET value we were able to estimate crop water requirement for each row and individual plants: if PET exceeds AET then water stress occurs and the crop should be irrigated. Water requirement is spatially varying for stochastic reasons. Besides there is a temporal effect on the variation of AET values during the growing season and even within a single day. Finally, different crop varieties could in principle occur. In agricultural production situations, such as those for grape trees in a vineyard area in Iran, only a single variety is cultivated. From the AET and PET obtained in the study area, there is limited water stress on these crops and plants have to be irrigated when stress is becoming considerable.

\subsection{Conclusions}

The aim of this research was to achieve high resolution information on the basis of rows and individual plants of vineyard from images of coarse spatial and spectral resolution. We derived the following conclusions:

- SRM is able to provide reliable positional information of the position and the extent of plants in rows, but that the information for individual plants has a higher uncertainty. 
- Evapotranspiration values provided by the standard Surface Energy Balance System are in good agreement with values derived by standard FAO methods.

- Further improvements are to be expected when satellite information also in the thermal band becomes available at a finer resolution. 


\section{Chapter 4 Tree detection in orchards from VHR satellite images using scale-space theory ${ }^{3}$}

${ }^{3}$ This chapter is based on the published paper:

Mahour, M., Tolpekin, V. A., \& Stein, A. (2016). Tree detection in orchards from VHR satellite images using scale-space theory. In L. Bruzzone, \& F. Bovolo (Eds.), Image and Signal Processing for Remote Sensing XXII, 22-29 September 2016, Edinburgh, United Kingdom (pp. -). (SPIE proceedings; No. 10004). Bellingham: SPIE. DOI: $10.1117 / 12.2241529$ 


\begin{abstract}
This study focused on extracting reliable and detailed information from very High Resolution (VHR) satellite images for the detection of individual trees in orchards. The images contain detailed information on spectral and geometrical properties of trees. Their scale level, however, is insufficient for spectral properties of individual trees, because adjacent tree canopies interlock. We modeled trees using a bell shaped spectral profile. Identifying the brightest peak was challenging due to sun illumination effects caused by differences in positions of the sun and the satellite sensor. Crown boundary detection was solved by using the NDVI from the same image. We used Gaussian scale-space methods that search for extrema in the scale-space domain. The procedures were tested on two orchards with different tree types, tree sizes and tree observation patterns in Iran. Validation was done using reference data derived from an UltraCam digital aerial photo. Local extrema of the determinant of the Hessian corresponded well to the geographical coordinates and the size of individual trees. False detections arising from a slight asymmetry of trees were distinguished from multiple detections of the same tree with different extents. Uncertainty assessment was carried out on the presence and spatial extents of individual trees. The study demonstrated how the suggested approach can be used for image segmentation for orchards with different types of trees. We concluded that Gaussian scale-space theory can be applied to extract information from VHR satellite images for individual tree detection. This may lead to improved decision making for irrigation and crop water requirement purposes in future studies.
\end{abstract}




\subsection{Introduction}

In precision agriculture, the management scale is of an increasing interest. Modern management focuses on plants or individual leaves, whereas in traditional agriculture the management scale commonly was the field (Mahour et al., 2015b). For precision agriculture in orchards, trees are the objects of interest, in particular when it concerns their water supply. Detection of individual trees and identification of the crown boundaries are therefore important, e.g. for efficient decision making on water supply. In irrigation orchard management, estimation of water requirement depends upon the type of a tree, which in most cases is a function of the crop coefficient and tree cover fraction (Allen et al., 1998).

Individual trees observable from remote sensing (RS) images have a spatial pattern at both coarse and fine scales. These patterns can be characterized by different parameters such as shape, location, tree species and tree crown size (Ke and Quackenbush, 2011). A row of trees, for example, may appear at the coarsest scale, whereas individual trees become visible at a finer scale level, showing more detail of texture and spatial variation. Even more details like branches and leaves become visible at an increasingly fine observation level. Extracting individual trees from RS images has been challenging, and coarse resolution of RS data in the past was improper to detect the tree crown boundaries (Ardila et al., 2012a).

Detection of reliable and detailed information of individual trees from RS images requires sufficient spectral and geometrical details. VHR images are adequate among current RS images. In particular, Worldview-2 (WV-2) contains panchromatic and multi-spectral images with spatial resolution of 0.5 $\mathrm{m}$ and $2 \mathrm{~m}$, respectively. This scale level, however, is still insufficient for detecting crown boundaries of individual trees, where adjacent tree canopies interlocks occur, especially during the growing season.

Region-based image segmentation (Erikson, 2004), image template matching (Wolf and Heipke, 2007), valley following by finding local minima pixels surrounding tree crowns (Gougeon and Leckie, 2006) and local maxima (Pouliot et al., 2002) have been proposed to solve this problem. An example is detection of individual trees by exploring local maxima image brightness value corresponding with the tops of the trees, followed by estimating their spatial extents (Ardila et al., 2012a). This method is heuristic and has a limitation as it does not properly work for trees and background with similar contrasts, e.g. caused by the presence of vegetation or weeds. In this paper we propose to use a Gaussian scale-space method that searches for extrema in the scalespace domain. The specific idea of using scale-space methods is to determine individual trees as meaningful objects over the specific range of scales (Hay et 
al., 2002). Scale-space has been proposed to bridge the gap between the complex object patterns and detailed geographical coordinates and the size of object. By using scale-space methods, the original image structure is smoothed gradually from finer to coarser scale (Lindeberg and Eklundh, 1991).

The objective of this research was to investigate the application of scale-space methods for individual tree detection from remote sensing images. It focused on two orchards with different tree types, tree sizes and observation patterns.

\subsection{Study area and data}

\section{The orchards}

The study area consists of two orchards with geographical coordinates $36^{\circ} 05^{\prime \prime} 49^{\prime} \mathrm{N}, 50^{\circ} 21^{\prime \prime} 10^{\prime} \mathrm{E}$ for orchard 1 and $36^{\circ} 06^{\prime \prime} 30 \mathrm{~N}, 50^{\circ} 18^{\prime \prime} 36^{\prime} \mathrm{E}$ for orchard 2 , both located in the Qazvin agricultural area in North-western Iran (Figure 2). Water supply is done by an advanced traditional irrigation network. The two orchards are cultivated by peach and walnut, respectively. The main reason to study orchards in this area is their importance of providing more than $70 \%$ of the food products to the more than 7 million inhabitants of Tehran. Walnut trees are large trees with a maximum height of 4 to $5 \mathrm{~m}$. They are economically important because of the value of the wood and the nuts they produce. Harvest time for walnut trees is in September and October. Peach trees are somewhat smaller $(3 \mathrm{~m})$ and come to harvest from middle to late summer. The study period is selected in the middle of growing season of the two tree types. In this period walnut and peach trees have adjacent tree crown interlocks with the maximum wide range of tree crowns. The selected orchards consist of trees planted in rows with different tree sizes. Table 4.1 indicates the geometrical and physical characteristics of different orchards with respect to how information of tree positions in each row can be defined by means of plant type, geographical row orientation of trees, tree adjacent interlocks direction, tree crown radius $(R)$, and distances between trees within rows (Figure 4.1).

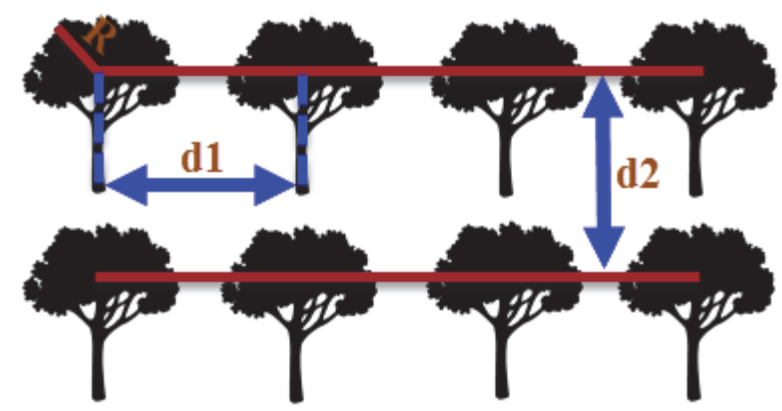

Figure 4.1: Information of tree position and crown radius, distance between rows and individual plants 
Table 4.1: Geometrical and physical characteristics of orchards

\begin{tabular}{cccccccc}
\hline & $\begin{array}{c}\text { Plant } \\
\text { type }\end{array}$ & Orientation & $\begin{array}{c}\text { Interlock } \\
\text { direction }\end{array}$ & $\begin{array}{c}\text { Minimum R } \\
(\mathbf{m})\end{array}$ & $\begin{array}{c}\text { Maximum R } \\
(\mathbf{m})\end{array}$ & $\mathbf{d 1}(\mathbf{m})$ & $\begin{array}{c}\mathbf{d 2} \\
\mathbf{( m )}\end{array}$ \\
\hline $\begin{array}{c}\text { Orchard } \\
\mathbf{1}\end{array}$ & Peach & NE-SW & NE & 0.5 & 1.6 & 3.5 & 3 \\
$\begin{array}{c}\text { Orchard } \\
\mathbf{2}\end{array}$ & Walnut & NE-SW & NE & 1.7 & 8.2 & 9 & 9 \\
\hline
\end{tabular}

\section{Remote sensing data images}

Two types of remote sensing images are used: a WV-2 VHR satellite image and an UltraCam digital aerial image. A four band (visible and near-infrared) pansharpened, eight bands multispectral image and a panchromatic image of WV2 were collected for the two orchards on July 7, 2012. Multispectral and panchromatic images were co-registered and projected in Universal Transfer Mercator (UTM) coordinate system, with the standard spheroidal reference surface WGS84. Both multispectral and panchromatic images were geometrically corrected. The UltraCam digital image was taken by a high resolution multichannel RGBI sensor at a $50 \mathrm{~cm}$ spatial resolution. The digital aerial image was orthorectified to eliminate lens distortion, topographic correction and camera tilt, and it was co-registered to the WV-2 image. The spatial and spectral characteristics of both images are indicated in Table 2. Figure 2 shows the two orchards as obtained from remote sensing digital aerial photos.

Table 4.2: Spatial and spectral characteristics of RS images

\begin{tabular}{cccc}
\hline & Spatial resolution & Spectral bands & Time of acquisition \\
\hline WV2 - Panchromatic & $0.5 \mathrm{~m}$ & - & July 7,2012 \\
$\begin{array}{c}\text { WV2 - Multispectral } \\
\text { UltraCam aerial } \\
\text { photo }\end{array}$ & $2 \mathrm{~m}$ & $8 \mathrm{bands}$ & July 7,2012 \\
\hline
\end{tabular}



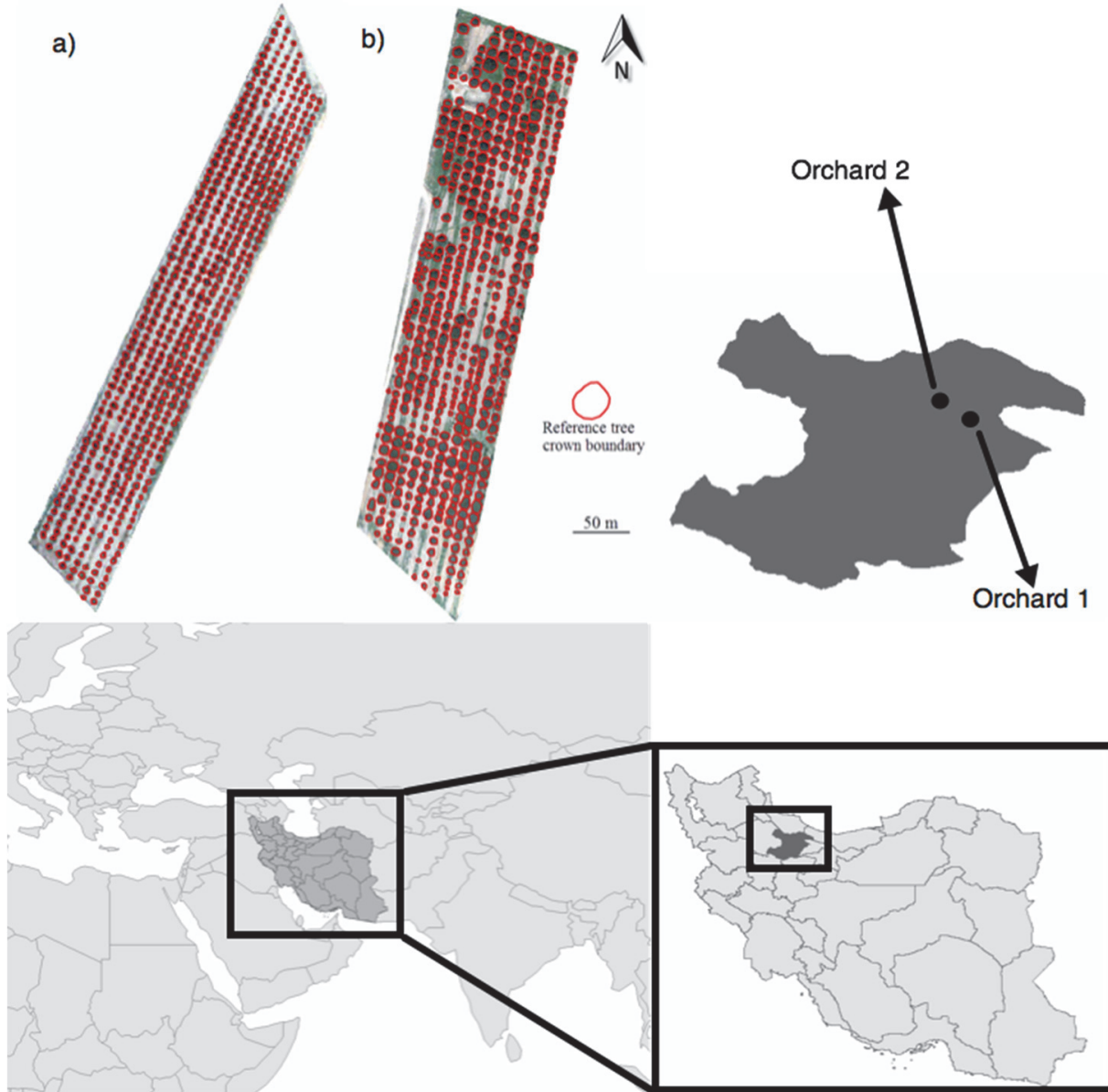

Figure 4.2: Study area with a. orchard 1 planted with peach and $\mathbf{b}$. orchard 2 planted with walnut taken from an Ultracam digital aerial photo (true color), red polygons are derived reference tree crown boundary

\subsection{Method}

Tree extraction consisted of three steps. First, scale-space blob detection was applied on the panchromatic band of the WV-2 to identify trees in orchard 1. Second, trees at orchard 2 were detected using the scale-space applied on the derived NDVI image obtained from the pansharpened image of WV-2. Third, the results were compared with reference object trees derived from the UltraCam digital aerial photo to quantify uncertainty for tree identification in both orchards. The schematic diagram of the methodology is provided in Figure 4.3. 


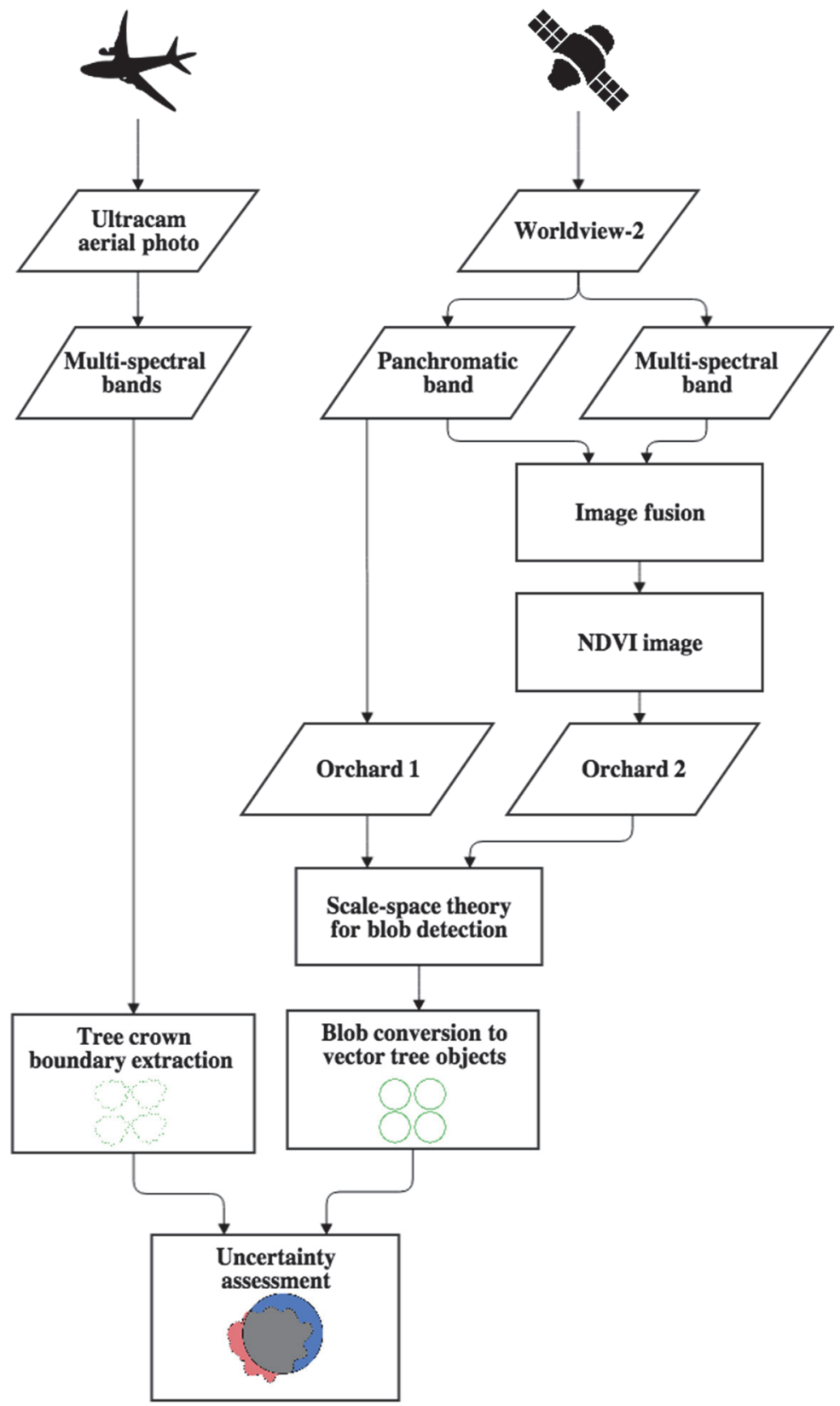

Figure 4.3: Schematic diagram for tree detection and its uncertainty assessment

\section{Scale-space theory}

Scale-space theory provides a framework dealing with image structure where objects occur at different scales and positions. The input in this study is given by a two-dimensional orchard image $f(x, y)$ resulting into a family $L(x, y ; s)$ of 
derived smoothed images from finer to coarser scale where tree objects are defined at any scale level (Lindeberg, 2010, 2008):

$L(x, y ; s)=g(x, y ; s) * f(x, y)=\iint_{(u, v) \in \mathbb{R}^{2}} f(x-u, y-v) \cdot g(u, v ; s) d u d v$

where $L(x, y ; s)$ is the Gaussian scale-space representation $(s \geq 0)$ which is defined by the convolution (*) of image $f(x, y)$ with $g(x, y ; s)$, the twodimensional Gaussian kernel:

$g(x, y ; s)=\frac{1}{2 \pi s} e^{-\left(x^{2}+y^{2}\right) / 2 s}$

The Gaussian scale-space representation resulted in a set of smoothed images at different scales. By increasing $s$ from fine to coarse scale in (1), smoothing of $f$ with a larger filter results in removing details from the image. For a twodimensional image, the initial condition is $L(x, y ; s)=f(x, y)$ where $f(x, y)$ is the representation at $s=0$, i.e. it is equal to the original image (Lindeberg, 2013), i.e. $L\left(x_{0}, y_{0} ; 0\right)=f(x, y)$.

\section{Grey-level blob detection}

We associate a tree in an image as a blob being a region of an image consisting of a bell shaped surface with smoothly varying intensity profile. This object can be expressed as a function of geographical coordinates and the size of the tree. Blob detectors are grouped into differential methods, and methods based on local extrema with respect to finding local extrema in scale-space. For feature detection using the scale-space representation $L$, points of interest are inside the blob, being an indication of individual tree objects.

The question to be answered is what properties are corresponding to blobs that are associated with the individual trees. Different properties of a blob are (Lindeberg, 2013):

- It is a connected region that is clearly brighter or darker than its background.

- It is an area corresponding to different scale levels in scale-space.

- It includes a natural significance measure such as the spatial extent and contrast.

- It includes at least one local extremum which is significantly brighter or darker than its background.

A two-dimensional grey-level blob is illustrated in Figure 4.4. The base-level blob is defined (Lindeberg, 2013), as:

$$
z_{\text {base }}(x, y)=\max _{z<f(x, y)} z
$$


For any grey-level $z<f(x, y)$, the base-level blob is the maximum value of $z_{\text {base }}(x, y)$. The grey-level blob corresponding to the local maximum $f$ and its extent are the elements of interest. A grey-level blob is thus given as a pair of points consisting of a local maximum and one local minimum or saddle point (Figure 4.4). It corresponds to those local maxima and minima values without reducing below the base-level.

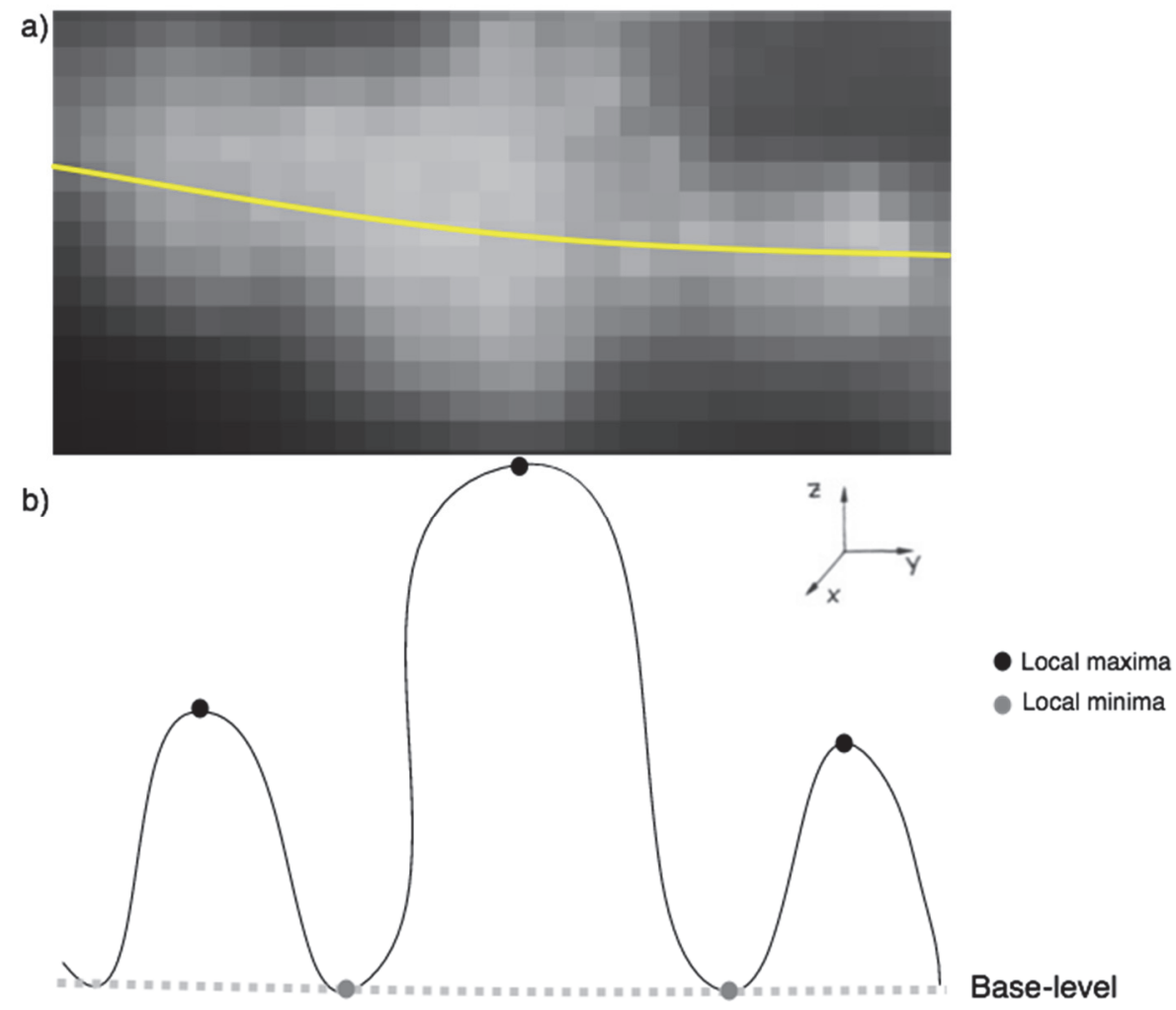

Figure 4.4: Illustration of the grey-level blob along the yellow line, a. on the row of trees of the NDVI image of orchard 2, b. grey-level blob with local maxima and local minima. This figure shows bright blobs on a dark background of the orchard image

\section{Scale-space blob detection}

Tree objects are dark areas that are well visible in the panchromatic band, and they are bright areas in the NDVI image of WV-2. A negative transform performed on the panchromatic band makes tree objects brighter than their background. A grey-level blob of two-dimensional image function consists of a local extremum and a saddle point or local minimum. The saddle point appears where a bright blob with the local maximum point meets a second blob. For each extremum along the different scales, there is a corresponding grey-level blob towards the local minimum. These grey-level blobs are extracted at each level of scale corresponding to the blob size as an object with spatial extent in 
space and grey-level. Linking those generated grey-level blobs by means of different scales gives blobs as higher order objects, i.e. the scale-space blobs corresponding to geographical coordinates, blob sizes and scale $(s)$.

Different scales play a predominant role in scale-space blob detection in particular if saddle points appear or disappear. To handle blob selection at a particular scale, the determinant of the Hessian (Lindeberg, 2012) as a blob detector is considered. The scale-normalized determinant of the Hessian equals:

$\operatorname{det} \mathcal{H} L(x, y ; s)=s^{2}\left(L_{x x} L_{y y}-L_{x y}^{2}\right)$

where $\mathcal{H} L$ is the Hessian matrix of the scale-space representation $L$. Automatic scale selection is performed with the scale-normalized differential expression (4.4), which assumes that local extrema of this operator with respect to the locations of the objects in a two-dimensional image function correspond to blobs. A tree as an object or a patch on an image can be determined using the Hessian matrix of the scale-space representation $L$ at different scale levels corresponding to the size of blob and location $\left(x_{0}, y_{0}\right)$. Hence, blob detection involves detection of a local maximum in scale-space, where the point with coordinates $x, y, s$ is a maximum in all three directions in (4). Here, $x, y$ determines the position, and $s$ is relates to the radius of the blob $r=\sqrt{2 s}$. In practice, $x, y$ and $s$ are discrete, and interpolation is used to refine the position of the local maximum.

\section{Implementation}

Individual tree detection was implemented on the WV-2 image. In orchard 1, a regular pattern in both size and tree texture exists. Therefore, scale-space theory was applied on the panchromatic band of the WV-2 image. A tree has a bell shaped spectral profile, whereas identifying the brightest peak is challenging due to sun illumination effects caused by differences in position of the sun and the satellite sensor. In orchard 2, trees are two times larger and more spatial variation can be observed within the tree crowns than in orchard 1. Crown boundaries related to the dark shaded pixels surrounding the boundary can be observed from the NDVI image obtained from the geometrically corrected multi-spectral bands of the same image. To obtain the NDVI at $0.5 \mathrm{~m}$ spatial resolution, we performed a Gram-Schmidt fusion (Laben and Brower, 2000) with the panchromatic band of the WV-2 image. Figure 4.5 illustrates the histogram of two orchards within the panchromatic image and the NDVI extraction. Within the NDVI image, background and trees can be observed separately from the histogram of orchard 2 (Figure 4.5). 

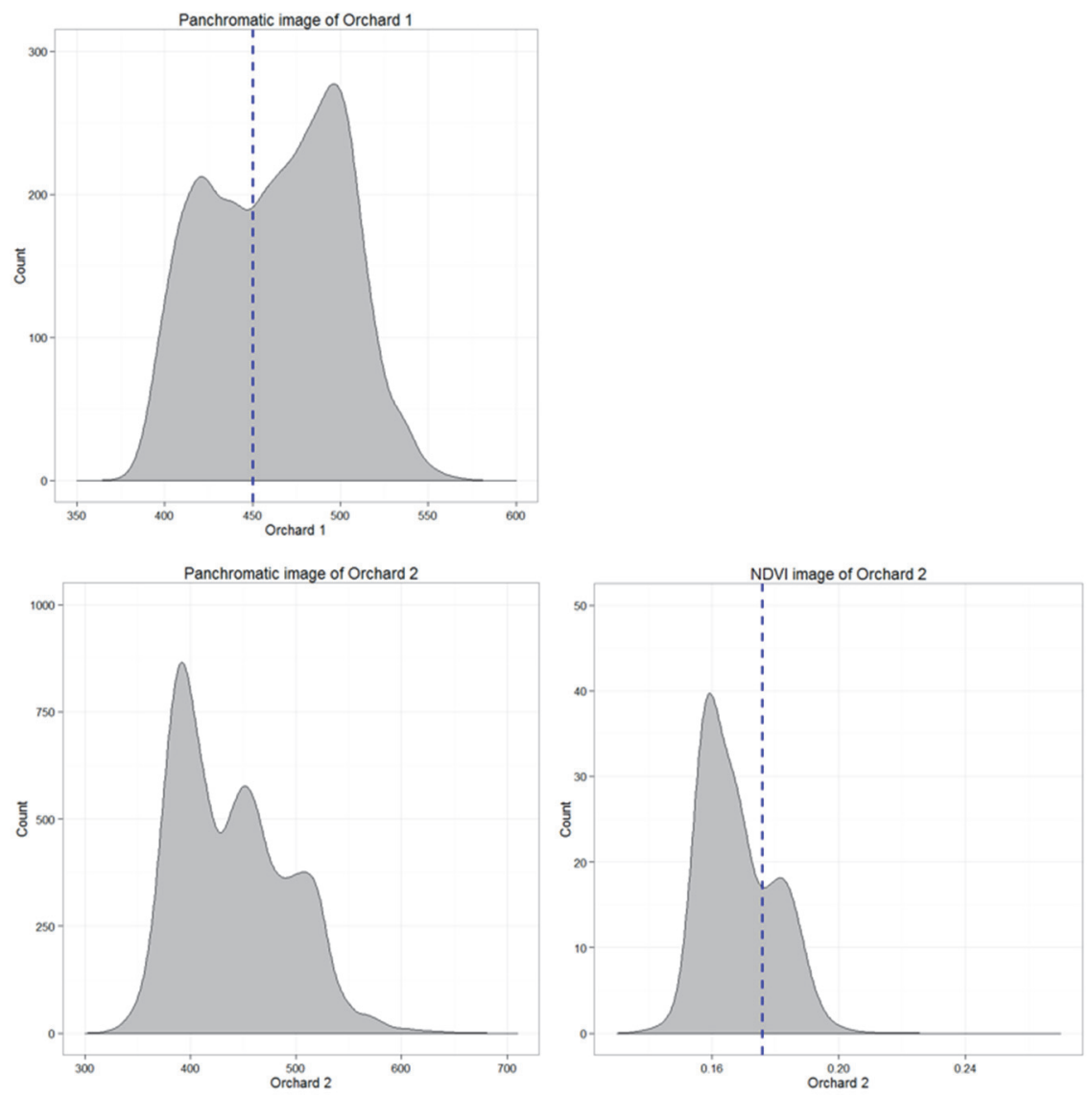

Figure 4.5: Histogram of the panchromatic image of orchard 1 and orchard 2 and the NDVI image of orchard 2, blue dash line indicates separation between trees and nontree on the panchromatic and the NDVI images

The main feature arising in the scale-space representation (4.1) is a blob as a smoothed region standing out from its surrounding pixels and it has at least one local extremum. At each scale level a blob is created. Their detection is done at an increasing scale level by steps of $0.5 \mathrm{~m}$. The size of the blob in the scale-space domain is based upon the local extrema of the $\operatorname{det} \mathcal{H} L(4.4)$, corresponding to the geographical coordinates of individual trees. When the scale increases, noise blobs gradually disappear, whereas blobs due to noise can survive at many levels of scale if they are located in the region with lower grey-level intensity. The main concern in automatic tree detection is thus how to treat the scale parameter. To properly choose this parameter, we need prior knowledge as geometrical characteristics of trees regarding the size of trees (Table 4.1). From visual interpretation we can determine the minimum and maximum tree sizes in an orchard. Next, the scale is treated from finer to coarser scale levels based upon the minimum size of the tree diameter as for 
the finer scale. This resulted in an increasing scale level on the basis of pixel resolution, here equal to $0.5 \mathrm{~m}$, to the maximum size of the trees in orchards at the coarser scale. Figure 6 shows the use of different scales on the small subset of the NDVI image at orchard 2.
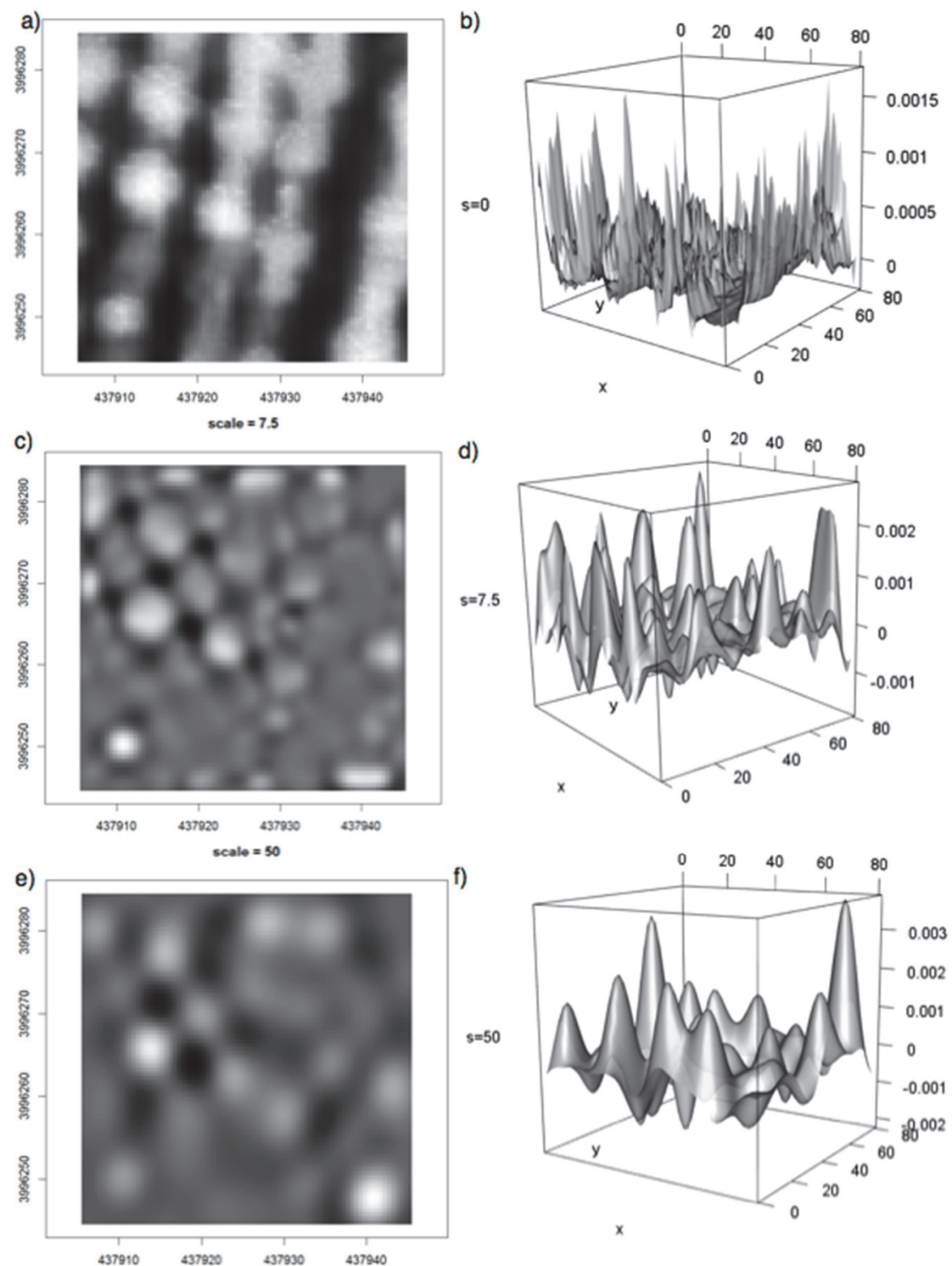

Figure 4.6: A set of smoothed images from a subset from NDVI image of orchard 2, a. original image at zero scale, b. 3D plot of image at scale 0 (original image), c. smoothed image at scale 7.5 , d. $3 \mathrm{D}$ plot of image at scale 7.5 , e. smoothed image at scale 50 , f. $3 \mathrm{D}$ plot of image at scale 50 


\section{Validation}

To validate the detected tree crown objects and their boundaries, two uncertainty assessments have been carried out, focusing on the presence and the spatial extents of individual trees (Figure 4.7). To do so, a polygon reference boundary layer was made manually using a visual interpretation from the Ultracam digital aerial image. Here we follow (Lucieer and Stein, 2002) who proposed an indicator to evaluate segmentation results of rectangular objects. We consider a local area tree object difference $\left(\Delta A_{i}\right)$, as:

$\Delta A_{i}=A_{R_{i}}-A_{D_{i}}$

where $A_{D_{i}}$ is the area of detected tree objects by scale-space blob detection and $A_{R_{i}}$ is the area of reference tree objects. If $\Delta A_{i}$ is close to 0 , a good match exists for detected tree crown boundary objects. Reference tree object $\left(R_{i}\right)$ is overestimated if $\Delta A_{i}>0$, i.e. $A_{R_{i}}>A_{D_{i}}$, and underestimated if $\Delta A_{i}<0$ (Figure 4.7). The error metrics indicator proposed by (Clinton et al., 2010) was used for evaluation of detected tree crown boundary object:

Overestimated $\left(A_{D_{i}}\right)=1-\frac{\operatorname{area}\left(A_{D_{i}} \cap A_{R_{i}}\right)}{\operatorname{area}\left(A_{D_{i}}\right)}$

Underestimated $\left(A_{D_{i}}\right)=1-\frac{\operatorname{area}\left(A_{D_{i}} \cap A_{R_{i}}\right)}{\operatorname{area}\left(A_{R_{i}}\right)}$

with overestimation and underestimation values between 0 and 1 . There is a good match between reference and detected tree crown boundary if the values of (4.6) and (4.7) are close to zero. The total detection error equals:

Total detection error $\left(\varepsilon_{D_{i}}\right)=\sqrt{\frac{\text { Overestimated }\left(A_{D_{i}}\right)^{2}+\text { Underestimated }\left(A_{D_{i}}\right)^{2}}{2}}$ 


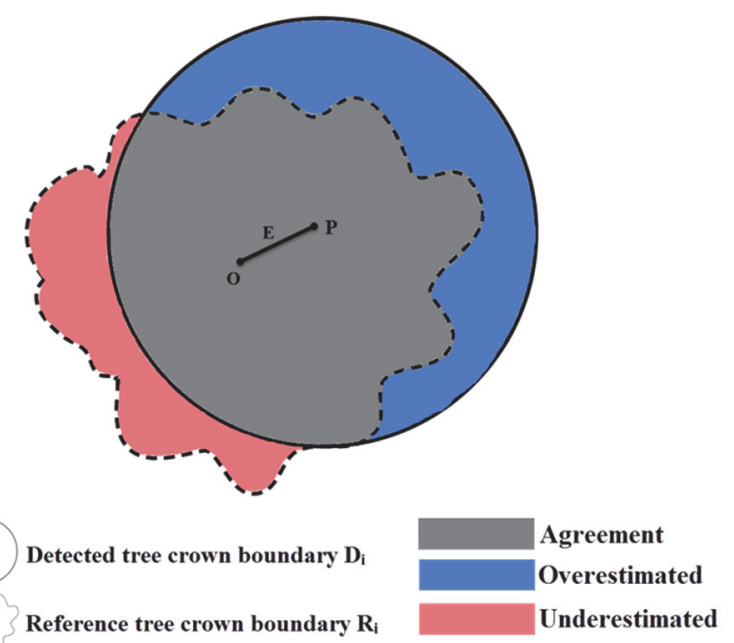

Figure 4.7: Over-estimate and under-estimate between reference $R_{i}$ and estimated $D_{i}$ tree objects

The index $\varepsilon_{D_{i}}$ is between 0 and 1 . Moreover, three object accuracy indicators are estimated that are related to the spatial extent of tree objects: detection ratio of true positives (TP) where trees exist in the reference vector polygon layers, false positives (FP) that concern improper detection of trees that are not present at reference layer, and false negatives (FN) where there is a failure to detect tree objects in the reference layer (Schuenemeyer and Drew, 2010).

To evaluate the distance between two centroids of detected tree object $P=$ $\left(X_{p}, Y_{p}\right)$ and reference tree crown boundary $O=\left(X_{o}, Y_{o}\right)$, the Euclidean distance (E) (Figure 7) was computed as:

$E=\sqrt{\left(X_{o}-X_{p}\right)^{2}+\left(Y_{o}-Y_{p}\right)^{2}}$

Note that acceptance of agreement is based on having the centroid of each detected and reference tree object inside the crown boundaries (Figure 4.8). 

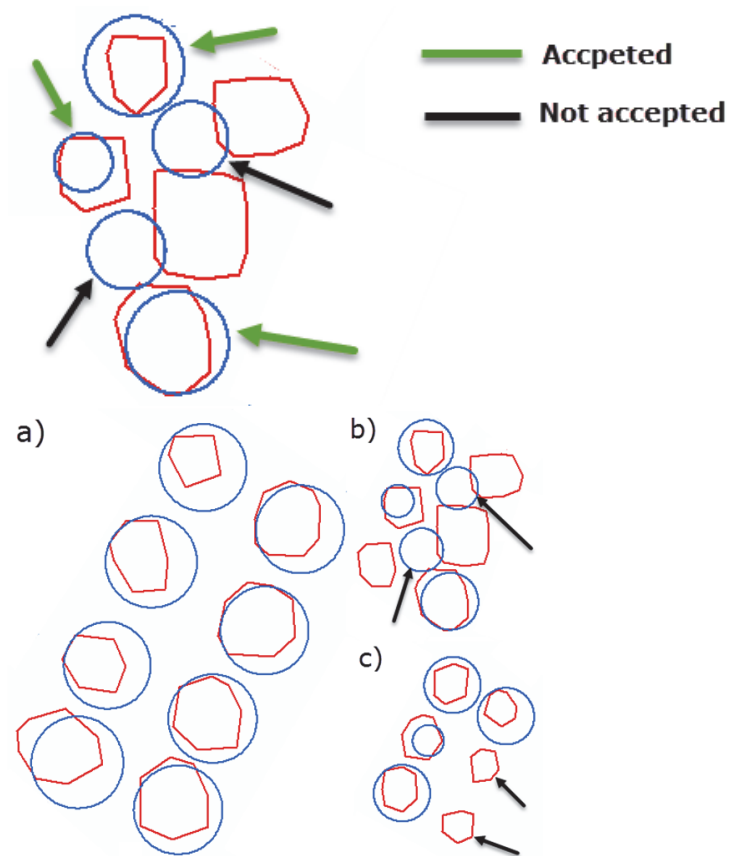

Figure 4.8: The matched objects are accepted when each center falls within each other. a) Correctly matched, b) False positives and c) False negatives

\subsection{Results}

Table 4.3 shows the results for the detection of 498 individual trees crown objects out of 519 reference objects in orchard 1 . In total, 468 tree objects $(90 \%)$ truly match with the reference data. In orchard 2, 462 objects are found among 500 reference objects, with 408 (81.6\%) tree objects covered by reference tree objects. This indicates an FP error rate of $5.5 \%$ and $11 \%$, and FN error rates of $9.0 \%$ and $12.0 \%$ for the two orchards, respectively.

Table 4.3: Tree crown positional accuracy, mean area difference and total detection error in orchard 1 vs. orchard 2

\begin{tabular}{cccccc}
\hline & $\begin{array}{c}\text { Positional } \\
\text { accuracy } \\
{[\mathrm{cm}]}\end{array}$ & $\begin{array}{c}\text { Area } \\
\text { difference } \\
{\left[\mathrm{m}^{2}\right]}\end{array}$ & Overestimated & Underestimated & $\begin{array}{c}\text { Total } \\
\text { detection } \\
\text { error }\end{array}$ \\
\hline $\begin{array}{c}\text { Orchard } \\
1\end{array}$ & 24 & 2.29 & 0.45 & 0.07 & 0.49 \\
$\begin{array}{c}\text { Orchard } \\
2\end{array}$ & 103 & 3.43 & 0.21 & 0.24 & 0.25 \\
\hline
\end{tabular}

Figures 4.9 and 4.10 show the results of the scale-space blob detection in the two orchards, including a map of true positives, false positives and false negatives. In orchard 1, most trees have a similar size (diameter: $1 \mathrm{~m}-3.2$ $\mathrm{m}$ ), exhibit a regular pattern in different rows and have only a few missing trees. Most of the false negatives are observed for trees smaller than the 
regular size of trees in the orchard, whereas the false positives occur if adjacent tree canopies interlock. In orchard 2, the size of trees is large (diameter: 3.4 $m-16.4 \mathrm{~m}$ ), and orchard trees were not planted in a regular pattern. As shown in Figure 4.10b, false negatives occur in places where there is an interlock between adjacent trees, whereas false positives are identified on detected tree crown boundaries where the position of a blob centroid is outside the reference tree.

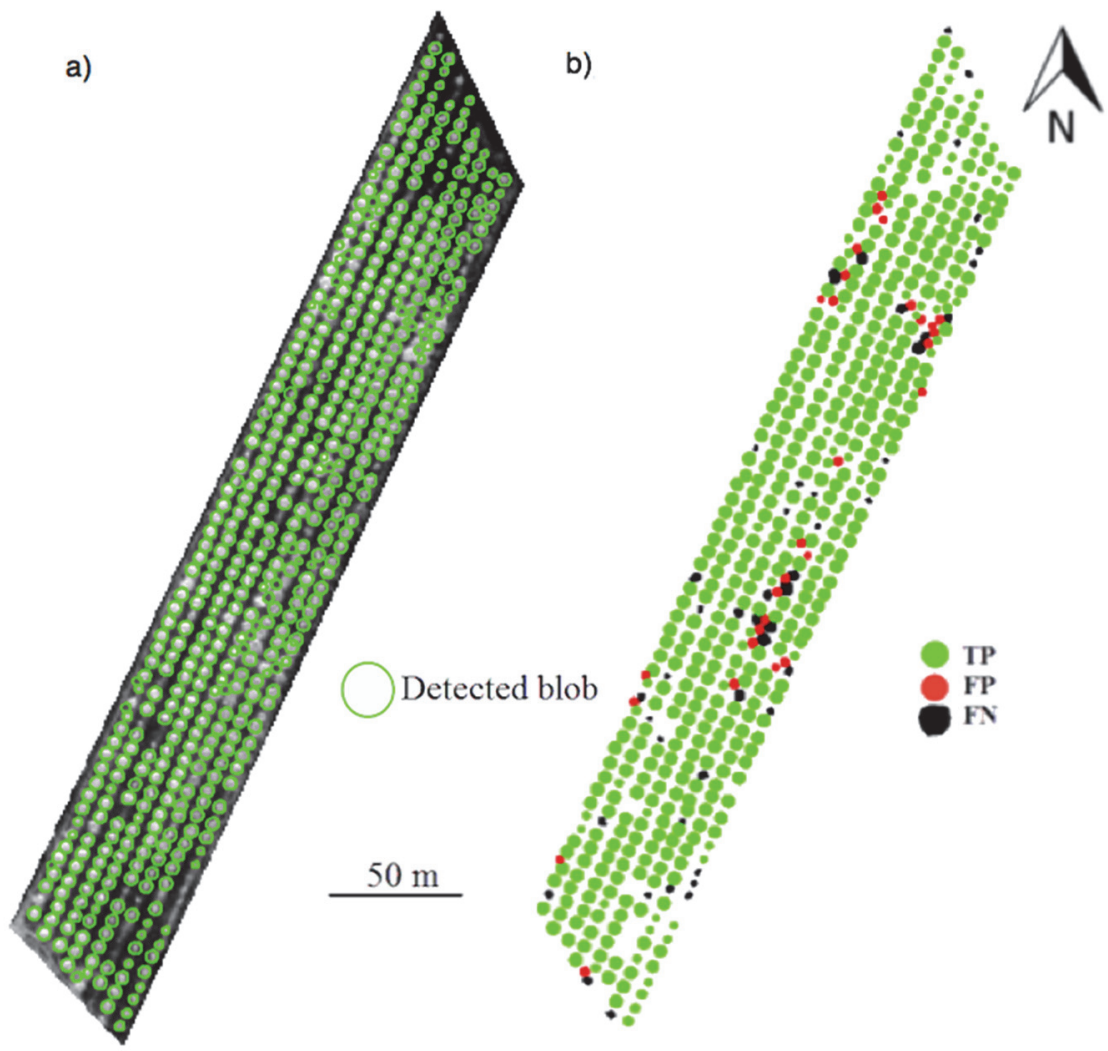

Figure 4.9: Results of the scale-space blob on a. the panchromatic image at orchard 1, b. error map 


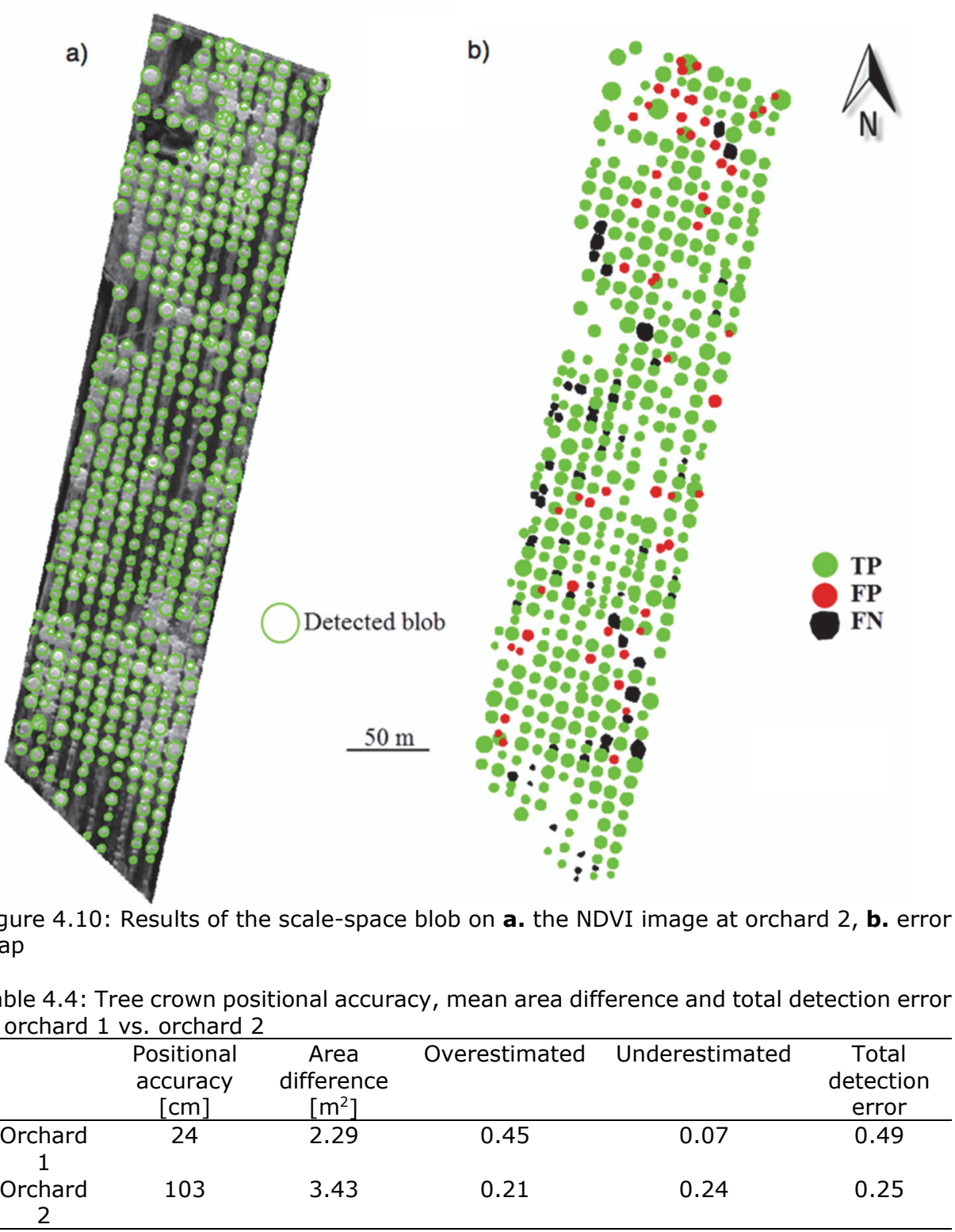

Table 4.4 shows that the positional accuracy for orchard 2 is higher than for orchard 1 , whereas for orchard 1 the value of $0.24 \mathrm{~m}$ is less than the spatial resolution of a pixel of panchromatic image. Moreover, the mean of area difference for the two orchards equals $2.29 \mathrm{~m}^{2}$ in orchard 1 and $3.43 \mathrm{~m}^{2}$ in orchard 2. The aggregated overestimation error for orchard $1(0.45)$ is higher than underestimation error $(0.07)$, whereas these errors are almost the same for orchard 2 (0.21 and 0.24 , respectively). The total detection error (4.8), for 
both orchards is different, where this error for orchard 2 is less than orchard 1.

\subsection{Discussion}

In this research we used Gaussian scale-space theory for extracting individual trees from VHR images addressing automatic detection on complex orchards with different tree size, texture and spatial variation. The scale-space theory considers a set of images smoothed at different scales. Representation of tree objects have an extent in space, scale and grey-level value. The image objects must be stable with respect to the scale variation. The minimum scale creates the appearance of blobs, whereas the maximum scale causes the disappearance of blobs. By controlling scale variation, we were able to minimize the blob noises and blob overestimation.

The scale-space blob detection requires the size of the trees in orchards from minimum to maximum diameter of crown boundary. This helps to treat the extracted object trees at different scales. Without this prior knowledge as supervised classification, it can also be done with no information on the tree sizes, e.g. from an unsupervised classification. This would bring an additional pre-processing step for automatically understanding the crown tree boundary size. The current study is potentially useful in automatic object-based image analysis with less prior knowledge, and as such it is at the edge of modern remote sensing. In traditional image analysis, where a set of training samples plays an important role, results can change from different user interpretations. This is the key contribution of this work, as the automatic extraction of individual trees from VHR images in two orchards with complex spatial variation can reduce the contribution of user interpretation.

Extracting individual trees is important for farmers and decision makers who want to make a decision in agricultural management. Although such tree detection is based on the availability of commercial VHR satellite images, it has been a challenge even for extracting small trees (Ardila et al., 2011). Nowadays, images captured by Unmanned Aerial Vehicles (UAV) may serve as an alternative to commercial VHR imagery to monitor orchards over time. Integrating results of scale-space theory with other sources of information for plants such as crop health via NDVI and crop water requirements will enable farmers to control and monitor their orchards from multiple sources.

An important problem in scale-space theory is the shape of blobs. Trees as patches on the ground with different spatial pattern may occur with random, regular and clustered patterns (Paulo et al., 2005), causing different shapes and sizes of trees. A tree that is present on a VHR satellite image consists of a group of pixels which can have different irregular and random shapes, but 
rarely regular shape as a blob. This causes overestimation and underestimation of trees (Table 4.4) as for example in our study orchard 1 resulted into a higher overestimation. The reason is due to sun illumination and a different position of satellite sensor causing dark shadows (Table 4.1) as compared to orchard 2. The proposed scale-space method thus shows better results when applied on the NDVI image in orchard 2 as compared to orchard 1 where it was applied on the panchromatic band of VHR image.

The implementation of the scale-space theory identified most tree objects in both orchards, with an accuracy of $90 \%$ for orchard 1 and $81.6 \%$ for orchard 2 (Figure 4.8). False positives at orchard 2 caused a higher positional accuracy $(103 \mathrm{~cm})$ as compared to orchard 1 with less false positives and positional accuracy $(24 \mathrm{~cm})$. False negatives for both orchards occurred where trees were pruned, e.g. to increase their fruitfulness and growth. False positives occurred as the proposed method may detect other objects on the image, for instance, the patch of wheat between the trees. Physically, however, a tree compared to the patch of wheat can have a different spectral behavior, showing a bell shape spectral profile on the RS imagery. This can help to better extract the spatial pattern of trees on a satellite imagery.

\subsection{Conclusions}

This research produced useful and meaningful delineations of individual trees from VHR satellite images. The Gaussian scale-space theory provided an automatic way to detect individual trees from two orchards with different sizes, species, spatial variation and limited prior information. Results from the two orchards are in good agreement as compared with reference data. The proposed modeling can potentially be useful if it is combined with applied RS irrigation management issues. Further improvements can be expected if a slight asymmetry of trees would be identified from multiple detections of the same tree. The straightforward flexibility of this modeling allows scientists, farmers and decision makers to apply it to other VHR images from different platforms. Further improvements are needed to study the role of saddle points and local minima to prevent multiple detections, and remove false positives where orchards have adjacent tree crown interlocks.

This work has been done in two orchards in semi-arid region in Iran. It aimed to explore the possibility of using modern RS techniques in agricultural field with a traditional irrigation network. Most agricultural products including fruits (70\%) for Tehran are provided from this region. The proposed modeling can help other scientists for further studies such as monitoring trees, change detection, mapping tree health and also crop water requirement. 


\section{Chapter 5 Refining blob model in scale-space for tree detection from VHR satellite images ${ }^{4}$}

${ }^{4}$ This chapter is under minor revision and has been submitted to:

Mahour, M., Tolpekin, V. A., \& Stein, A. (2017). Automatic detection of individual trees

from VHR satellite images using scale-space methods. Remote sensing of environment 


\begin{abstract}
This research investigated the use of scale-space theory to detect individual trees in orchards from Very High Resolution (VHR) satellite images. Trees are characterized by blobs, e.g., bell shaped surfaces. Their modelling requires the identification of local maxima in Gaussian scale-space, whereas location of the maxima in the scale direction provides information about the tree size. To avoid false detections and imprecise estimates of tree sizes, an accurate characterization of blobs is required. The study presents a two-step procedures to relate the detected blobs to tree objects in the field. First, a Gaussian blob model identified tree crowns in Gaussian scale-space. Second, an improved tree crown model was applied by modifying a Gaussian blob model in the scale direction. The procedures were tested on three representative cases: an area with vitellaria trees in Mali, an orchard with walnut trees in Iran and one with oil palm trees in Indonesia. Results showed that the refined Gaussian blob model improved upon the traditional Gaussian blob model by discriminating well between false and correct detections and accurately identifying size and position of trees. We conclude that the presented two-step modeling procedure of tree crowns using Gaussian scale-space is useful to automatically detect individual trees from VHR satellite images for at least three representative cases.
\end{abstract}




\subsection{Introduction}

Remote sensing (RS) imagery and technologies can help scientists to detect and delineate individual trees in precision orchard management. This is important information for the efficient decision making on crop health and crop water requirement. Trees establish a spatial pattern at both coarse and fine spatial resolutions. These patterns can be characterized by different parameters such as shape, location, species and crown size ( $\mathrm{Ke}$ and Quackenbush, 2011). There is a need to precisely estimate tree parameters like tree size and biomass from an image. In the past, the relatively coarse resolution of images was inadequate to delineate tree crowns individually (Ardila et al., 2012b). Such images provide insufficient spectral and geometrical detail information. In contrast, high resolution images may provide the necessary detailed information that e.g., to allow for identifying adjacent tree canopy interlocks.

Obtaining detailed and reliable information on each individual tree from RS images requires many spectral and geometrical details. In particular, Worldview- 2 imagery (WV-2) contains panchromatic and multi-spectral images with spatial resolution of $0.5 \mathrm{~m}$ (panchromatic band) and $2 \mathrm{~m}$ (visible and NIR bands), respectively. This resolution level is still too coarse for delineating interlocking tree crown boundaries, despite several image processing techniques that have been proposed to do so. For instance, regionbased image segmentation (Erikson, 2004) requires prior knowledge information on tree shape and size, image template matching (Pollock, 1996; Wolf and Heipke, 2007) is useful for trees of the same height, size, and species, and watershed segmentation (Chen et al., 2006; Persson et al., 2002; Pouliot and King, 2005; Schardt et al., 2002) suffers from over and under segmentation due to differences in tree heights and variation in the density of tree crowns (Hamraz et al., 2016). Also, other methods are not solving this problem. Valley following (Gougeon, 1999) explores local minima of neighboring tree crown boundaries in a way similar to edge detection (Gougeon and Leckie, 2006; Brandtberg and Walter, 1998; Culvenor, 2002; Koch et al., 2006; Popescu et al., 2003; Pouliot et al., 2002). The local maxima technique (Culvenor, 2000; Wulder et al., 2000) searches local maxima corresponding to image brightness values at the center of the trees (Pouliot et al., 2002). This technique, however, suffers from two limitations: it only detects the location of the tree and it has a problem for multiple detections in irregular tree crown surface (Figure 5.1b). Figure 5.1 illustrates the local maxima of a coniferous tree in a natural forest area and a broad-leaved tree with several local maxima in an orchard area where the number of local maxima depends upon spatial and spectral resolution of the sensor. The local maxima technique has been used in several studies to detect coniferous trees, but for broad-leaved trees it is inconvenient. 
To overcome the multiple maxima problem of the broad-leaved trees, Ardila et al. (2012b) proposed a pre-smoothing Gaussian filter on a tree crown, followed by fitting a two-dimensional Gaussian function. This method separates multiple trees prior to fitting (Figure 5.1d), and causes inaccuracies in tree size estimates and tree positions for interlocked trees in the presence of background noise. The parameters of the pre-smoothing filter are adjusted empirically, and depend upon the spatial resolution of images, tree size and the degree of irregularity of tree crowns.

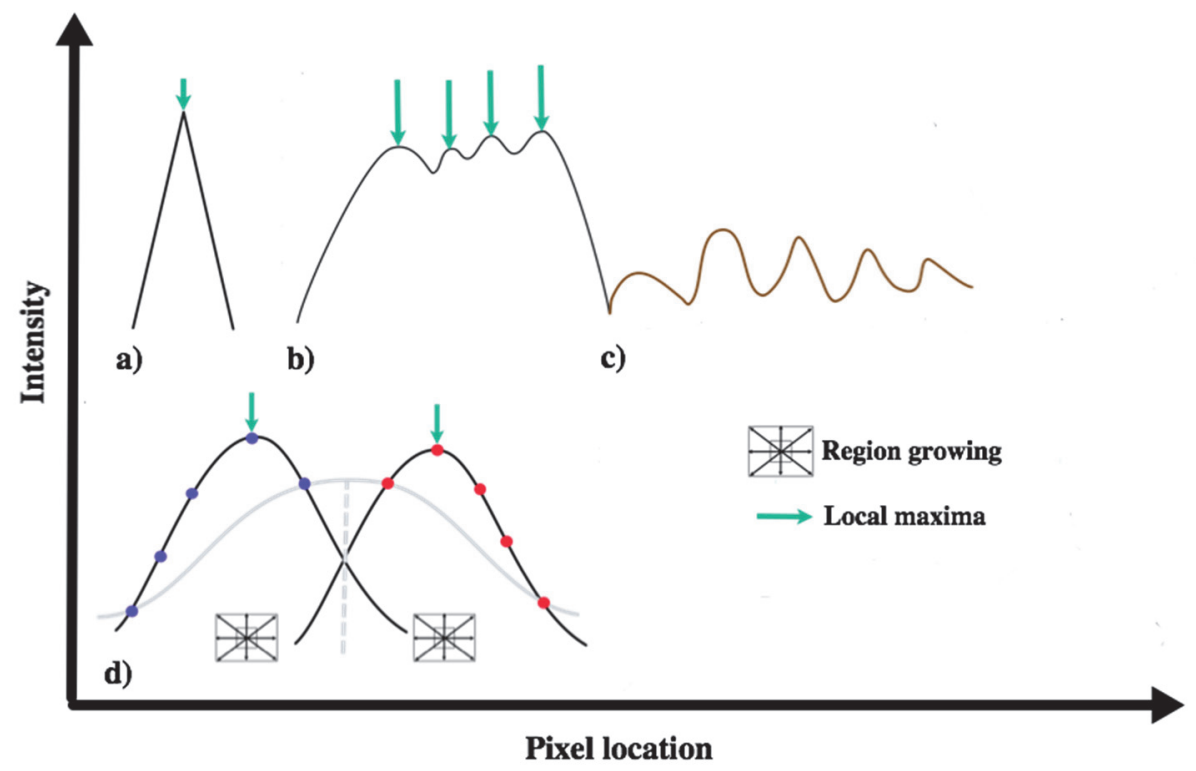

Figure 5.1: The intensity profile of a) a coniferous tree with a single maximum, b) a broad-leaved tree with several local maxima and c) a noisy background. d) Represents the fitted Gaussian functions after region growing between two interlocked trees, colored blue and red. The grey curve is obtained if the Gaussian function is fitted to all points, whereas the black curves are obtained if region growing is applied on the two separate tree objects.

Gaussian scale-space theory (Brandtberg and Walter, 1998; Lindeberg, 1998; Skurikhin et al., 2013; Wang, 2010; Witkin, 1983) has been proposed to bridge the gap between the complex object patterns, detailed geographical coordinates and sizes of objects. It is based upon detection of local maxima in the scale-space domain, detecting trees by providing their location and diameter (Mahour et al., 2016). It had as an assumption that a bell shaped function similar to the Gaussian function can describe tree intensity in space. In Mahour et al. (2016) four limitations were identified. First, false detections occurred for trees that were cut in the past but were still identified as trees. Second, groups of trees were detected as a single tree. Third, tree size measurements were not consistently accurate. Fourth, the use of sampled 
Gaussian function in computation of scale-space failed to detect small trees resulted in false negatives. The present study aims to follow up on that research by addressing the four limitations. Precise estimates for the parameters of a spatial tree intensity function are important to discriminate real trees from false detections in particular if the contrast between trees and their background is low. Moreover, the presence of high frequency irregularities of tree crowns (Figure 5.1b) leads to problems in spatial modeling of the tree intensity function, and this can be compensated by applying a smoothing filter. However, the parameters of the filter should depend upon tree size, image resolution, and the size of the irregularities such as width, height and distance between them. In contrast, scale-space includes such filters implicitly, where small irregularities are only apparent at small scales, and such modelling remains unaffected at coarse scales of the scale-space.

The objective of this research is to further improve automatical detection of individual trees from VHR satellite images. For this purpose, we model tree crown responses in the scale direction and introduce an improved real tree crown model by modifying a Gaussian blob model in Gaussian scale-space. The model is applied to three study areas: two orchards that are different in size, tree species, and planting pattern, and an area with irregularly positioned trees.

\subsection{Scale-space blob detection}

Scale-space theory provides a framework for objects that occur at different scales and positions and that can be observed from a two-dimensional grayscale image $f(x, y)$. The Gaussian scale-space representation $L(x, y ; s)$ of $f(x, y)$ is a family of derived smoothed images at different scales $(s)$ and locations $(x, y)$ (Lindeberg, 2010, 2008) as

$L(x, y ; s)=g(x, y ; s) * f(x, y)$,

where $*$ denotes the convolution operator, and $s \geq 0$. The function $g(x, y ; s)$ is either the two-dimensional sampled Gaussian kernel

$g_{u}(x, y ; s)=\frac{1}{2 \pi s} e^{-\left(x^{2}+y^{2}\right) / 2 s}$,

or the two-dimensional discrete Gaussian kernel

$g_{v}(x, y ; s)=I_{x}(s) I_{y}(s) e^{-s}$.

In (5.3), $I_{n}(s), n=x, y$, is the modified Bessel function of the first kind (Lindeberg, 1990) with integer orders. The Gaussian smoothing kernel (5.2) as the predominant part of the Gaussian scale-space maintains the structure 
at a coarser scale similar to the finer scale of the original image. The initial condition of the Gaussian scale-space representation is that $L(x, y ; 0)=f(x, y)$ at the finest scale, i.e. for $s=0$.

a)

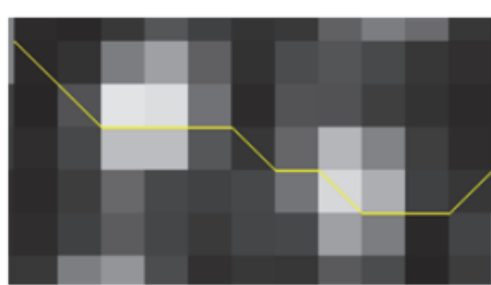

Spectral intensity

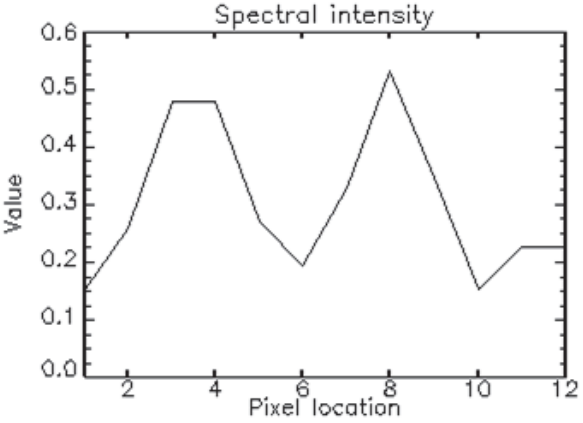

b)
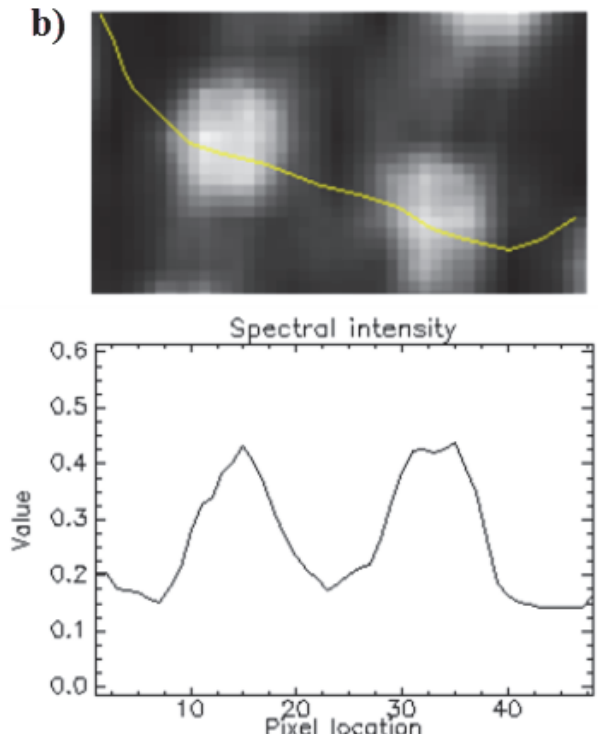

Figure 5.2: The spectral profile of tree crowns on a) the NDVI image of WV-2 $(2.0 \mathrm{~m})$ and $b$ ) the NDVI image of WV-2 at $0.5 \mathrm{~m}$ spatial resolution.

A tree in a remote sensing image can be described by a bell shaped spectral profile. The position of the brightest peak is subject to the position of the sun and the satellite sensor. A relative transformation such as NDVI corrects for the uneven sun illumination of the crown (Ardila et al., 2012a). A tree object is then a bright region on a dark background in an image with a smoothly varying intensity profile and a maximum at the center of the tree (Figure 5.2). We call such an object a blob that can be expressed as a function of geographical coordinates $\left(x_{0}, y_{0}\right)$ and size of the tree $\left(r_{0}\right)$.

Figure 5.3 depicts how Gaussian scale-space theory is used for blob detection. Blobs are detected in scale-space using the local maxima of the scalenormalized determinant of the Hessian (Lindeberg, 2012)

$H(x, y, s)=s^{2}\left(L_{x x} L_{y y}-L_{x y}^{2}\right)$,

where $L_{x}=\frac{\partial L}{\partial x}$. Due to the associativity of convolution, $L_{x}$ can be expressed as $\frac{\partial g_{u}}{\partial x} * f$, i.e. the original image $f$ convolved by the kernel's derivative $\frac{\partial g_{u}}{\partial x}$, performing a single raster convolution operation in the sampled Gaussian scale-space. In contrast, the computation of a derivative in the discrete 
Gaussian scale-space requires an additional convolution operation, $L_{x}=\partial_{x} * L_{v}$, where $\partial_{x}=\frac{1}{2}\left[\begin{array}{lll}-1 & 0 & 1\end{array}\right]$.

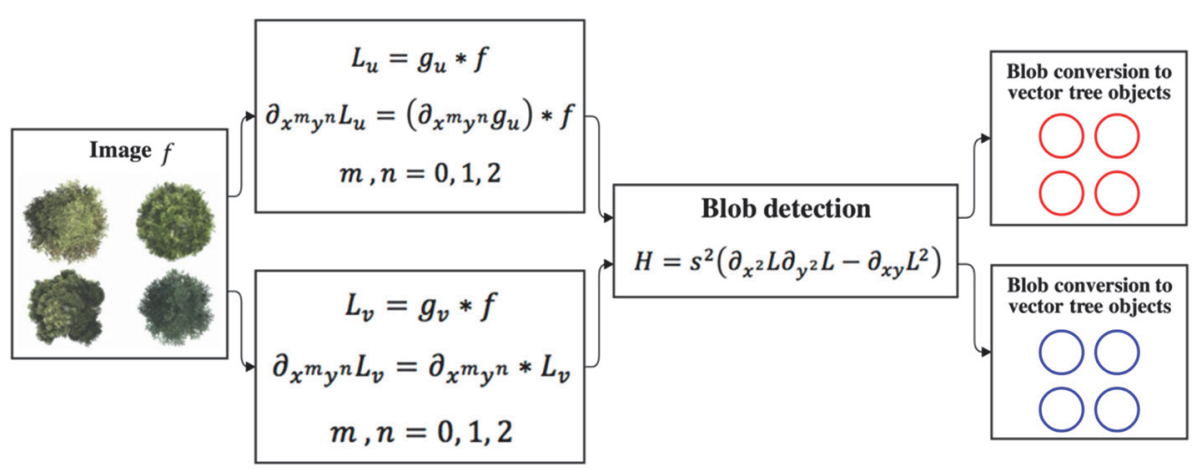

Figure 5.3: Schematic diagram of the scale-space for blob detection from the twodimensional sampled Gaussian kernel, indexed by $u$, and the two-dimensional discrete Gaussian kernel, indexed by $v$. The detected red and blue blob objects are from the sampled and discrete Gaussian kernels, respectively.

We denote a local maximum of $H$ over scale by its position $\left(x_{0}, y_{0}\right)$, and size $s_{0}$. For a blob, $s_{0}=\frac{1}{2} r_{0}{ }^{2}$. In images, $x, y$ and $s$ have discrete values, and by interpolation the position $\left(x_{0}, y_{0}, s_{0}\right)$ of the local maximum is refined.

\subsection{Modeling tree crown in the scale direction}

\section{Gaussian blob models}

For a Gaussian blob the intensity profile is modeled as a Gaussian bell shaped surface function centered at $x_{0}$ and $y_{0}$. Taking these values equal to 0 we obtain

$G_{b}(x, y)=c+\frac{a}{2 \pi s_{0}} e^{-\left(x^{2}+y^{2}\right) / 2 s_{0}}$

where $a$ describes the contrast between the blob and background, and the parameter $c$ is the background assumed to be constant, i.e. independent from $x$ and $y$, and $s_{0}>0$ specifies the size of the Gaussian blob. A scale-space extension of (5) includes the scale parameter $s$

$L(x, y ; s)=c+\frac{a}{2 \pi\left(s_{0}+s\right)} e^{-\left(x^{2}+y^{2}\right) / 2\left(s_{0}+s\right)}$

Substituting (5.6) into (5.4) and setting $x=y=0$ and $h(s)=H(0,0 ; s)$, we obtain a response of a Gaussian blob in the scale direction

$h(s)=\left(\frac{a}{2 \pi}\right)^{2} \cdot \frac{s^{2}}{\left(s+s_{0}\right)^{4}}$ 
A major reason for considering the scale direction is that instead of the analysis of two dimensional signal $f(x, y)$ we analyze a one-dimensional signal $h(s)$ and the noise associated with the background and irregularities of the tree crown is limited to small values of $s$. Model (5.7) is monotonically increasing for $0 \leq$ $s<s_{0}$ and decreasing for $s>s_{0}$. Its maximum occurs at $s_{1}=s_{0}$ and equals

$h_{0}=h\left(s_{0}\right)=\left(\frac{a}{8 \pi s_{0}}\right)^{2}$.

A relatively simple model is the Gaussian blob model, where it is obtained from (5.7) as $f_{1}(s)=h(s)$. To account for the sub-pixel shift $\Delta \mathrm{r}=\sqrt{\Delta x^{2}+\Delta \mathrm{y}^{2}}$ between the Gaussian blob center and the discrete raster pixel location we define $f_{2}(s)$ as an adjustment to $f_{1}(s)$ as

$f_{2}(s)=\left(\frac{a}{2 \pi}\right)^{2} \cdot\left(\frac{s^{2}}{\left(s+s_{0}\right)^{2}} \cdot \frac{\left(s+s_{0}\right)-\Delta \mathrm{r}^{2}}{\left(s+s_{0}\right)^{3}} \cdot e^{\frac{-\Delta \mathrm{r}^{2}}{s+s_{0}}}\right)$.

The global maxima of model $f_{2}(s)$ with respect to $s$ is attained at $s_{1}=s_{0}$ and $s_{2}=s_{0}+\frac{\Delta \mathrm{r}^{2}}{2}$, assuming $\Delta r^{2} \ll t_{0}$.

\section{Models for real tree crown}

We observed in all our experiments that $f_{1}(s)$ and $f_{2}(s)$ are relatively crude approximations for real tree crowns especially for $s>s_{0}$ (see example in Figure 5.5). Therefore, we modified the real tree model $f_{1}(s)$ as $f_{3}(s)$ by including a parameter $\delta>0$

$f_{3}(s)=\left(\frac{a}{2 \pi}\right)^{2} \cdot\left(\frac{s}{\left(s+s_{0}\right)^{2}}\right)^{2 \delta}$.

This real tree model can again be shifted from the center by $\Delta \mathrm{r}$, yielding the model $f_{4}(s)$ as

$f_{4}(s)=\left(\frac{a}{2 \pi}\right)^{2} \cdot\left(\frac{s^{2}}{\left(s+t_{0}\right)^{2}} \cdot \frac{\left(s+s_{0}\right)-\Delta \mathrm{r}^{2}}{\left(s+s_{0}\right)^{3}} \cdot e^{\frac{-\Delta \mathrm{r}^{2}}{s+s_{0}}}\right)^{\delta}$.

Upon implementation, the parameter $\delta$ is to be estimated, where $\delta \neq 1$ distinguishes $f_{3}(s)$ and $f_{4}(s)$ from $f_{1}(s)$ and $f_{2}(s)$, respectively.

The global maxima of models $f_{3}(s)$ and $f_{4}(s)$ with respect to $s$ are attained at $s_{3}=s_{1}$ and $s_{4}=s_{2}$, respectively.

\section{Practical implementation}

Upon implementation, we first identify the location of the local maximum with respect to space and scale on the discrete grid for $x, y, s$ and refine it $x_{0}, y_{0}, s_{0}$ 
using polynomial second order interpolation. Next, we identify the range $\left[s_{\min }, s_{\max }\right]$ and $b_{\text {life }}=s_{\max }-s_{\min }$ corresponding to a single blob where $b_{\text {life }}$ is the lifetime. We do this by region growing into the direction $s$ such that $h(s)$ decreases if $\left|s-s_{0}\right|$ increases and $h(s)$ exceeds a small positive threshold value (Figure 5.4). At $s>s_{0}, h(s)$ may include a contribution from the surrounding trees, for example, when several trees are found in a cluster. This contribution may affect fitting the models $f_{k}(s)$. Therefore, we limit the value of $s_{\max }=2 s_{0}$. Fitting all models to the discrete observations $\left\{s_{i}, h_{i}\right\}$ in the range $\left[s_{\min }, s_{\max }\right]$ was done by numerically minimizing the sum of the squares cost function using LBFGS-B (Byrd et al., 1995), and the tree size $r_{k}$ from all four models is determined from $s_{k}=\frac{1}{2} r_{k}^{2}$.

The models (5.8-5.11) for $h$ are proportional to $a^{2}$ and therefore include dark objects $(a<0)$. We eliminate those by checking whether the scale-normalized Laplacian of the Gaussian scale-space

$\Delta L(x, y, s)=s\left(L_{x x}+L_{y y}\right)$

is at a minimum or at a maximum at $s_{0}$. This is achieved by checking the sign of the second derivative of the $\Delta L$ with respect to $s$.

The volume of a blob, $b_{\text {volume, }}$ is determined in the scale direction as

$b_{\text {volume }}=s_{\text {life }} \int_{s_{\min }}^{s_{\max }} h(s) d s$,

being the area between $s_{\min }$ and $s_{\max }$ below $h(s)$ (Figure 5.4). The blob volume is small for blobs with a low contrast with the background, whereas it is large for blobs with a high contrast. Relating blob volume to tree detection, we notice that a tree object has a larger scale-space volume and hence blob of a low volume can be discarded. In addition, the total relative error $\left(\varepsilon_{r}\right)$ for all models used to discriminate larger blobs consisting of several tree objects and it equals

$\varepsilon_{r}=\sqrt{\sum_{i=1}^{s_{\max }\left(\frac{f_{k}\left(s_{i}\right)-h\left(s_{i}\right)}{f\left(s_{0}\right)}\right)^{2}}}$

for $k=1, \ldots, 4$. 


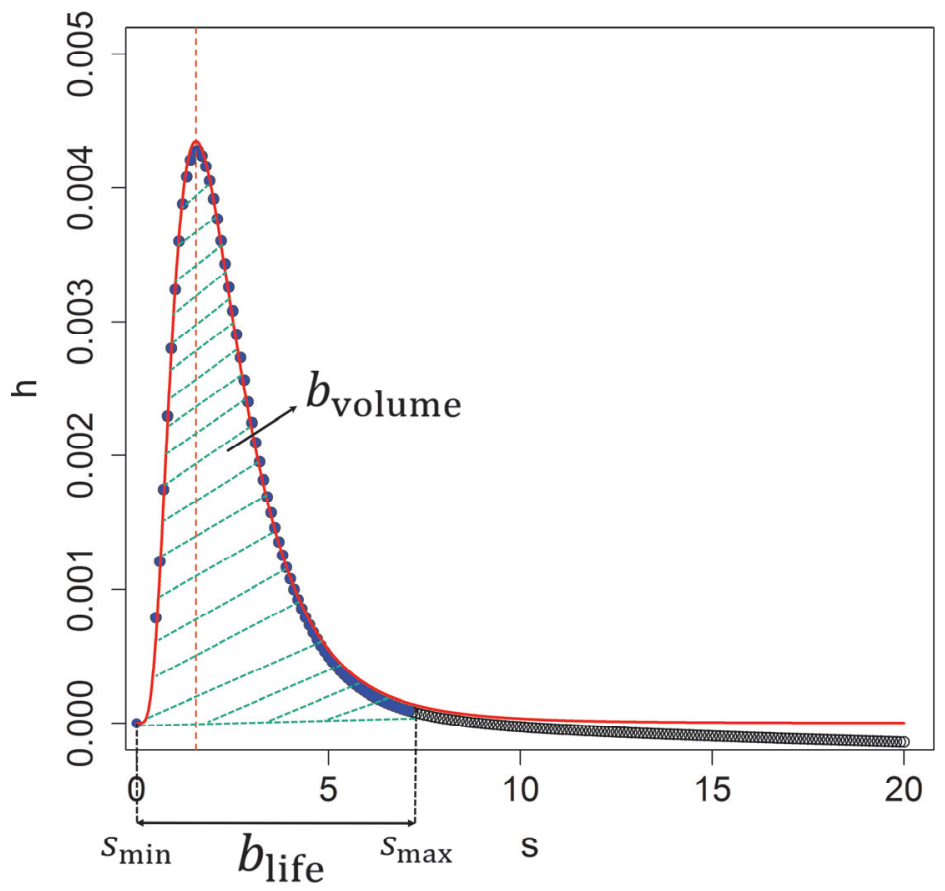

Figure 5.4: The blob volume $b_{\text {volume }}$ and the blob lifetime $b_{\text {life }}$. A blob volume is the area below the fitted model $f_{3}(s)$ at scale direction profiles $h(s)$. The vertical dashed line indicates the location of the maximum $t_{0}$ from model $f_{3}(s)$ (dashed line red color). Closed blue symbols show the range $\left[s_{\min }, s_{\max }\right]$.

\subsection{Uncertainty assessment}

Two uncertainty assessments were carried out to validate tree crown boundary detection, focusing on the presence and the spatial extent of individual trees.

We follow Mahour et al. (2016) to accept the number of correctly detected trees object when the center of each falls within the spatial extent of the reference data for further analysis. Clinton et al. (2010) proposed over- and underestimation error metrics when assessing the area of a detected object $A_{D_{i}}$ with respect to the area of reference object $A_{R_{i}}$, as

$\overline{\mathrm{A}}_{D_{i}}=1-\frac{\operatorname{area}\left(A_{D_{i}} \cap A_{R_{i}}\right)}{\operatorname{area}\left(A_{D_{i}}\right)}$

and

$A_{D_{i}}=1-\frac{\operatorname{area}\left(A_{D_{i}} \cap A_{R_{i}}\right)}{\operatorname{area}\left(A_{R_{i}}\right)}$ 
respectively, where $i$ refers to the number of an individual object. Both (5.15) and (5.16) result in values between 0 and 1 , and there is a good match between detected and reference tree crown boundaries $\left\{D_{i}, R_{i}\right\}$ if these are close to zero. Furthermore, the total detection error is

$\varepsilon_{D_{i}}=\sqrt{\frac{\left(\overline{\mathrm{A}}_{D_{i}}\right)^{2}+\left(A_{D_{i}}\right)^{2}}{2}}$

with $0 \leq \varepsilon_{D_{i}} \leq 1$. We consider three object accuracy indicators concerning the spatial extent of the tree objects: true positives (TP) where tree objects exist in the reference polygon layers, false positives (FP) that consider inappropriate detection where the trees are not present at the reference layer, and false negatives (FN) where there is a failure to detect objects in the reference layer (Schuenemeyer and Drew, 2010). The Euclidean distance $(E)$ evaluates the distance between the centroid of a detected tree object $P=\left(X_{p}, Y_{p}\right)$ and the centroid of a reference tree crown boundary $O=\left(X_{o}, Y_{o}\right)$ as a positional accuracy indicator

$E=\sqrt{\left(X_{o}-X_{p}\right)^{2}+\left(Y_{o}-Y_{p}\right)^{2}}$.

\subsection{Study area, data and tools}

\section{The walnut orchard}

The first study area is an orchard cultivated with walnut trees located in the Qazvin agricultural area in North-western Iran with geographical coordinates $36^{\circ} 06^{\prime} \mathrm{N}, 50^{\circ} 18^{\prime} \mathrm{E}$. The main reason to select this study site is the economic importance of the wood and nuts of the trees. The selected orchard contains trees of different crown shapes and sizes planted in rows. The study period is the middle of the growing season (July), when walnut tree crowns interlock with adjacent tree crowns.

A four bands (visible and near-infrared) multispectral images of WV-2 was taken on July 7, 2012 at a $2 \mathrm{~m}$ spatial resolution. An UltraCam digital image was collected on July 17,2012 by a high resolution multichannel RGBI sensor of a $0.5 \mathrm{~m}$ spatial resolution. The digital aerial image was delivered as an orthorectified image, corrected for lens distortion and camera tilt, and was coregistered to the panchromatic WV-2 image. The UltraCam image was used as a reference image for uncertainty assessment. For this validation, a polygon reference boundary layer was extracted manually from the UltraCam digital aerial photo using a visual interpretation. 


\section{Oil palm trees}

The second study area is an orchard with oil palm trees planted in the Kutai Timur Regency, Kalimantan Timur province in Indonesia, located at geographical coordinates $00^{\circ} 58^{\prime} \mathrm{N}, 118^{\circ} 03^{\prime} 0 \mathrm{E}$. The oil palm trees are planted mainly with little differences in crown size and shape following a hexagonal pattern. The oil palm trees are commercially predominant in the food industry because of their fruit nutrition and oil production.

A panchromatic image and a four bands multispectral GeoEye images with visible and infrared bands were acquired on May 25, 2010 at a $0.5 \mathrm{~m}$ and a 2.0 $\mathrm{m}$ spatial resolution, respectively. The images were co-registered and projected in Universal Transfer Mercator (UTM) coordinates, with the standard spheroidal reference surface WGS84 and were geometrically corrected. The panchromatic GeoEye image was used as a reference image for validation. For this purpose, a polygon reference boundary layer was extracted manually representing the oil palm trees.

\section{Vitellaria trees}

The third study area contains vitellaria trees located at $12^{\circ} 09^{\prime} \mathrm{N}, 05^{\circ} 12^{\prime} 0 \mathrm{~W}$ in Mali, commonly known as shea trees. This type of trees is found throughout Africa and their economic value is their oil rich seeds from which shea butter is extracted. In fact, the trees produce shea nuts for up to 200 years.

Multispectral and a panchromatic images of WV-2 were taken on September 9, 2015 having spatial resolution of $2 \mathrm{~m}$ and $0.5 \mathrm{~m}$, respectively. The images were preprocessed using a workflow described in Stratoulias et al. (2017). A polygon reference layer representing the vitellaria trees was manually extracted from the panchromatic WV-2 image.

\section{Tools}

In this research, we used the R software (2017) with the Rcpp package (Eddelbuettel and François, 2011) for the Gaussian scale-space blob detection and tree crown modeling. Ggplot2 (Wickham, 2009) was used for visualization and data analysis.

\subsection{Results}

\section{Tree detection using discrete Gaussian scale-space}

Figure 5.5 shows the four applied models on the walnut trees detecting a tree objects. From Figure 5.5 we observe that $f_{3}(s)$ and $f_{4}(s)$ provide a better fit to the data than $f_{1}(s)$ and $f_{2}(s)$. Next, we observe that the difference between $f_{3}$ $(r=0.653)$ and $f_{4}(s)(r=0.654)$ is negligible in terms of $s_{0}$ parameter related to tree size as compared to reference data. Moreover, the local maxima $\left(s_{0}\right)$ of $f_{1}(s)(r=0.578)$ and $f_{2}(s)(r=0.579)$ are different from those of $f_{3}(s)$ and $f_{4}(s)$. For accurate estimation of $s_{0}$ one needs either large number of points at scale 
levels $s_{i}$ for local interpolation which is increasing computational time or an accurate model, here $f_{4}(s)$.

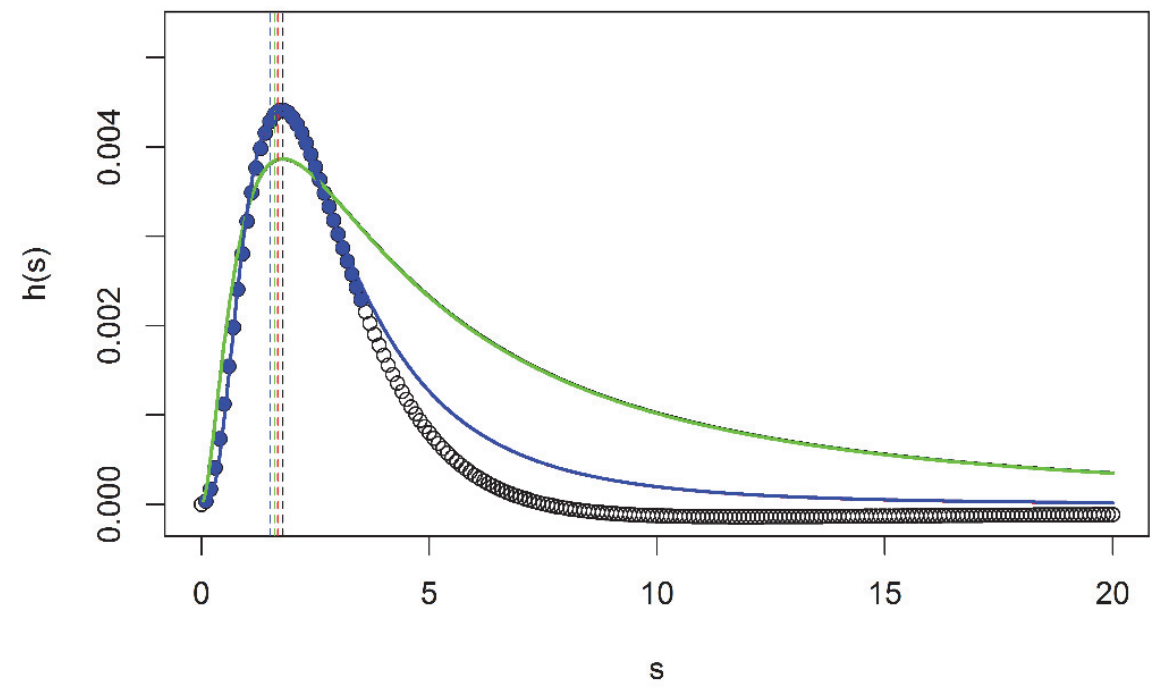

Figure 5.5: Scale direction profile $h(s)$ for a real tree. Green, black, blue and red lines represent models $f_{1}(s), f_{2}(s), f_{3}(s)$ and $f_{4}(s)$, respectively. The red and black curve are invisible because their values are nearly identical to the blue and green curves, respectively. Green, black, blue and red vertical dashed lines indicate the location of the $s_{k}$ for all four models, whereas closed symbols show the obtained range $\left[s_{\min }, s_{\max }\right]$.

Table 5.1 gives the results from applying the discrete Gaussian scale-space using $f_{3}(s)$. It resulted in the detection of 391 individual trees out of 434 reference objects for the walnut orchard (90\%), 252 individual trees out of 306 reference tree objects for oil palm trees (82\%) and 238 trees out of 251 reference tree objects (94\%) for vitellaria trees. FP error rates of $8.4 \%, 3.9 \%$, and $5.0 \%$, and $\mathrm{FN}$ error rates of $7.1 \%, 6.8 \%$ and $5.1 \%$ occur for walnut orchard, oil palm and vitellaria trees, respectively. In fact, FN is lower for vitellaria trees because of the lower contrast between the trees and their background, whereas FP is lower for palm trees because of the low degree of adjacent tree crowns interlock.

Table 5.1: Detected tree objects based on the discrete scale-space and using the $f_{3}(s)$ model.

\begin{tabular}{ccccc}
\hline Tree types & Reference & TP & FP & FN \\
\hline Walnut & 434 & $391(90.09 \%)$ & $33(8.43 \%)$ & $31(7.14 \%)$ \\
Oil palm & 306 & $252(82.35 \%)$ & $10(3.96 \%)$ & $21(6.86 \%)$ \\
Vitellaria & 251 & $238(94.82 \%)$ & $12(5.04 \%)$ & $13(5.17 \%)$ \\
\hline
\end{tabular}


Figures 5.6, 5.7 and 5.8 illustrate the modeling of $f_{3}(s)$ for the different tree types, including a map of TP, FP, and FN. We observe that most trees have a different size parameter, ranging from $3.4 \mathrm{~m}$ to $16.4 \mathrm{~m}$ for walnut, and from $1.5 \mathrm{~m}$ to $19 \mathrm{~m}$ for vitellaria. Oil palm trees have similar range parameters, between $1.5 \mathrm{~m}$ and $3 \mathrm{~m}$. The high FP values for walnut $(8.4 \%)$ is due to the regular tree pattern (Figures 6 and 7). FNs for walnut and oil palm trees occur if adjacent tree crowns interlock, whereas for vitellaria trees they occur where the position of a detected blob centroid is outside the reference tree crown boundary.

Table 5.2: Positional inaccuracy, overestimation and underestimation metrics based upon the modified tree size measurement at $s_{0}$ using the $f_{3}(s)$ model.

\begin{tabular}{ccccc}
\hline Tree types & $\begin{array}{c}\text { Positional } \\
{[\mathrm{m}]}\end{array}$ & $\begin{array}{c}\overline{\mathrm{A}}_{D_{i}} \\
{[\mathrm{~m}]}\end{array}$ & $\begin{array}{c}\mathrm{A}_{D_{i}} \\
{[\mathrm{~m}]}\end{array}$ & $\begin{array}{c}\varepsilon_{D_{i}} \\
{[\mathrm{~m}]}\end{array}$ \\
\hline Walnut & 0.91 & 0.32 & 0.13 & 0.27 \\
Oil palm & 1.50 & 0.42 & 0.33 & 0.57 \\
Vitellaria & 1.19 & 0.31 & 0.06 & 0.33 \\
\hline
\end{tabular}

Table 5.2 presents the positional inaccuracy of the different trees. For oil palm trees it is higher than for vitellaria trees, whereas for walnut trees the value of $0.91 \mathrm{~m}$ is slightly lower than that for vitellaria and oil palm trees. The reason is the different sun elevation angle during capturing of the VHR satellite images, resulting in small shadows, which made identification of tree crown boundaries more difficult. Moreover, the aggregated $\bar{A}_{D_{i}}$ and $A_{D_{i}}$ values for oil palm trees $(0.42$ and 0.33$)$ are higher than those for walnut and vitellaria trees. The total detection error $\left(\varepsilon_{D_{i}}\right)$ is lower for both walnut $(0.27)$ and vitellaria (0.33) trees than for oil palms, because of their larger tree size and because they are located in an area with a clear contrast between background and trees. 

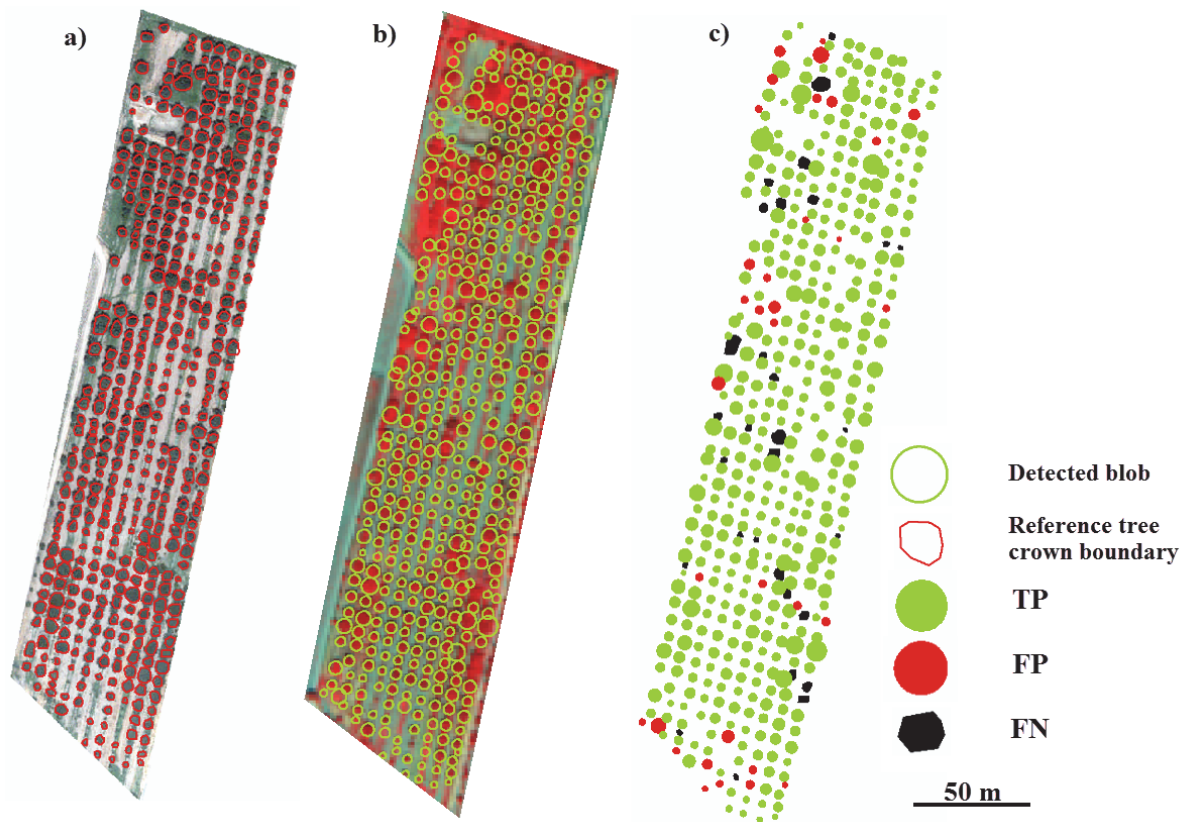

Figure 5.6: Results of the discrete Gaussian scale-space with modified tree size measurement using model $f_{3}(s)$; a) reference data from an UltraCam image b) walnut orchard with detected blobs and c) the error map. 

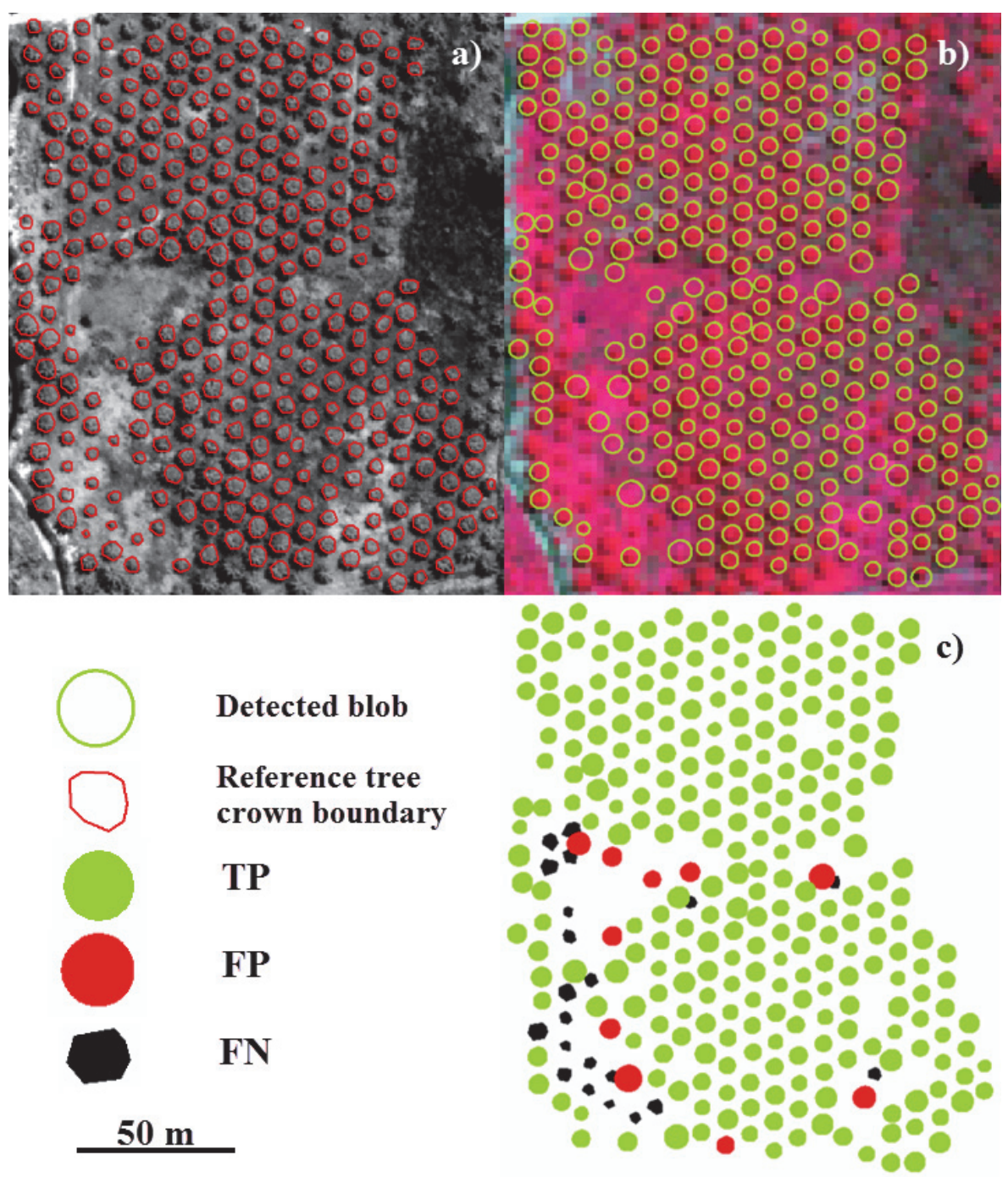

Figure 5.7: Results of the discrete Gaussian scale-space with modified tree size measurement using model $f_{3}(s)$; a) reference data from a panchromatic image, b) the oil palm orchard with detected blobs and c) the error map. 

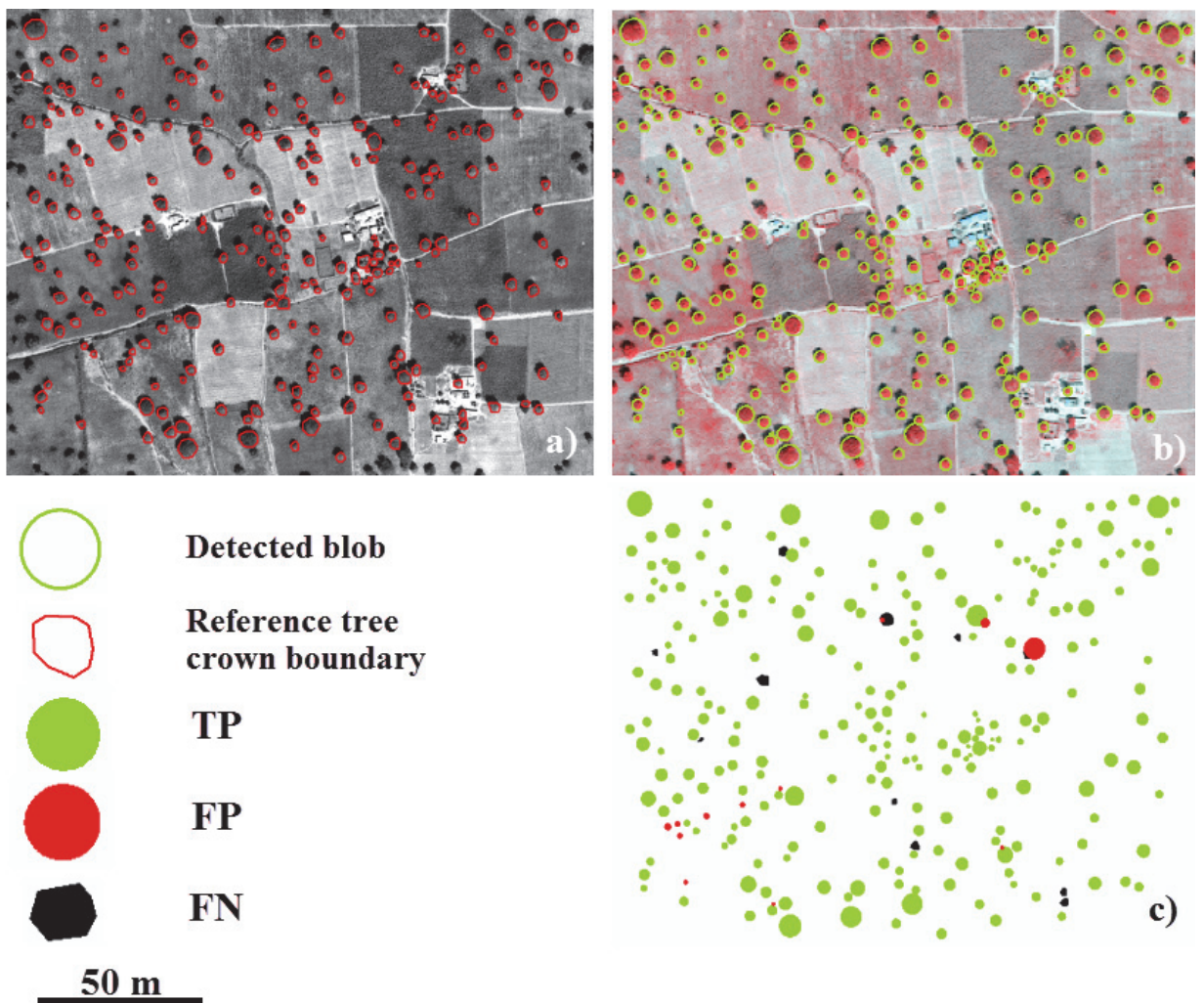

Figure 5.8: Results of the discrete Gaussian scale-space with modified tree size measurement using model $f_{3}(s)$; a) reference data from a panchromatic image, b) vitellaria trees with detected blobs and c) the error map. Original image data is (C) COPYRIGHT 2014 DigitalGlobe, Inc., Longmont CO USA 80503.

\section{Comparison between the sampled Gaussian kernel and the discrete Gaussian kernel}

Figures 5.9, 5.10 and 5.11 compare the two dimensional sampled Gaussian kernel $g_{u}$ and the two dimensional discrete Gaussian kernel $g_{v}$ for walnut, oil palm, and vitellaria trees, respectively. Figure 5.9 shows that the scale-space with $g_{v}$ is capable of detecting 55 very small trees with a tree diameter lower than pixel size as compared to the average size of walnut trees on the bottom and top rows of the orchard. The kernel $g_{u}$ performs better for the area where adjacent trees interlock. Figure 5.10 shows that for oil palm trees $g_{v}$ can detect 60 small trees more than $g_{v}$ in the hexagonal pattern, whereas $g_{u}$ performs better for detecting larger trees. For vitellaria trees Figure 5.11 shows that, $g_{v}$ detects 12 small trees, whereas $g_{u}$ is able to delineate trees with crown sizes that are larger than the pixel size. However, $g_{v}$ better approximates the local maxima at (5.4) when obtaining the derivatives at finer scales for small trees. 


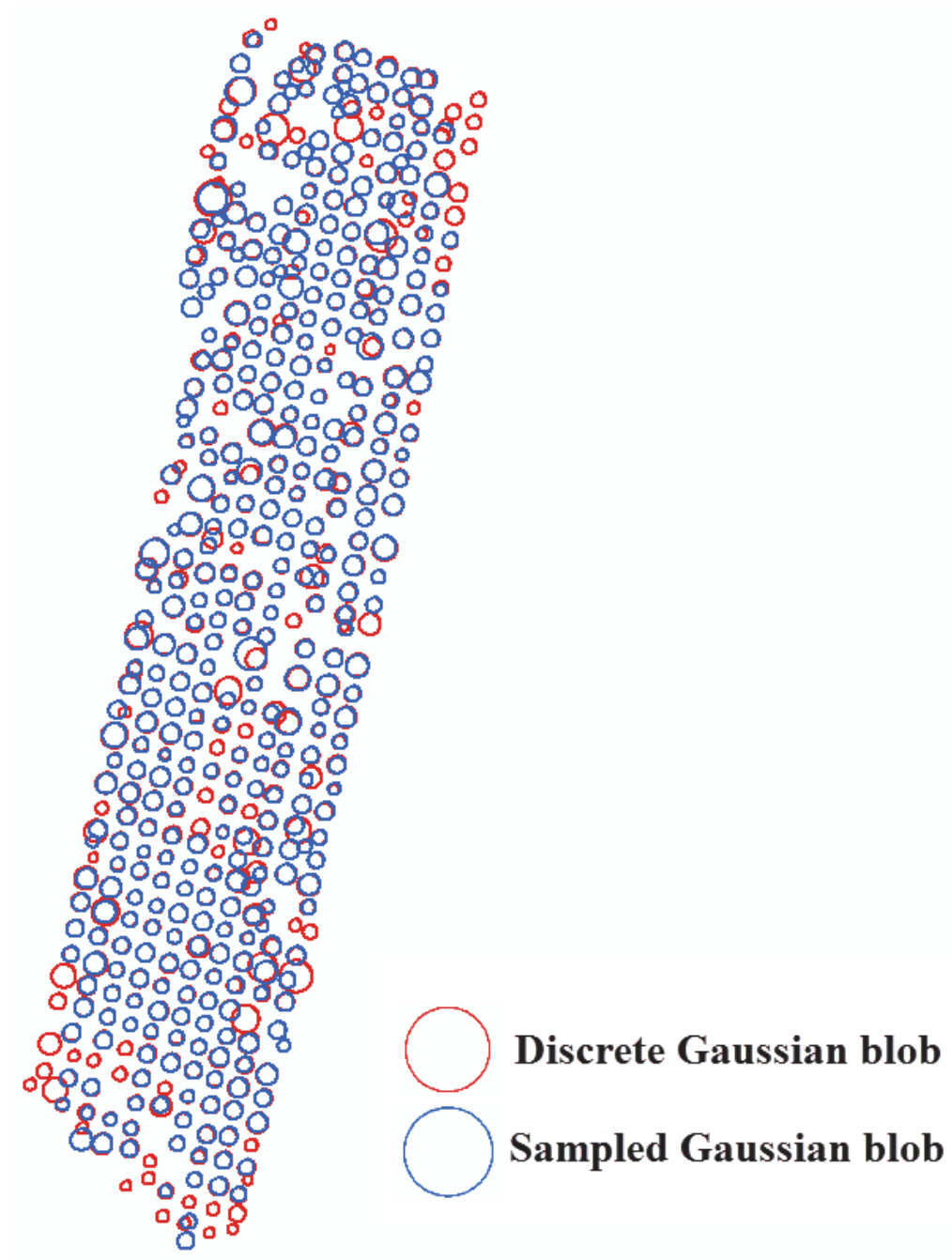

Figure 5.9: Differences between sampled and discrete Gaussian scale-space blob detection for the walnut orchard. 


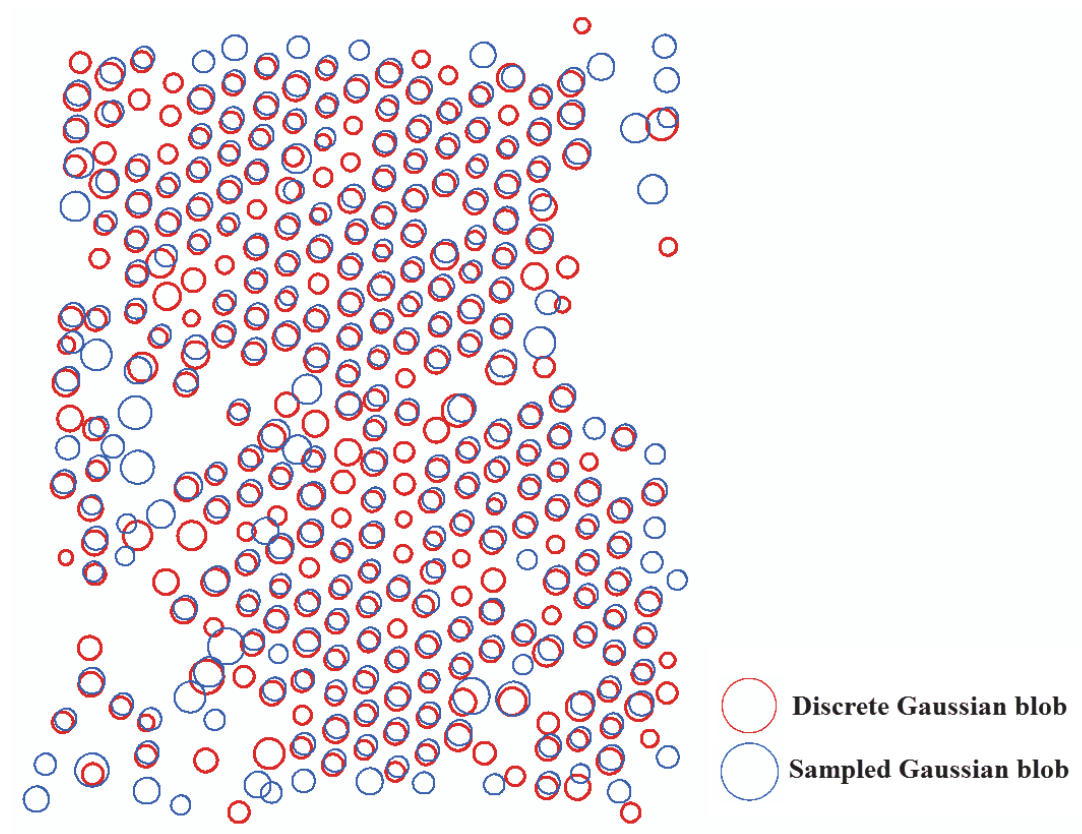

Figure 5.10: Differences between sampled and discrete Gaussian scale-space blob detection for the oil palm orchard.

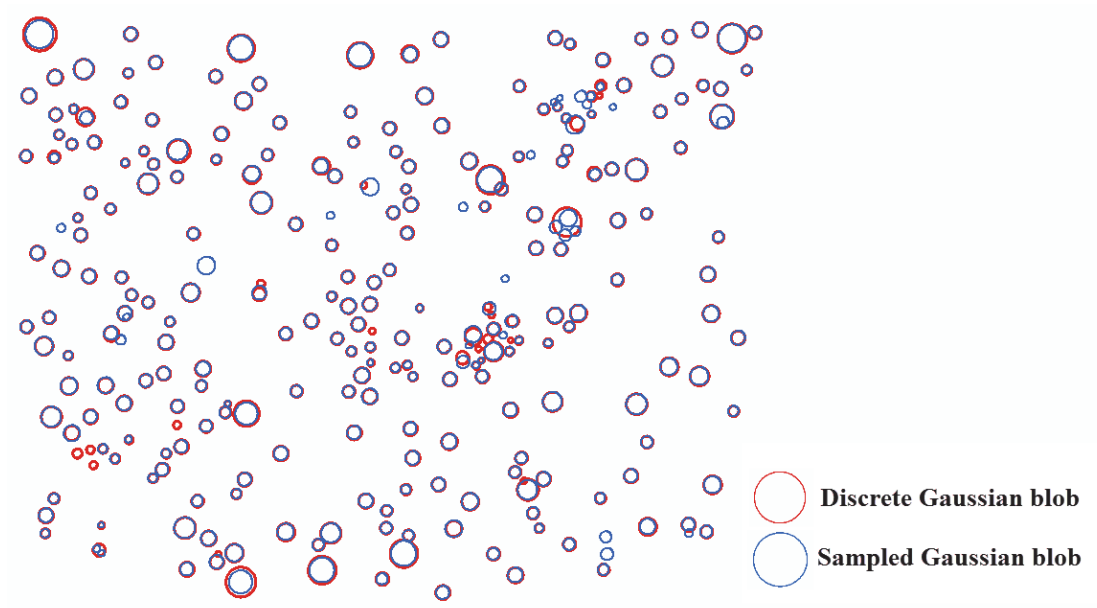

Figure 5.11: Differences between sampled and discrete Gaussian scale-space blob detection for vitellaria trees.

\section{The parameter $\delta$ for different tree types}

Figure 5.12 illustrates the density distributions of the parameter $\delta$ for different tree types, and for tree crown objects detected using $f_{3}(s)$ with the discrete Gaussian scale-space. For all tree types, we observe one mode that is substantially larger than 1 . For vitellaria, the average of parameter $\delta$ is lower than for trees in the two types of orchards, whereas close values for $\delta$ are 
obtained for oil palm trees and for walnut trees. The explanation most likely is that could be due to internal or external causes: tree species or arrangement of trees in space.
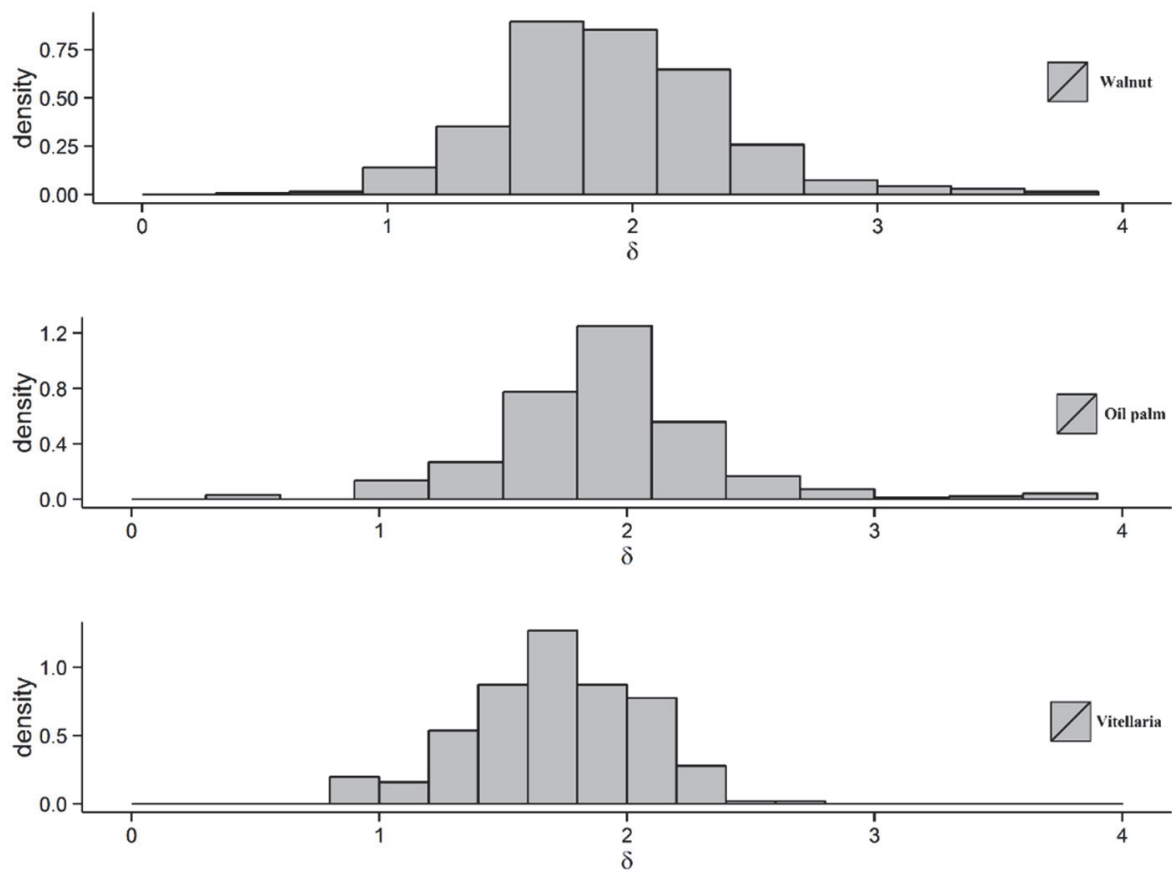

Figure 5.12: Distributions of parameter $\delta$ for different trees types obtained with model $f_{3}(s)$.

\subsection{Discussion}

In this study, the intensity profile of a tree in the scale-space domain was characterized in an NDVI image by a bell shaped surface as Gaussian blobs. The Gaussian blob models $f_{1}(s)$ and $f_{2}(s)$ inadequately described the trees, and their use caused overestimation and inaccurate tree size parameter estimation. The empirical models introduced in this paper $f_{3}(s)$ and $f_{4}(s)$ provided a better description of the trees and more accurately estimated the tree size parameter $s_{0}$. Indeed, models $f_{3}(s)$ and $f_{4}(s)$ adequately detected individual trees at the different scale levels (see Figure 5.5). All four models are asymmetric and in this sense their use extends local maximum interpolation as in Mahour et al., (2016). Moreover, model $f_{3}(s)$ reduced the positional uncertainty of walnut trees from $103 \mathrm{~cm}$ in Mahour et al., (2016) to $91 \mathrm{~cm}$ in this study.

Models $f_{3}(s)$ and $f_{4}(s)$ provide a better fit to the data (5.4) in the scale direction than models $f_{1}(s)$ and $f_{2}(s)$ because of the different $\delta$ values for individual trees. Differences between models $f_{3}(s)$ and $f_{4}(s)$ were negligible in this study, whereas the parameter $\Delta r$ in $f_{4}(s)$ was affected by the resolution of the satellite 
image. For estimating trees under similar conditions as in this study, model $f_{3}(s)$ is to be preferred, as it is sparser and requires less input for estimating the tree crown parameters. In fact, model $f_{4}(s)$ more accurately estimates tree sizes as compared to model $f_{3}(s)$ with differences from $3 \mathrm{~cm}$ to $5 \mathrm{~cm}$. This difference can be larger if coarse resolution pixels or smaller trees are considered.

Walnut and vitellaria trees both had a large variation in tree size. Figures 5.9 and 5.11 show that the sampled Gaussian scale-space cannot detect trees with a slightly lower diameter than the pixel size of the image. The reason is that the local maxima of the blobs occur at finer scale levels than the image resolution. In contrast, the discrete Gaussian scale-space overcomes this problem and is able to also detect small trees at the finer scale level. The sampled Gaussian scale-space, however, better delineates a large tree at coarser scale levels if adjacent trees interlock (Figure 5.9 and 5.10).

The scale-space representation (5.1) is the convolution between the discrete original image $f$ and the Gaussian kernel $\left(g_{u}\right.$ or $\left.g_{v}\right)$. For both Gaussian kernels, the convolution is associative: by taking the derivative of the sampled Gaussian kernel we can either convolve it with the original image $L_{x}=\partial_{x} L=\left(\partial_{x} g\right) * f$ or reconstruct a sampled image $f$, and then obtain the derivative $L_{x}=\partial_{x} L=$ $\partial_{x}(g * f)$. As the derivative of the sampled Gaussian $\frac{\partial \mathrm{g}_{\mathrm{u}}}{\partial_{\mathrm{x}}} \rightarrow \infty$ if $s \rightarrow 0$. As a result, the derivatives in the scale-space cannot be correctly computed for fine scales, corresponding to the smallest trees. Therefore, for small values of $s$ we used $g_{v}$ in (5.1) to effectively obtain and detect small trees.

We also compared the results of the presented scale-space methods with methods for tree detection in other studies. Brandberg and Walter (1998) applied the multiple-scale algorithm to identify tree crown edge contours from local maxima on aerial imagery of a $10 \mathrm{~cm}$ spatial resolution. For evaluation, they visually interpreted the mean area overlap between delineated and reference tree crown, resulting in an overall detection rate of $54 \%$. Skuikhin et al. (2013) identified tree crown centers in a forest area on the two multispectral pan-sharpened VHR satellite imageries of a $60 \mathrm{~cm}$ spatial resolution. Using the estimated local maxima of the Laplacian in the Gaussian scale-space on the classified RS imageries, they obtained detection rates of $93 \%$ and $86 \%$ for the first and the second images, respectively.

Recio et al. (2013) performed a plot-based method on the citrus orchard without tree crown interlock using aerial imagery of a $50 \mathrm{~cm}$ spatial resolution. They combined image filtering with a weighted average filter and an unsupervised image classification followed by individualization of a tree using iterative local maximum filtering. They achieved an overall $90 \%$ detection rate, 
and a $40 \mathrm{~cm}$ positional error for individual trees. Jiang et al. (2017) used scalespace filtering on a papaya and a lemon orchard with isolated individual trees from images obtained by unmanned aerial vehicles (UAV). Applying the Laplacian of the Gaussian function resulted in a $95 \%$ detection rate for trees. FP $(6 \%)$ and FN (5\%) errors were due to multiple detections of a single tree, and even detection of a dead tree.

All these studies were done on individual trees and delineation was done for different forest types and various tree species. Also, different sensors and RS images have been used with varying spatial and spectral resolution, making it difficult to compare the method. Our method is able to automatically detect individual tree crowns at a slightly higher detection rate. In addition, the refined model $f_{3}(s)$ in the scale direction provides an accurate estimation of tree parameters for three economically important tree species.

A final issue we like to address concerns the precise boundary of the tree crown, which is undefined and its estimation is unstable. We note that tree crowns have fragmented boundaries, and that stability of its estimate, and hence of the size of a tree and its position, depends upon the wind speed, canopy density and noise in the background. To estimate tree size, our method reports the scale parameter, $s_{0}$, assuming a circular shape gives the crown radius of an individual tree. Trees, however, may have an ellipsoidal or a truncated cone crown shape, or even have an asymmetric crown in other environments, such as in natural forests, where tree species and management practices, such as pruning, differ from those considered in this study. Therefore, other types of tree shapes should be considered in future modeling of tree crowns in scale-space.

This research considered two orchards and an area with isolated tree crowns of different shapes, sizes and species. The scale of management is important in precision agriculture, as modern management of nutrient and water supply focuses on treatment of individual trees. An improved detection of individual trees and delineation of their crowns as shown in this study may likely improve irrigation management, which depends upon the type and crown size of a tree, being in most cases a function of the tree cover fraction (Allen et al., 1998).

\subsection{Conclusions}

In this research, we improved the Gaussian scale-space modeling for detecting and delineating individual trees from VHR images on three tree types at different continents. We did so by refining a Gaussian blob model in the scale direction and proposing the discrete Gaussian scale-space. In doing so, we were able to more accurately determine the tree size and discriminate between real tree objects and false detections. The main finding in this study was that 
our proposed model provides a better description of real tree crowns in scalespace than the Gaussian blob model. Our method reduced the number of false negatives, whereas the discrete Gaussian scale-space model resulted in the detection of small trees. In this way, our work improved upon the automatic detection and delineation of trees with varying tree crown sizes that more accurate than the existing models. 
Chapter 6 Synthesis 


\subsection{Research findings and conclusions}

This chapter provides the conclusions to the research objectives and summarizes the aims of the research objectives. It also provides a reflection and contributions to precision orchard management and its potential to other applications such as optimal water allocation at different scale levels, and monitoring tree health. At the end, it presents suggestions and recommendations for future directions of the research.

Objective 1: To generate high resolution daily AET maps and consider uncertainties of downscaling in both data and methods.

Downscaling cokriging was applied with two different procedures in order to increase the spatial resolution of mapping Actual Evapotranspiration (AET). First, downscaling cokriging was applied to a $1000 \mathrm{~m}$ resolution Land Surface Temperature (LST) MODIS product. With its outcome, I obtained a $250 \mathrm{~m}$ resolution daily AET map using the SEBS model. Second, a $1000 \mathrm{~m}$ resolution daily AET map at was downscaled towards a $250 \mathrm{~m}$ resolution using downscaling cokriging. For both procedures, MODIS NDVI of $250 \mathrm{~m}$ resolution played an important role as a co-variable to increase the spatial resolution of both LST and AET. In downscaling cokriging, the key is to find the relationship between co-variables in order to obtain the downscaled image at a finer spatial resolution. The results showed that the two AET maps were similar to each other, whereas AET presented a higher spatial variability if downscaled with LST. In addition, geometrical anisotropy was observed in the range and zonal anisotropy was observed in the sill for different geographical directions of the variograms. This resulted into a complex model for downscaling cokriging. The directional variograms showed that the anisotropy was caused by the different directions of the lateral canals in the agricultural irrigation network. Furthermore, the results were evaluated using Landsat 8 images, where LST and AET were obtained from the thermal bands and Surface Energy Balance System (SEBS), respectively. Both downscaled LST and AET were in a good agreement with the reference data from Landsat 8 images.

The study concluded that downscaling cokriging was successfully applied on MODIS products, and provided a relatively smooth fine resolution LST map that was influenced by the NDVI. The procedure can be applied on other MODIS products where a strong relationship exists between the predictive variable and a co-variable. Moreover, LST has a large effect on producing AET maps from RS imageries, and that downscaling cokriging is helpful to provide daily AET maps at medium spatial resolution. 
Objective 2: To disaggregate from the field scale to the rows and individual trees for AET estimation integrating SRM and image fusion.

In this objective, I investigated to which degree the available RS images can be of help in precision orchard management at different scale levels of detail. The aim was to obtain high resolution information on the basis of the rows and individual trees at a vineyard from a coarse spatial resolution image of AET map, and integrate it with the results of the SRM. In order to achieve this, Super Resolution Mapping (SRM) was applied to a high resolution satellite image with the aim to detect the rows of trees and individual trees in a vineyard. In addition, the SEBS model was applied to Landsat images in order to obtain a $30 \mathrm{~m}$ resolution AET map. Image fusion was carried out to integrate the results of the SRM and AET map at the field scale, for separate rows and for individual trees. In addition, I assessed the results of SRM using an UltraCam aerial photo as reference data at the different level of scales i.e. fields, rows and individual trees. The high resolution AET map was validated by means of the FAO Penman-Monteith to overcome the lack of in-situ data.

The study concluded that SRM can provide the positional information and the extent of the canopy crown in rows. The obtained information for individual trees, however, indicated a higher uncertainty, where uncertainty is defined as position and the extent of plants in rows and individual trees. The AET values obtained by the SEBS model showed a good agreement as compared to ET values derived by the standard FAO methods.

Objective 3: To investigate the application of scale-space methods for individual tree detection from VHR remote sensing imageries.

In this objective, Gaussian scale-space modeling was carried out to address the detection of individual trees from VHR satellite images. The aim was to investigate how individual trees could automatically be detected on two complex orchards with different tree types (peach and walnut), sizes, texture and spatial variation. The peach orchard contained a regular pattern in both tree texture and tree sizes, whereas the walnut orchard showed higher spatial variability in terms of tree sizes and the lower contrast between trees and the background covered with grass. Larger tree crowns in the walnut orchard were observed because of stronger shadow effects. Those were caused in turn by differences in position of the sun and the satellite sensor. To avoid the shadow effects and also to accurately estimate the extent of the tree crown, I used the NDVI image from the walnut orchard and applied scale-space blob detection. For the peach orchard, this was performed on the panchromatic image. Scalespace blob detection focused on the local maxima from the tree object in the scale-space domain, where the space referred to the geographical coordinates of the tree and the scale is related to the tree size. The different scale levels in the Gaussian scale-space plays a predominant role for detecting individual trees in particular if the orchard consists of trees with slightly different sizes. 
Scale-space blob detection identified the brightest peak as an extreme in the scale-space domain with respect to the bell shaped spectral profile of a tree in an image.

The detected tree crown objects were assessed and their boundaries with the use of polygon reference boundary from the UltraCam digital aerial image. Two uncertainty assessment carried out on the presence and the spatial extents of the detected individual trees. Results from the two orchards were in a good agreement compared with the reference data.

The study concluded that the Gaussian scale-space can be used to detect and delineate the individual trees from VHR satellite images leading to improve the monitoring crop health for the precision orchard managements.

Objective 4: To improve automatic detection of individual tree crowns from VHR satellite images by refining a Gaussian blob model in the Gaussian scale-space.

A tree crown model in Gaussian scale-space was improved to address the fourth objective. This was done by modifying the Gaussian blob model in the scale direction using a discrete Gaussian scale-space. A two-step procedure related the identified blob to the tree object in the field. I modified the traditional Gaussian tree crown model by introducing two new models in the scale direction that determined accurately tree size measurement. Those were evaluated on two orchards in Iran and Indonesia, and one area in Mali with isolated tree crowns of different shapes, tree sizes and species.

Results of tree detection and delineation were evaluated with reference data. This resulted in an uncertainty assessment of the tree crown boundary and position estimation focusing on the spatial extent and the presence of the tree crowns. The refined tree detection procedure resulted in reducing the false negatives detections combined with providing a better description of the tree crowns in the scale-space than the Gaussian blob model.

The study concluded that the modified Gaussian tree crown modeling procedure with the use of the discrete Gaussian scale-space improved the tree size measurements with respect to the tree crown extents and tree positions being able to detect very small trees. The main finding was the refined model yielded adequate description of the real tree crowns in the scale-space than the Gaussian blob model. Moreover, my method improved upon the automatic detection and delineation of trees with varying tree crown sizes for at least three representative cases. 


\subsection{Precision tree management from different methods}

Precision orchard management aims at providing management strategies at different levels of scale to adopt a management policy supporting farmers and decision makers. The scale of management is important, as it assists in deciding upon the best treatment level for individual trees. This concerns tree nutrient management, water supply, treatment of trees that are under stress, harvesting and even planting trees. The key issue is how the products obtained with this research and reported in this thesis can be useful with respect to the different level of scales. The scale level is defined from an orchard to row of trees, through individual trees towards leaves. For instance, aspects of an individual tree can influence a group of trees or even an orchard in management issues. The main issue is to know how precision tree management affects precision orchard management and in the end provides the optimal management strategy. To assist in this development, high quality observations in space, time and spectral information are essential.

This research investigated how to improve tree detection in orchards and beyond using different methods at different level of scales. The proposed methods improved the quality of tree detection from the traditional to modern methods. In this way, different methods were explored, ranging from MRF as a contextual classification method to Gaussian scale-space methods bridging the gap between the complex tree object pattern, detailed geographical coordinates, and the size of individual trees at different scale levels.

In this thesis, four methods are identified that are important for image processing and image classification. Moreover, it is vital to understand what the impact of each method from the Remote Sensing perspective is on precision orchard management.

- SRM is able to partition pixels into smaller sub-pixels with the use of Markov Random Fields (MRF) as a contextual classification in order to assign the class label from coarser pixel to finer pixels. It also considers the spatial dependency of the surrounding pixels based on the spatial distance to assign the class labels with higher probability to the sub-pixels. In this way, the finer sub-pixels maps can be integrated with multiple sources like ET maps yielding a new product for the precision orchard managements.

- Downscaling cokriging changes the footprint support which for remote sensing images is equal to the pixel size from a coarse to a fine spatial resolution. In this way, pixel support turns to point support with (in principle) an infinite numbers of points inside the pixel support. Hence, points within the pixel support can be aggregated to any positive spatial resolution. In addition, point support variograms and cross-variograms can 
be helpful to model and predict spatial variation of the coarser pixel to finer pixels. Therefore, downscaling cokriging can provide applications including other satellite image products where a strong relationship exists between co-variable and the variable to be predicted.

- Gaussian scale-space methods search for extrema in the scale-space crown over the specific range of scales. Such extremum is related to the size of the tree object and the detailed geographical position of the tree. These methods provide a framework to produce meaningful and accurate tree detection from VHR satellite images. The key issue is that this method is able to work over complex orchards with different tree sizes, species and thus showing a large spatial variation. In fact, the methods are straightforward in modelling tree crowns and can be applied as well to other VHR images from different platforms like UAVs.

- The refined model for tree crown response in the scale direction of the scale-space domain is presented as the fourth method. It showed that it improved the real tree crown detection regarding the tree size measurement and reduced the number of the false negatives compared to the traditional Gaussian blob model.

For the proposed methods I can also identify several limitations:

SRM based on MRF can be applied on categorical data. It is also able to define the extent and positional information of the tree in rows, but information for individual trees has a higher uncertainty where the tree boundaries meets the background to be distinguished from the tree crown boundary. Moreover, SRM cannot be applied on images displaying continuous data like LST or AET maps.

- Downscaling cokriging requires a strong relationship between the predictive variable and a co-variable. Moreover, the variogram and crossvariogram are based upon different geographic directions; if anisotropy is observed from both variogram and co-variogram, then cokriging becomes more complicated and it will require complicated procedures to account for anisotropies.

- Traditional Gaussian scale-space modelling depends upon the scale parameter selection. Such modelling detects tree crown objects with respect to the traditional Gaussian blob model. The sampled Gaussian blob model describes the spectral profile of the tree crown in a rather imprecise way and it failed to detect the small tree crowns where the size of the tree is smaller than the original pixel size.

- Any tree crown has a fragmented boundary. This causes instability in tree crown extent estimation. Also, a tree crown boundary depends upon canopy density, background noise and wind speed. To delineate the extent of the tree crown boundary, the method proposed in this thesis with the refined model of tree crown estimation relates the estimated scale 
parameter to the crown radius of the individual tree assuming a circular shape. For trees with different shapes such as a truncated cones or an ellipsoidal shape this may be overly simplistic. Moreover, other environments, such as natural forests, may have trees of different species and more complex shapes and this will prohibit to apply a uniform assessment procedure.

\subsection{Reflections}

We can observe trees on the ground with the use of remote sensing images at different levels of scale. The question is how and to what extent we are capable of using derived information from space. Different aspects from a variety of different trees are objects of interest to be measured and estimated. There is a gap between remote sensing and ground truth because of indirectly measuring with remotely sensed images. Therefore, it is important to know how to best interpret remote sensing products that can estimate as close as possible to the desired aspects of reality.

There are several types of remote sensing products, mainly raster images, that can be useful for modeling trees in an orchard. In this way, captured images are capable of recording objects of interests at the specific time and location. In particular in orchards the objects are changing fast in terms of time and location. For instance, a tree crown with its attributes observed from space can be changed rapidly because of the wind. The latest developments in remote sensing technologies like capturing video from space may provide better opportunities to observe those changes.

Scale is of interest for precision orchard management. In traditional management, the smallest scale was the field, whereas modern management is able to consider individual trees and even individual leaves. In fact, scale is a key issue in remote sensing images as there are plenty of images from different sensors that capture the real world at different levels of scale. For example, a row of trees may observable from a coarse resolution image but it may still be impossible to observe individual trees at the same resolution. In contrast, very high resolution images provide more geometrical and spectral details of an individual tree. This scale level, however, is insufficient because of the lack of limited spectral information to provide biophysical properties.

Methods used in this research aim to reduce the gap between the complex objects on the ground and their geographical information. For this reason, there is a possibility to link these techniques to management purposes for precision agriculture. In precision orchard management, a tree or group of trees may observable for the farmer on the ground. It can be monitored if that tree suffers from a water shortage, whereas other groups of trees maybe be 
located far from the farmer's daily inspection round and even may be difficult to be accessed. For remote sensing techniques, in particular, scale-space methods can provide meaningful information to farmers and decision makers to improve upon their management purposes. In fact, with outcomes of this research, we can rely on what was measured with remotely sensed imageries in order to automatically detect individual trees with precise spatial extent and geographical location. That may help and change future precision orchard management.

\subsection{Future work}

Precision orchard management from an ecological perspective depends upon understanding the biophysical properties and the biological information of the trees with respect to the tree species, tree sizes and the tree density. The scale of modern management aims at providing adopted policies in precision orchard management focusing on individual trees or leaves, where the knowledge of tree crown parameters such as shape, height and crown closure is desirable. A tree is a plant with a permanent shoot system that is reinforced with a single woody stem. For understanding biological properties of a tree, the biophysical structure of a tree needs to be understood. The question is what makes one species of the tree look different on an image from another type of tree and what properties can help us to identify different trees. Trees are geometrically characterized by size and shapes whereas species and type of leaves are related to biophysical properties of a tree. A tree grows its leaves according to the available amount of sun light, and it is vital to distinguish and measure the contributions of leaves in different parts of a tree crown. There are several biophysical parameters as a key issue for monitoring tree properties such as the Leaf Area Index (LAI). LAI is the amount of green leaf area per unit ground area which represents the total amount of green vegetation in a tree that horizontally projected into the ground surface area. In particular, trees can be categorized into broadleaf tree and needle tree regarding their biophysical properties. Leaf angle distribution (LAD) refers to the varying directional leaves orientations, and often described by the mean leaf angle (MLA). Plants like trees with mostly horizontal foliage reflect light differently than vertically oriented foliage, like grass. The LAI can help us to understand how healthy trees occur in an orchard by measuring the vertical intensity profile of a tree crown and monitoring how changes in climate affect tree growth.

Remote sensing images with varying spectral bands are capable of estimating the biophysical properties, like LAI in the large scale of forest area. To be able to assess the contribution of leaves along the profile of a tree, Lidar images can help measuring the height of the trees. Providing Lidar images requires a huge investment for a particular orchard, and it is expensive for monitoring the crop health and biophysical properties of trees. Optical VHR satellite images 
are capable of measuring the spectral and geometrical properties of trees, in particular, Worldview-2 with $2 \mathrm{~m}$ and $0.5 \mathrm{~m}$ spatial resolution for multispectral images and panchromatic image, respectively. According to crop health and biophysical monitoring, VHR images are available every three days or less as temporal resolution. Therefore, it is vital to understand and derive the geometrical properties of the trees with different species, tree sizes, shapes and spatial variation from RS imageries.

There is a variation in spectral response of a single tree crown. This is related mainly to the variation in leave density. This variation has two main components: 1) a low frequency radial dependence and 2) a high frequency irregularities of tree crowns that bring problems when spatial modelling tree intensity profiles. The low frequency component can be observed from VHR satellite images of trees with a crown diameter of a few pixels. In this way, the focus can be on the low frequency component to find a mathematical model that can describe it. The need for this model as the following:

- It is able to detect trees and distinguish them from uneven noisy background.

- It may help to differentiate different tree species.

- It may help to investigate overall tree stress, related e.g. to health or water shortage.

- It allows accurate position determination of individual trees.

- It is more accurate than simple boundary delineation, because the boundary can be affected by wind, and by the different looking angles of sensor.

Full development for such models is outside the scope of the current thesis and should be addressed in future research. Scale-space methods, however, can provide the generic steps of generating an ideal synthetic model for a tree crown that can be comparable with a single tree from satellite images. The real tree model can be simulated through coarsening. There are examples of tree models such as Pollock, truncated Pollock, Gaussian, truncated Gaussian, and constant. They may hold for many tree species, but probably not for all of them.

It is not so difficult to imagine that the work presented in this thesis and at present focusing on orchards could possibly be extended as well to patches of trees that are not orchards, and even to larger forested areas. To explore this direction is, again, possibly interesting research of future studies. 


\section{Bibliography}

Aiazzi, B., Alparone, L., Baronti, S., Garzelli, A., 2002. Context-driven fusion of high spatial and spectral resolution images based on oversampled multiresolution analysis. IEEE Trans. Geosci. Remote Sens. 40, 23002312. https://doi.org/10.1109/TGRS.2002.803623

Allen, R., Pereira, L., Raes, D., Smith, M., 1998. Crop evapotranspirationGuidelines for computing crop water requirements-FAO Irrigation and drainage paper 56. FAO 56, D05109.

Allen, R.G., Tasumi, M., Trezza, R., 2007. Satellite-Based Energy Balance for Mapping Evapotranspiration with Internalized Calibration (METRIC)Model. J. Irrig. Drain. Eng. 133, 380-394. https://doi.org/10.1061/(ASCE)0733-9437(2007)133:4(380)

Ardila, J.P., Bijker, W., Tolpekin, V.A., Stein, A., 2012a. Context-sensitive extraction of tree crown objects in urban areas using VHR satellite images. Int. J. Appl. Earth Obs. Geoinf. 15, 57-69. https://doi.org/10.1016/j.jag.2011.06.005

Ardila, J.P., Bijker, W., Tolpekin, V.A., Stein, A., 2012b. Quantification of crown changes and change uncertainty of trees in an urban environment. ISPRS J. Photogramm. Remote Sens. 74, 41-55. https://doi.org/10.1016/j.isprsjprs.2012.08.007

Ardila, J.P., Tolpekin, V.A., Bijker, W., Stein, A., 2011. Markov-random-fieldbased super-resolution mapping for identification of urban trees in VHR images. ISPRS J. Photogramm. Remote Sens. 66, 762-775. https://doi.org/10.1016/j.isprsjprs.2011.08.002

Atkinson, P.M., 2009. Issues of uncertainty in super-resolution mapping and their implications for the design of an inter-comparison study. Int. J. Remote Sens. 30, 5293-5308. https://doi.org/10.1080/01431160903131034

Atkinson, P.M., Pardo-Iguzquiza, E., Chica-Olmo, M., 2008. Downscaling Cokriging for Super-Resolution Mapping of Continua in Remotely Sensed Images. IEEE Trans. Geosci. Remote Sens. 46, 573-580. https://doi.org/10.1109/TGRS.2007.909952

Bastiaanssen, W.G.., 2000. SEBAL-based sensible and latent heat fluxes in the irrigated Gediz Basin, Turkey. J. Hydrol. 229, 87-100. https://doi.org/10.1016/S0022-1694(99)00202-4

Bierkens, M., Finke, M., Willigen, P. DE, 2000. Upscaling and downscaling methods for environmental research, Kluwer Academic.

Boucher, A., Kyriakidis, P.C., 2006. Super-resolution land cover mapping with indicator geostatistics. Remote Sens. Environ. 104, 264-282. https://doi.org/10.1016/J.RSE.2006.04.020

Bouma, J., 2007. Precision Agriculture: Introduction to the Spatial and Temporal Variability of Environmental Quality. John Wiley \& Sons, Ltd., pp. 5-17. https://doi.org/10.1002/9780470515419.ch2 
Brandtberg, T., Walter, F., 1998. Automated delineation of individual tree crowns in high spatial resolution aerial images by multiple-scale analysis. Mach. Vis. Appl. 11, 64-73. https://doi.org/10.1007/s001380050091

Braswell, B.H., Hagen, S.C., Frolking, S.E., Salas, W.A., 2003. A multivariable approach for mapping sub-pixel land cover distributions using MISR and MODIS: Application in the Brazilian Amazon region. Remote Sens. Environ. 87, 243-256. https://doi.org/10.1016/j.rse.2003.06.002

Brisco, B., Brown, R.J., Hirose, T., McNairn, H., Staenz, K., 2014. Precision Agriculture and the Role of Remote Sensing: A Review. Can. J. Remote Sens. 24, 315-327. https://doi.org/10.1080/07038992.1998.10855254

Brutsaert, W., 1982. Evaporation into the Atmosphere: Theory, History and Applications. Springer Netherlands.

Byrd, R.H., Lu, P., Nocedal, J., Zhu, C., 1995. A Limited Memory Algorithm for Bound Constrained Optimization. SIAM J. Sci. Comput. 16, 1190-1208. https://doi.org/10.1137/0916069

Chen, Q., Baldocchi, D., Gong, P., Kelly, M., 2006. Isolating Individual Trees in a Savanna Woodland Using Small Footprint Lidar Data. Photogramm. Eng. Remote Sens. 72, 923-932. https://doi.org/10.14358/PERS.72.8.923

Clinton, N., Holt, A., Scarborough, J., Yan, L., Gong, P., 2010. Accuracy Assessment Measures for Object-based Image Segmentation Goodness. Photogramm. Eng. Remote Sens. 76, 289-299. https://doi.org/10.14358/PERS.76.3.289

Culvenor, D.S., 2002. TIDA: An algorithm for the delineation of tree crowns in high spatial resolution remotely sensed imagery. Comput. Geosci. 28, 3344. https://doi.org/10.1016/S0098-3004(00)00110-2

Culvenor, D.S., 2000. Development of a Tree Delineation Algorithm for Application to High Spatial Resolution Digital Imagery of Australian Native Forest.pdf.

Eddelbuettel, D., François, R., 2011. Rcpp: Seamless R and C++ Integration. J. Stat. Softw. 40, 1-18. https://doi.org/10.18637/jss.v040.i08

Erikson, M., 2004. Species classification of individually segmented tree crowns in high-resolution aerial images using radiometric and morphologic image measures. Remote Sens. Environ. 91, 469-477. https://doi.org/10.1016/j.rse.2004.04.006

Fisher, P., 1997. The pixel: A snare and a delusion. Int. J. Remote Sens. 18, 679-685. https://doi.org/10.1080/014311697219015

Gougeon, F.A., 1999. Automated individual tree crown delineation using a valley-following algorithm and rule-based system.

Gougeon, F.A., Leckie, D.G., 2006. The individual tree crown approach applied to Ikonos images of a coniferous plantation area. Photogramm. Eng. Remote Sensing 72, 1287-1297. https://doi.org/10.14358/PERS.72.11.1287

Gowda, P.H., Chavez, J.L., Colaizzi, P.D., Evett, S.R., Howell, T.A., Tolk, J.A., 
2007. ET mapping for agricultural water management: present status and challenges. Irrig. Sci. 26, 223-237. https://doi.org/10.1007/s00271007-0088-6

Ha, W., Gowda, P.H., Howell, T.A., 2012a. A review of downscaling methods for remote sensing-based irrigation management: part I. Irrig. Sci. 31, 831-850. https://doi.org/10.1007/s00271-012-0331-7

Ha, W., Gowda, P.H., Howell, T.A., 2012b. A review of potential image fusion methods for remote sensing-based irrigation management: part II. Irrig. Sci. 31, 851-869. https://doi.org/10.1007/s00271-012-0340-6

Hamraz, H., Contreras, M.A., Zhang, J., 2016. A robust approach for tree segmentation in deciduous forests using small-footprint airborne LiDAR data. Int. J. Appl. Earth Obs. Geoinf. 52, 532-541. https://doi.org/10.1016/j.jag.2016.07.006

Hay, G.J., Dubé, P., Bouchard, A., Marceau, D.J., 2002. A scale-space primer for exploring and quantifying complex landscapes. Ecol. Modell. 153, 2749. https://doi.org/10.1016/S0304-3800(01)00500-2

Jiang, H., Chen, S., Li, D., Wang, C., Yang, J., 2017. Papaya Tree Detection with UAV Images Using a GPU-Accelerated Scale-Space Filtering Method. Remote Sens. 9, 721. https://doi.org/10.3390/rs9070721

Jimenez-Munoz, J.-C., Sobrino, J.A., 2008. Split-Window Coefficients for Land Surface Temperature Retrieval From Low-Resolution Thermal Infrared Sensors. IEEE Geosci. Remote Sens. Lett. 5, 806-809. https://doi.org/10.1109/LGRS.2008.2001636

Jimenez-Munoz, J.C., Sobrino, J.A., Skokovic, D., Mattar, C., Cristobal, J., 2014. Land Surface Temperature Retrieval Methods From Landsat-8 Thermal Infrared Sensor Data. IEEE Geosci. Remote Sens. Lett. 11, 1840-1843. https://doi.org/10.1109/LGRS.2014.2312032

Kasetkasem, T., Arora, M.K., Varshney, P.K., 2005. Super-resolution land cover mapping using a Markov random field based approach. Remote Sens. Environ. 96, 302-314. https://doi.org/10.1016/J.RSE.2005.02.006

Kassaye, R.H., 2006. Suitability of Markov Random Field-based Method for Super-Resolution Land Cover Mapping.

Ke, Y., Quackenbush, L.J., 2011. A review of methods for automatic individual tree-crown detection and delineation from passive remote sensing. Int. J. Remote Sens. 32, 4725-4747. https://doi.org/10.1080/01431161.2010.494184

Koch, B., Heyder, U., Weinacker, H., 2006. Detection of Individual Tree Crowns in Airborne Lidar Data. Photogramm. Eng. Remote Sens. 72, 357-363. https://doi.org/10.14358/PERS.72.4.357

Kustas, W., 2004. Effects of remote sensing pixel resolution on modeled energy flux variability of croplands in Iowa. Remote Sens. Environ. 92, 535-547. https://doi.org/10.1016/j.rse.2004.02.020

Kustas, W.P., Norman, J.M., Anderson, M.C., French, A.N., 2003. Estimating subpixel surface temperatures and energy fluxes from the vegetation 
index-radiometric temperature relationship. Remote Sens. Environ. 85, 429-440. https://doi.org/10.1016/S0034-4257(03)00036-1

Laben, C.A., Brower, B. V, 2000. Processing for Enhancing the Spatial Resolution of Multispectral Imagery Using Pan-Sharpening. https://doi.org/10.1074/JBC.274.42.30033.(51)

Li, S.Z., 2009. Markov random field modeling in image analysis. Springer.

Liang, S., 2001. Narrowband to broadband conversions of land surface albedo I: Algorithms. Remote Sens. Environ. 76, 213-238. https://doi.org/10.1016/S0034-4257(00)00205-4

Lindeberg, T., 2013. Scale-Space Theory in Computer Vision. Springer Science \& Business Media.

Lindeberg, T., 2012. Scale Selection Properties of Generalized Scale-Space Interest Point Detectors. J. Math. Imaging Vis. 46, 177-210. https://doi.org/10.1007/s10851-012-0378-3

Lindeberg, T., 2010. Generalized Gaussian Scale-Space Axiomatics Comprising Linear Scale-Space, Affine Scale-Space and Spatio-Temporal ScaleSpace. J. Math. Imaging Vis. 40, 36-81. https://doi.org/10.1007/s10851-010-0242-2

Lindeberg, T., 2008. Scale-Space, in: Wah, B.W. (Ed.), Wiley Encyclopedia of Computer Science and Engineering. John Wiley \& Sons, Inc., Hoboken, NJ, USA. https://doi.org/10.1002/9780470050118.ecse609

Lindeberg, T., 1998. Feature Detection with Automatic Scale Selection. Int. J. Comput. Vis. 30, 79-116. https://doi.org/10.1023/A:1008045108935

Lindeberg, T., 1990. Scale-Space for Discrete Signals. IEEE Trans. Pattern Anal. Mach. Intell. 12, 234-254. https://doi.org/10.1109/34.49051

Lindeberg, T., Eklundh, J.O., 1991. On the computation of a scale-space primal sketch. J. Vis. Commun. Image Represent. 2, 55-78. https://doi.org/10.1016/1047-3203(91)90035-E

López, J.P.A., 2012. Object-based methods for mapping and monitoring of urban trees with multitemporal image analysis. Fac. geo-information Sci. earth Obs. University of Twente.

Lucieer, A., Stein, A., 2002. Existential uncertainty of spatial objects segmented from satellite sensor imagery. IEEE Trans. Geosci. Remote Sens. 40, 2518-2521. https://doi.org/10.1109/TGRS.2002.805072

Luo, Y., Trishchenko, A.P., Khlopenkov, K. V., 2008. Developing clear-sky, cloud and cloud shadow mask for producing clear-sky composites at 250meter spatial resolution for the seven MODIS land bands over Canada and North America. Remote Sens. Environ. 112, 4167-4185. https://doi.org/10.1016/J.RSE.2008.06.010

Mahour, M., Stein, A., Sharifi, A., Tolpekin, V., 2015a. Integrating Super Resolution Mapping and SEBS modeling for evapotranspiration mapping at the field scale . Precis. Agric. 1-28. https://doi.org/10.1007/s11119015-9395-8

Mahour, M., Stein, A., Sharifi, A., Tolpekin, V., 2015b. Integrating super 
resolution mapping and SEBS modeling for evapotranspiration mapping at the field scale. Precis. Agric. 16, 571-586. https://doi.org/10.1007/s11119-015-9395-8

Mahour, M., Tolpekin, V., Stein, A., 2016. Tree detection in orchards from VHR satellite images using scale-space theory, in: Bruzzone, L., Bovolo, F. (Eds.), Proc. SPIE 10004, Image and Signal Processing for Remote Sensing XXII. International Society for Optics and Photonics. https://doi.org/10.1117/12.2241529

Matheron, G., 1963. Principles of geostatistics. Econ. Geol. 58, 1246-1266. https://doi.org/10.2113/gsecongeo.58.8.1246

Mertens, K.C., Verbeke, L.P.C., Ducheyne, E.I., De Wulf, R.R., 2003. Using genetic algorithms in sub-pixel mapping. Int. J. Remote Sens. 24, 42414247. https://doi.org/10.1080/01431160310001595073

Oliver, M.A., 2010. Geostatistical Applications for Precision Agriculture. Springer Netherlands, Dordrecht. https://doi.org/10.1007/978-90-4819133-8

Papoulis, A., Pillai, S.U., 2002. Probability, Random Variables, and Stochastic Processes.

Pardo-Igúzquiza, E., Chica-Olmo, M., Atkinson, P.M., 2006. Downscaling cokriging for image sharpening. Remote Sens. Environ. 102, 86-98. https://doi.org/10.1016/j.rse.2006.02.014

Paulo, M.J., Tome, M., Otten, A., Stein, A., 2005. Comparison of three sampling methods in the characterization of cork oak stands for management purposes. Can. J. For. Res. Can. Rech. For. 35, 2295-2303. https://doi.org/10.1139/x05-156|issn 0045-5067

Persson, A., Holmgren, J., Södermann, U., 2002. Detecting and measuring individual trees using an airborne laser scanner. Photogramm. Eng. Remote Sens. [0099-1112] 68, 925-932.

Pidwirny, M., 2006. Actual and Potential Evapotranspiration, in: Fundamentals of Physical Geography.

Pierce, F.J., Nowak, P., 1999. Advances in Agronomy Volume 67, Advances in Agronomy, Advances in Agronomy. Elsevier. https://doi.org/10.1016/S0065-2113(08)60513-1

Pollock, R.J., 1996. The automatic recognition of individual trees in aerial images of forests based on a synthetic tree crown image model. Univ. Br. Columbia Canada. National Library of Canada = Bibliothèque nationale du Canada. https://doi.org/10.14288/1.0051597

Popescu, S.C., Wynne, R.H., Nelson, R.F., 2003. Measuring individual tree crown diameter with lidar and assessing its influence on estimating forest volume and biomass. Can. J. Remote Sens. 29, 564-577. https://doi.org/10.5589/m03-027

Pouliot, D., King, D., 2005. Approaches for optimal automated individual tree crown detection in regenerating coniferous forests. Can. J. Remote Sens. 31, 255-267. https://doi.org/10.5589/m05-011 
Pouliot, D.A., King, D.J., Bell, F.W., Pitt, D.G., 2002. Automated tree crown detection and delineation in high-resolution digital camera imagery of coniferous forest regeneration. Remote Sens. Environ. 82, 322-334. https://doi.org/10.1016/S0034-4257(02)00050-0

R Core Team, 2017. A Language and Environment for Statistical. R Found. Stat. Comput. https://doi.org/citeulike-article-id:2400517

Rahman, H., Dedieu, G., 1994. SMAC: A simplified method for the atmospheric correction of satellite measurements in the solar spectrum. Int. J. Remote Sens. 15, 123-143. https://doi.org/10.1080/01431169408954055

Recio, J.A., Hermosilla, T., Ruiz, L.A., Palomar, J., 2013. Automated extraction of tree and plot-based parameters in citrus orchards from aerial images. Comput. Electron. Agric. 90, 24-34. https://doi.org/10.1016/j.compag.2012.10.005

Ren, H., Du, C., Qin, Q., Liu, R., Meng, J., Li, J., 2014. Atmospheric water vapor retrieval from Landsat 8 and its validation, in: 2014 IEEE Geoscience and Remote Sensing Symposium. IEEE, pp. 3045-3048. https://doi.org/10.1109/IGARSS.2014.6947119

Richards, J.A., 2013. Remote Sensing Digital Image Analysis. Springer Berlin Heidelberg, Berlin, Heidelberg. https://doi.org/10.1007/978-3-64230062-2

Rodriguez-Galiano, V., Pardo-Iguzquiza, E., Sanchez-Castillo, M., Chica-Olmo, M., Chica-Rivas, M., 2012. Downscaling Landsat 7 ETM+ thermal imagery using land surface temperature and NDVI images. Int. J. Appl. Earth Obs. Geoinf. 18, 515-527. https://doi.org/10.1016/j.jag.2011.10.002

Schardt, M., Ziegler, M., Wimmer, A., Wack, R., Data, L.S., 2002. Assessment of forest parameters by means of laser scanning. Int. Arch. Photogramm. Remote Sens. Spat. Inf. Sci. 34, 302-309.

Schuenemeyer, J.H., Drew, L.J., 2010. Statistics for Earth and Environmental Scientists. John Wiley \& Sons, Inc., Hoboken, NJ, USA.

Senay, G.B., Budde, M., Verdin, J.P., Melesse, A.M., 2007. A Coupled Remote Sensing and Simplified Surface Energy Balance Approach to Estimate Actual Evapotranspiration from Irrigated Fields. Sensors 7, 979-1000. https://doi.org/10.3390/s7060979

Sharifi, M.A., 2013. Increasing water productivity through demand management and improved operation. Qazvin.

Skurikhin, A.N., Garrity, S.R., McDowell, N.G., Cai, D.M., 2013. Automated tree crown detection and size estimation using multi-scale analysis of high-resolution satellite imagery. Remote Sens. Lett. 4, 465-474. https://doi.org/10.1080/2150704X.2012.749361

Sobrino, J. a., Li, Z.-L., Stoll, M.P., Becker, F., 1996. Multi-channel and multiangle algorithms for estimating sea and land surface temperature with ATSR data. Int. J. Remote Sens. 17, 2089-2114. https://doi.org/10.1080/01431169608948760

Sobrino, J.A., Jiménez-Muñoz, J.C., Paolini, L., 2004. Land surface temperature 
retrieval from LANDSAT TM 5. Remote Sens. Environ. 90, 434-440. https://doi.org/10.1016/J.RSE.2004.02.003

Stein, A., Corsten, L.C.A., 1991. Universal Kriging and Cokriging as a Regression Procedure. Biometrics 47, 575-587. https://doi.org/10.2307/2532147

Stratoulias, D., Tolpekin, V., de By, R.A., Zurita-Milla, R., Retsios, V., Bijker, W., Hasan, M.A., Vermote, E., 2017. A workflow for automated satellite image processing: From raw VHSR data to object-based spectral information for smallholder agriculture. Remote Sens. https://doi.org/10.3390/rs9101048

Su, Z., 2002. The Surface Energy Balance System (SEBS) for estimation of turbulent heat fluxes. Hydrol. Earth Syst. Sci. 6, 85-100. https://doi.org/10.5194/hess-6-85-2002

Tang, Y., Atkinson, P.M., Zhang, J., 2015. Downscaling remotely sensed imagery using area-to-point cokriging and multiple-point geostatistical simulation. ISPRS J. Photogramm. Remote Sens. 101, 174-185. https://doi.org/10.1016/j.isprsjprs.2014.12.016

Tatem, A.J., Lewis, H.G., Atkinson, P.M., Nixon, M.S., 2001. Super-resolution target identification from remotely sensed images using a Hopfield neural network. IEEE Trans. Geosci. Remote Sens. 39, 781-796. https://doi.org/10.1109/36.917895

Tolpekin, V.A., Stein, A., 2009. Quantification of the Effects of Land-CoverClass Spectral Separability on the Accuracy of Markov-Random-FieldBased Superresolution Mapping. IEEE Trans. Geosci. Remote Sens. 47, 3283-3297. https://doi.org/10.1109/TGRS.2009.2019126

Tso, B., Mather, P.M., 2009. Classification methods for remotely sensed data. CRC Press.

van Oort, P.A.J., 2006. Spatial data quality: from description to application. Netherlands Geod. Comm.

Verhoeye, J., De Wulf, R., 2002. Land cover mapping at sub-pixel scales using linear optimization techniques. Remote Sens. Environ. 79, 96-104. https://doi.org/10.1016/S0034-4257(01)00242-5

Wang, L., 2010. A Multi-scale Approach for Delineating Individual Tree Crowns with Very High Resolution Imagery. Photogramm. Eng. Remote Sens. 76, 371-378. https://doi.org/10.14358/pers.76.4.371

Wickham, H., 2009. Ggplot2 : elegant graphics for data analysis. Springer.

Witkin, A.P., 1983. Scale-space filtering. Int. Jt. Conf. Artif. Intell. 2, 10191022. https://doi.org/10.1109/ICASSP.1984.1172729

Wolf, B.-M., Heipke, C., 2007. Automatic extraction and delineation of single trees from remote sensing data. Mach. Vis. Appl. 18, 317-330. https://doi.org/10.1007/s00138-006-0064-9

Wu, B., Yan, N., Xiong, J., Bastiaanssen, W.G.M., Zhu, W., Stein, A., 2012. Validation of ETWatch using field measurements at diverse landscapes: $A$ case study in Hai Basin of China. J. Hydrol. 436-437, 67-80. 
https://doi.org/10.1016/j.jhydrol.2012.02.043

Wu, H., Li, Z.-L., 2009. Scale issues in remote sensing: a review on analysis, processing and modeling. Sensors (Basel). 9, 1768-93. https://doi.org/10.3390/s90301768

Wulder, M.A., Niemann, K.O., Goodenough, D.G., 2000. Local maximum filtering for the extraction of tree locations and basal area from high spatial resolution imagery.

Yang, F., White, M.A., Michaelis, A.R., Ichii, K., Hashimoto, H., Votava, P., Zhu, A.-X., Nemani, R.R., 2006. Prediction of Continental-Scale Evapotranspiration by Combining MODIS and AmeriFlux Data Through Support Vector Machine. IEEE Trans. Geosci. Remote Sens. 44, 34523461. https://doi.org/10.1109/TGRS.2006.876297

Yu, X., Guo, X., Wu, Z., 2014. Land Surface Temperature Retrieval from Landsat 8 TIRS-Comparison between Radiative Transfer Equation-Based Method, Split Window Algorithm and Single Channel Method. Remote Sens. 6, 9829-9852. https://doi.org/10.3390/rs6109829

Zhang, N., Wang, M., Wang, N., 2002. Precision agriculture-a worldwide overview. Comput. Electron. Agric. 36, 113-132. https://doi.org/10.1016/S0168-1699(02)00096-0 